\title{
Design Centrado no Usuário de um Ambiente de Reunião Instrumentado
}

\author{
Vivian Genaro Motti
}

Orientadora: Prof ${ }^{a}$. Dr ${ }^{a}$. Maria da Graça Campos Pimentel

Dissertação apresentada ao Instituto de Ciências Matemáticas e de Computação - ICMC-USP, como parte dos requisitos para obtenção do título de Mestre em Ciências de Computação e Matemática Computacional.

USP - São Carlos

Janeiro de 2009 

Design Centrado no Usuário de um Ambiente de Reunião Instrumentado

Vivian Genaro Motti 

Aos meus pais. 

"C'est le temps que tu as perdu pour ta rose qui fait ta rose si importante."

Antoine de Saint-Exupéry 



\section{AGRADECIMENTOS}

Aos meus pais, minha origem e meu norte.

À minha orientadora, Graça Pimentel, por ampliar horizontes, indicar caminhos, pela confiança e pelo incentivo.

Aos professores, em especial à Renata, ao Rudinei e à Júnia, pelo apoio, sugestões e experiências compartilhadas.

Ao Vinicius, pela compreensão e apoio em todos os momentos.

Aos colegas da equipe TIDIA (Flávia, Sandro, Leandro, Cláudia, Cássio e aos membros do Lince), que tornaram possivel a concretização do DiGaE.

Aos colegas do Intermídia (Fagá, Danilo, Tim, Rigolin, André e Silvana) pela amizade e colaboração.

Aos alunos de pré-IC (Vinicius, Renan, Ana P. e Wilson) pelo apoio nas avaliações.

Ao CNPq pelo apoio financeiro. 



\section{Resumo}

A computação ubíqua explora o fato de que é possivel embutir em um ambiente sistemas computacionais que transparentemente apóiem tarefas cotidianas do usuário. Sistemas desse tipo podem ser aplicados a diferentes domínios - contribuindo, por exemplo, com atividades educacionais, médicas ou administrativas. A captura automática de informação em ambientes de computação ubíqua visa documentar atividades cotidianas de modo a possibilitar, posteriormente, o acesso às informações capturadas. O nível de transparência da interação do usuário com as chamadas aplicações ubíquas de captura e acesso é um desafio para projetistas, uma vez que os requisitos da aplicação devem ser conhecidos em profundidade para que a interação usuário-ambiente seja eficiente, eficaz e satisfatória. O trabalho realizado teve por objetivo especificar uma versão da aplicação para comunicação síncrona entre usuários que participem de reuniões distribuídas usando o DiGaE (Distributed Gathering Environment), desenvolver protótipos de interfaces, avaliá-los e sugerir soluções que facilitem a interação do usuário, aproximando o modelo conceitual da aplicação de seu modelo mental. Foram utilizados conceitos de Engenharia de Software para especificação e modelagem do sistema, e de Interação Humano-Computador para o desenvolvimento e a avaliação das interfaces. O projeto realizado orientou a implementação de um protótipo do ambiente DiGaE pela equipe do Projeto TIDIA-Ae, em cujo contexto este trabalho se insere. A principal contribuição do trabalho é um projeto que considera usabilidade em ambientes ubíquos para comunicação remota entre usuários, de modo a tornar a interação fácil, eficiente, eficaz e satisfatória até mesmo para usuários não especialistas em informática.

Palavras-chave: Captura e Acesso, Interação Humano-Computador, Ambientes Instrumentados de Computação Ubíqua. 


\begin{abstract}
Ubiquitous computing explores the possibility of instrumenting an environment with computational infrastructure that transparently supports users in their daily tasks. This kind of systems can be applied in different contexts - contributing in medical, educational or administrative activities, for instance. The automatic capture of information in ubiquitous computing environments aims at documenting daily activities so that the corresponding information can be later accessed for review. Achieving a high level of transparency concerning the user interaction in such environments is a challenge to designers, since many users' requirements must be gathered so that the user-environment interaction is efficient, effective and satisfactory. The main objective of the work reported is the specification of a version of the DiGaE (Distributed Gathering Environment) application - which allows the synchronous communication among remote users in distributed meetings developing interfaces prototypes, evaluating them and suggesting solutions to facilitate users' interaction. Concepts from Software Engineering were employed to specify and model the application, and Human-Computer Interaction concepts were employed to develop and evaluate the interfaces. The project guided the implementation of a DiGaE prototype by TIDIA-Ae Project team, in which context this work is inserted. The main contribution of this work is a project which considers usability in ubiquitous distributed gathering environments in order to make the interaction easy, efficient, effective and satisfactory, even for non-expert users.
\end{abstract}

Keywords: Capture and Access, Human-Computer Interaction and Ubiquitous Computing Instrumented Environments. 


\section{Sumário}

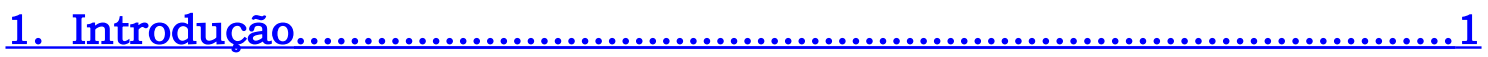

1.1 Contextualização..............................................................

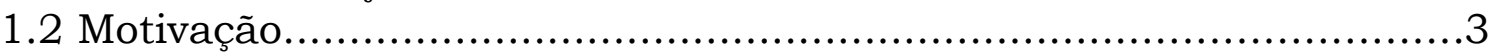

1.3 Objetivos ................................................................... 5

1.4 Metodologia e Resultados Obtidos..................................... 5

1.5 Estrutura da Dissertação.................................................

2. Conceitos Fundamentais.................................................8

2.1 Considerações Iniciais....................................................... 8

2.2 Computação Ubíqua....................................................... 8

2.3 Modelagem e Especificação............................................. 10

2.4 Design e Avaliação........................................................ 11

2.5 Considerações Finais......................................................... 21

3. Trabalhos Relacionados...................................................23

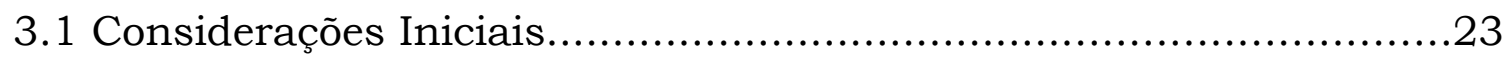

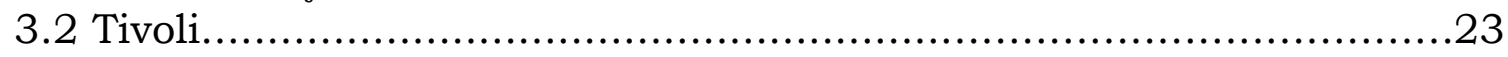

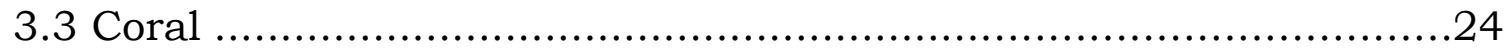

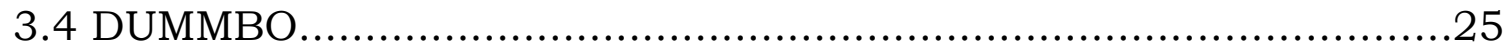

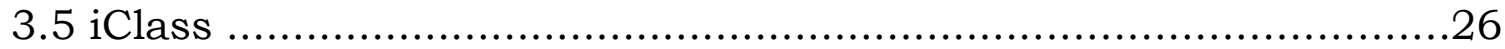

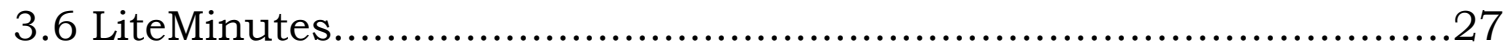

3.7 Portable Meeting Recorder..................................................28

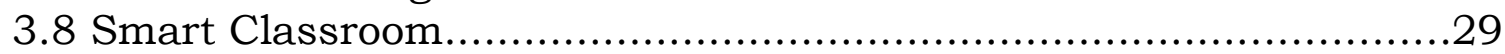

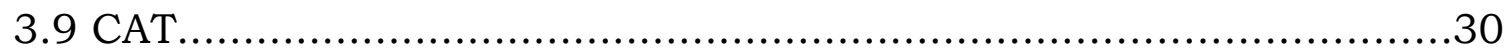

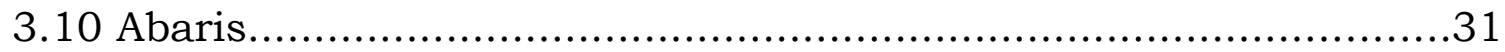

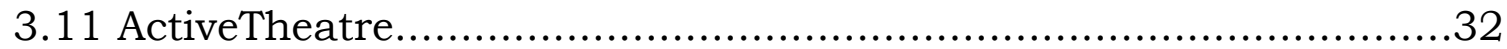

3.12 CAS (Serviço de Captura e Acesso) ...................................... 33

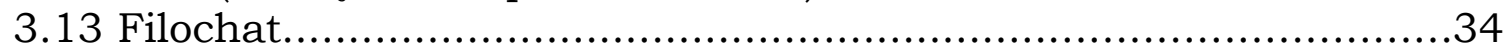

3.14 Aplicações convencionais para reunião distribuída.....................35

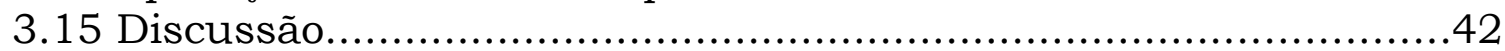

3.16 Considerações Finais................................................... 44

4. Metodologia e Desenvolvimento.........................................47

4.1 Considerações Iniciais....................................................47

4.2 Especificação do DiGaE.............................................. 48

4.2.1 Levantamento dos Requisitos....................................48

4.2.2 Casos de Uso.............................................................. 51

4.2.3 HTA (Hierarchical Task Analysis)...................................52

4.3 Prototipação............................................................. 54

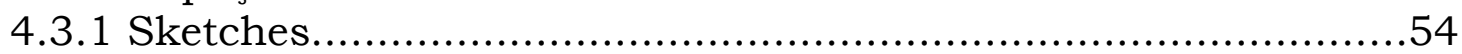

4.3.2 Avaliação dos Sketches .................................................56

4.4 Ferramentas Utilizadas.................................................62

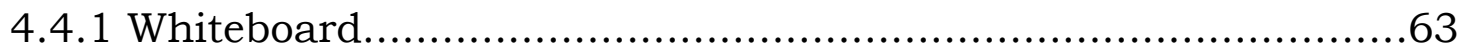

4.4.2 Comunicador Instantâneo.........................................64

4.4.3 Chat..................................................................65 
4.5 Avaliação das Ferramentas Utilizadas.....................................66

4.5.1 Avaliação da Ferramenta Whiteboard (WB).........................67

4.5.2 Avaliação da Ferramenta Comunicador Instantâneo...............69

4.5.3 Avaliação da Ferramenta Chat.......................................72

4.6 Estudo de Caso: Ambiente Instrumentado..................................74

4.6.1 Descrição............................................................. 75

4.6.2 Configuração e Uso.................................................. 76

4.6.3 Avaliação.............................................................. 78

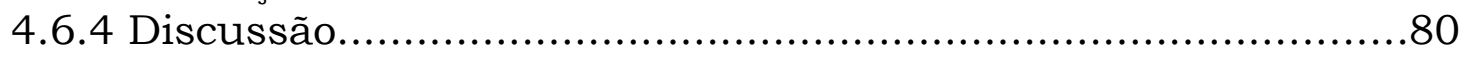

4.7 Considerações Finais....................................................... 81

5. Conclusões ...............................................................82

5.1 Contribuições........................................................... 82

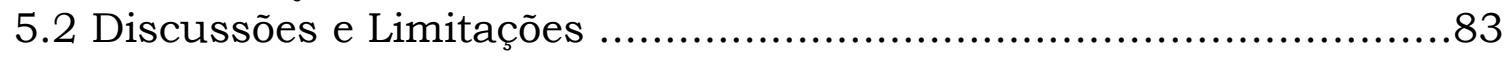

5.2 .1 Transparência................................................... 83

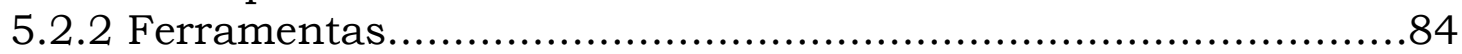

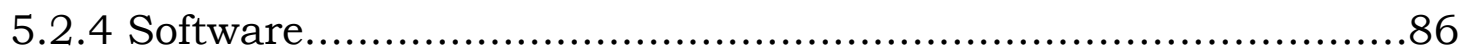

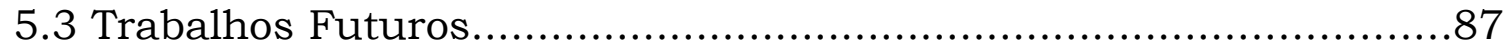

5.4 Considerações Finais..................................................90

6. Publicações.................................................................92

7. Referências.................................................................93

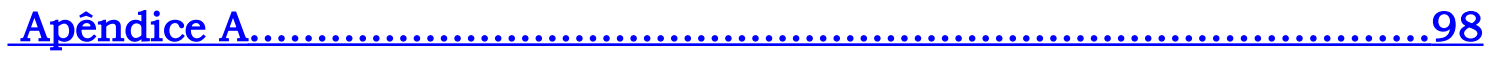

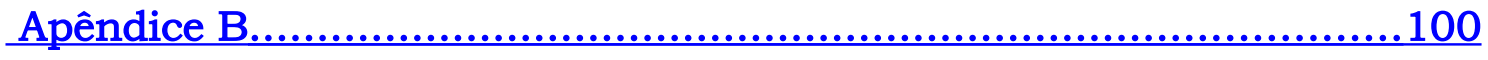

Apêndice C.......................................................................101 


\section{Lista de Figuras}

Figura 1: Proposta do DiGaE: a rede KyaTera, de alta velocidade e baixa latência, integra três ambientes remotos instrumentados com câmeras, projetores, computadores e PDAs...................................2

Figura 2: Cartão USP com etiqueta RFID e leitor RFID.....................10

Figura 3: Relação entre número de erros e de avaliadores da Avaliação Heurística (Nielsen e Molich, 1990)............................................. 15

Figura 4: Dificuldade em encontrar os erros $\mathbf{x} \mathrm{N}^{\circ}$ de avaliadores (Nielsen, 1992)............................................................................. 16

Figura 5: Janela do Tivoli com slide em branco (Pedersen et al., 1993). 24

Figura 6: Uma sessão de captura. O microfone, a câmera, a LiveBoard e o laptop capturam áudio, vídeo e anotações em uma reunião (Minneman

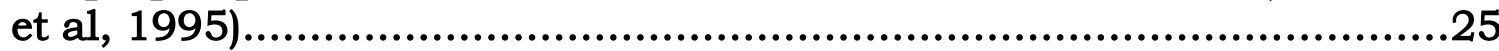

Figura 7: A vista de frente da lousa DUMMBO (à esquerda) e a de trás (à direita) com os equipamentos (Brotherton et al., 1999).....................26

Figura 8: O professor escreve na lousa usando iClass (esquerda). $O$ aluno usa o iClass em um tablet (direita) (Pimentel et al., 2005).........27

Figura 9: Sala de reuniões com um display grande, um pequeno e notebook wireless para anotações (Chiu et al., 2001)........................28

Figura 10: Interface para visualizar a reunião (Lee et al., 2002)...........29

Figura 11: Sala de aula aumentada - Smart Classroom (Shi et al. 2003).

Figura 12: Interface CAT para criação de sessões (Cattelan, 2004).......31

Figura 13: Interface de captura do Abaris (Kientz et al., 2005)............32

Figura 14: Acesso a imagens e registros eletrônicos médicos durante a cirurgia (Hansen e Bardram, 2005).

Figura 15: Interface para edição manual de informação de contexto do CAS (Portella, 2008).

Figura 16: Interface para navegação pelas informações capturadas de uma reunião (Whittaker et al., 2008)...........................................35

Figura 17: Interface do NetMeeting comentada................................36

Figura 18: Interface do Windows Meeting Space (Windows, 2008).......37

Figura 19: Quatro cenários de uso para o MS Conference XP (Conference

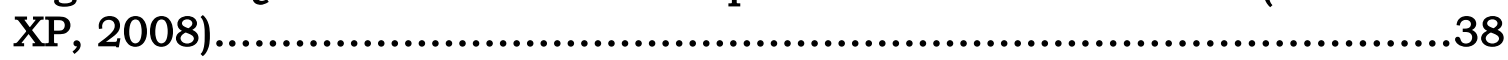

Figura 20: Interface do Adobe Acrobat Connect (Connect, 2008)..........39 
Figura 21: Interface de uso do EVO (Evo, 2008)..............................40

Figura 22: Interfaces do OpenMeeting (OpenMeeting, 2008)................41

Figura 23: Quatro opções de uso para o TalkAndWrite (TalkAndWrite, 2008).............................................................................42

Figura 24: Diagrama de Fluxos do DiGaE........................................50

Figura 25: Diagrama de Casos de Uso do DiGaE...............................51

Figura 26: Diagrama HTA do DiGaE.............................................53

Figura 27: Protótipo de Interface da Sessão DiGaE...........................55

Figura 28: Interface da Ferramenta Whiteboard..............................63

Figura 29: Interface da Ferramenta Comunicador Instantâneo.............65

Figura 30: Interface da Ferramenta Chat........................................66

Figura 31: Ambiente instrumentado: DiGaE. À esquerda, sobre a mesa há o leitor de RFID. Ao fundo há a lousa eletrônica (Smartboard). À direita há três monitores, dois para áudio e vídeo, com câmera entre eles e o monitor à frente executa o Chat e o programa que lê a tag RFID.....75

Figura 32: Interface para agendamento da sessão DiGaE.....................77

Figura 33: Utilização da Whiteboard na lousa eletrônica.....................78

Figura 34: Tablet PC (esquerda) e Tablet (direita) com interação por caneta. 


\section{Lista de Tabelas}

Tabela 1: Exemplo de escala por diferencial semântico para avaliação de uma página web...............................................................18

Tabela 2: Exemplo de escala Likert com intervalo numérico.................19

Tabela 3: Exemplo de escala Likert por diferencial semântico..............19

Tabela 4: Sentenças de avaliação SUMI............................................20

Tabela 5: Requisitos Funcionais do DiGaE.....................................49

Tabela 6: Resultados da Avaliação Heurística sobre os Sketches (problemas e recomendações)........................................................58

Tabela 7: Questionário para avaliação da ferramenta Comunicador Instantâneo...........................................................................70

Tabela 8: Resultados da avaliação da ferramenta Comunicador

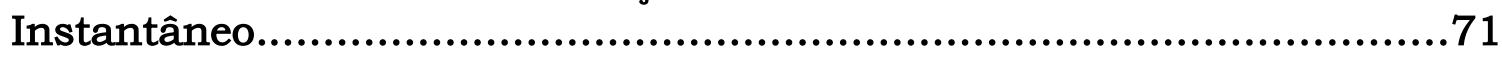

Tabela 9: Resultados da avaliação da ferramenta Chat......................73 


\section{Lista de Siglas}

$\begin{array}{ll}\text { AV } & \text { Áudio e Vídeo } \\ \text { API } & \text { Application Programming Interface (Interface de Programação de } \\ \text { ASCII } & \text { American Standard Code for Information Interchange } \\ \text { ASR } & \text { Automatic Speech Recognition } \\ \text { BP } & \text { Bate-Papo } \\ \text { CAS } & \text { Capture Access Service } \\ \text { CAT } & \text { Capture and Acess Toolkit } \\ \text { C\&A } & \text { Captura e Acesso } \\ \text { CI } & \text { Comunicador Instantâneo } \\ \text { CPU } & \text { Central Processing Unit } \\ \text { CSCW } & \text { Computer Supported Collaborative Work } \\ \text { DiGaE } & \text { Distributed Gathering Environment } \\ \text { DUMMBO Dynamic Ubiquitous Mobile Meeting Board } \\ \text { HSV } & \text { Hue, Saturation and Value } \\ \text { HTML } & \text { Hypertext Markup Language } \\ \text { ICMC } & \text { Instituto de Ciências Matemáticas e de Computação } \\ \text { ICR } & \text { Information Capture and Retrieval } \\ \text { IHC } & \text { Interação Humano-Computador } \\ \text { JVM } & \text { Java Virtual Machine (Máquina Virtual Java) } \\ \text { LINCE } & \text { Laboratório de Inovação em Computação e Engenharia } \\ \text { Mhz } & \text { Megahertz } \\ \text { MUMMS } & \text { Measuring the Usability of Multi-Media Software } \\ \text { NCL } & \text { Nested Context Language } \\ \text { OMG } & \text { Object Management Group } \\ \text { QUIS } & \text { Questionnaire for User Interaction Satisfaction } \\ \text { RFID } & \text { Radio-Frequency Identification } \\ \text { RGB } & \text { Red, Green and Blue } \\ \text { SDK } & \text { Software Development Kit } \\ \text { SUMI } & \text { Software Usability Measurement Inventory } \\ \text { SUS } & \text { System Usability Scale } \\ & \text { Tecnologia da Informação no Desenvolvimento da Internet } \\ \text { TIDIA } & \text { Avançada } \\ & \text { Tecnologia da Informação no Desenvolvimento da Internet } \\ \text { TIDIA-Ae } & \text { Avançada - Aprendizado Eletrônico } \\ \text { TV } & \text { Televisão } \\ \text { UFSCar } & \text { Universidade Federal de São Carlos } \\ \text { USP } & \text { Universidade de São Paulo } \\ & \end{array}$


UML Unified Modeling Language

XML Extensible Markup Language

WAMMI Websites Analysis and MeasureMent Inventory

WB Whiteboard

3D Três Dimensões 


\section{INTRODUÇÃO}

A literatura relata vários trabalhos sobre a captura e o correspondente acesso a informações de áudio e vídeo relativos a eventos cotidianos. Nos trabalhos reportados na literatura há uma preocupação com o desenvolvimento da aplicação no que tange a aspectos de arquitetura, modularidade e serviços. Apesar disso, há vários fatores em uma aplicação ubíqua que estão diretamente relacionados ao usuário, como por exemplo sua identificação no ambiente, o modo como ocorre a interação deste para acessar os serviços oferecidos pela aplicação desenvolvida, e a recuperação das informações capturadas.

\subsection{Contextualização}

O Projeto TIDIA - Tecnologia da Informação no Desenvolvimento da Internet Avançada - visa o desenvolvimento colaborativo de novas tecnologias para a Internet, envolvendo pesquisadores de várias universidades e centros de pesquisa. O Projeto TIDIA é composto por três subprojetos: (i) TIDIA-Kyatera, que investiga problemas associados ao provimento e ao uso de uma rede de computadores de grande largura de banda e baixa latência; (ii) TIDIA-Ae (Aprendizado Eletrônico), que investiga a construção de um ambiente de ensino-aprendizagem com ferramentas de apoio à educação que utilizem a capacidade da rede Kyatera; e (iii) TIDIAIncubadora, que provê uma incubadora virtual de conteúdos e de projetos de software.

Os objetivos do subprojeto TIDIA-Ae são a pesquisa e o desenvolvimento de software na área de tecnologia da informação voltados para a especificação, o planejamento e a implementação de ferramentas no contexto educacional. O subprojeto TIDIA-Ae visa soluções flexíveis de grande impacto social a um baixo custo, disponibilizando seus resultados como software de código aberto e gratuito.

O Laboratório Intermídia do Instituto de Ciências Matemáticas e de Computação (ICMC), da USP - São Carlos -SP, propôs o ambiente DiGaE, a 
ser instalado em três salas remotas, ligadas pela rede do Projeto Kyatera. O Projeto DiGaE (Distributed Gathering Environment) se insere no contexto do Projeto TIDIA e prevê a disponibilização de três ambientes de computação ubíqua para comunicação síncrona de qualidade entre usuários remotos. Esses ambientes devem estar instrumentados com dispositivos de captura de informações, como por exemplo leitores de RFID para identificação do usuário, microfones para captura de áudio, câmeras de vídeo, projetores e lousas eletrônicas com interação via caneta para documentação das informações escritas pelos usuários. Prevê-se também um sistema de áudio para retorno do sinal do ambiente remoto, monitores para visualização do vídeo remoto capturado e computador desktop para utilização da ferramenta de comunicação textual do tipo chat $^{1}$.

É necessário estruturar o ambiente DiGaE de modo que, assim que um usuário entre na sala, esta esteja automaticamente preparada para uso. Isto porque qualquer sobrecarga relativa à configuração dos dispositivos e das ferramentas disponíveis para iniciar a captura de uma sessão pode comprometer o uso do ambiente. A Figura 1 ilustra a proposta do ambiente DiGaE com a rede KyaTera, integrando três ambientes remotos instrumentados com câmeras HDV, dois projetores XGA, lousa eletrônica, tablets e PDAs para capturar interação baseada em caneta.

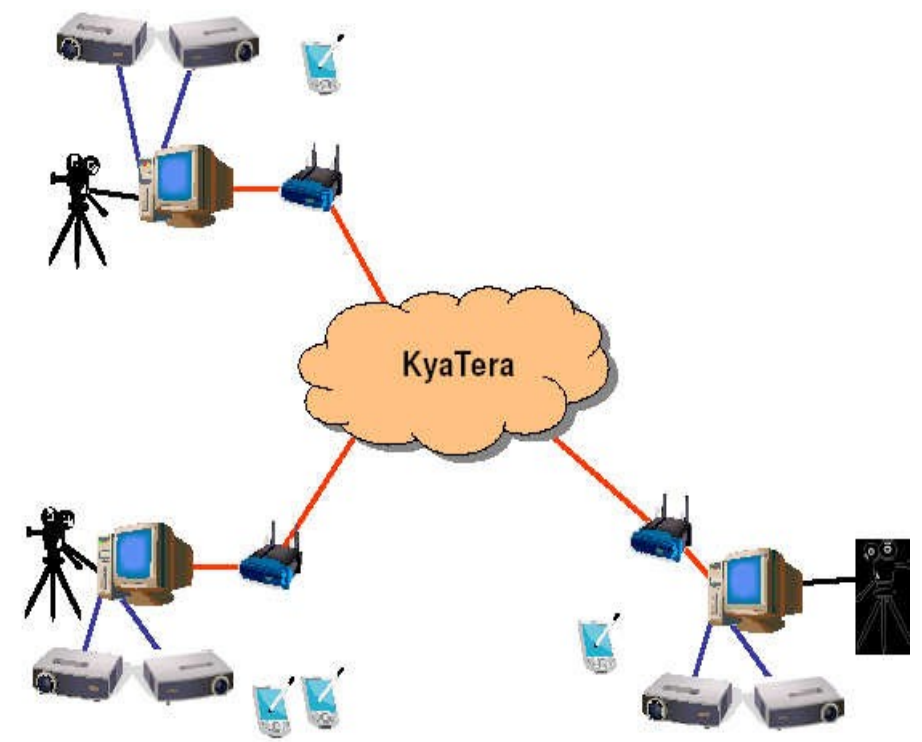

Figura 1: Proposta do DiGaE: a rede KyaTera, de alta velocidade e baixa latência, integra três ambientes remotos instrumentados com câmeras, projetores, computadores e PDAs.

\footnotetext{
${ }^{1}$ Chat na tradução para o português é Bate-Papo, para esta dissertação foi adotado o uso do termo Chat.
} 
Para que o ambiente DiGaE funcione e suas interfaces possam ser utilizadas por pessoas inexperientes em computação, são necessárias pesquisas que esclareçam e aprofundem as questões sobre como projetar a interação humano-computador (IHC). Esta necessidade se dá principalmente pelo fato de cada usuário precisar de um conjunto diferente de ferramentas para cada sessão. Uma possibilidade é permitir que o próprio usuário configure ou personalize o ambiente e suas ferramentas de acordo com as necessidades da sessão que será iniciada (person-to-person, person-to-room, room-to-room).

O projeto Sakai, que envolve uma parceria internacional, foi adotado como plataforma de gerenciamento de $\operatorname{cursos}^{2}$ por diversas universidades do exterior. O projeto fornece ao professor ferramentas para apoio ao oferecimento de um curso, como por exemplo controle de acesso, wiki, portfólio, chat, videoconferência, podcast, whiteboard, comunicador instantâneo e quiz. Suas ferramentas têm sido desenvolvidas em parceria com várias instituições ao redor do mundo.

No início da fase II do Projeto TIDIA-Ae foi estabelecida uma parceria com o Projeto Sakai, o que trouxe beneficios para ambos projetos. O Sakai não contempla a utilização de redes de alta velocidade, o que limita o uso de conteúdo multimídia, como áudio e vídeo em suas ferramentas síncronas. Esse é um dos aspectos onde o TIDIA-Ae mais pode contribuir com o Sakai. A parceria TIDIA-Sakai pode se beneficiar da experiência adquirida com o desenvolvimento de ferramentas síncronas do TIDIA-Ae e da robustez e da estabilidade oferecidos pelo framework Sakai para o desenvolvimento de ferramentas para educação a distância. Por este motivo, as ferramentas síncronas desenvolvidas na fase I do Projeto TIDIA-Ae: o Comunicador Instantâneo (Lobato et al., 2005), o Chat (Moraes et al., 2008) e a Whiteboard (Jardim et al., 2005) foram migradas para a plataforma Sakai.

\subsection{Motivação}

A captura da informação em ambientes físicos, tais como salas de aula e em reuniões é motivada pela perda de informações importantes que são

\footnotetext{
${ }^{2}$ LMS - Learning Management System é um sistema de gerenciamento de cursos com softwares que auxiliam a promoção da educação virtual ou semipresencialmente.
} 
geradas durante a comunicação entre usuários nesses diferentes contextos, o que faz com que os participantes tenham dificuldade de registrar decisões importantes ou, mesmo, repitam discussões. Whittaker et al. (2008) detectaram em um estudo que $70 \%$ dos participantes de reuniões que foram avaliados tinham problemas com suas práticas de anotação, como a perda de informação, ilegibilidade de termos, abreviaturas impossiveis de interpretar, além do pouco tempo para anotar e da redução da participação no evento por estar com a atenção dividida.

Para permitir a captura automática das informações associadas a eventos são necessários sistemas computacionais específicos embutidos nos ambientes. O DiGaE prevê a utilização de um conjunto de dispositivos que são necessários para captura de informações geradas mas que consequentemente exigem configuração e integração. A configuração desses dispositivos é uma tarefa complexa, especialmente para os usuários não especialistas no domínio da informática.

Assim, para que dispositivos físicos possam ser utilizados é necessária uma aplicação que suporte seus serviços e os integre. Para que as informações capturadas possam ser acessadas, pode-se publicá-las em uma página web, mas para isso os diferentes tipos de mídia devem estar sincronizados. Também devem ser integradas diferentes ferramentas de comunicação para que os participantes que tenham feito login no ambiente acessem todas as informações ao vivo e possam colaborar com elas também. Com uma lousa eletrônica, por exemplo, pode-se utilizar a ferramenta Whiteboard (Jardim et al., 2005) que provê ao usuário slides (vazios ou provenientes de um arquivo preparado para uma apresentação) onde ele pode fazer anotações textuais ou gráficas com caneta, especificar cor, espessura e inserir imagens.

Ao considerar um conjunto de dispositivos de hardware em um ambiente instrumentado, integrados por softwares de aplicações ubíquas, para comunicação remota, há uma série de questões a serem analisadas com relação à interação do usuário. Neste caso é um desafio aliar diferentes funcionalidades assegurando simplicidade na interação. 
Três elementos são fundamentais para se considerar no design de um sistema ubíquo adequado: o perfil dos usuários, as funcionalidades da interface e as informações de contexto (Roibás e Sala, 2007). A abordagem de design centrado no usuário é crucial para identificar cenários realistas e aplicações para sistemas multimídia interativos pervasivos que forneçam aos usuários experiências positivas.

\subsection{Objetivos}

Este trabalho tem por objetivo geral estudar a interação do usuário com ferramentas de comunicação remota em um ambiente instrumentado (DiGaE) para que, a partir desse estudo, possam ser definidas algumas diretivas para desenvolver, avaliar e propor soluções de interface gráfica e interação do usuário, visando a construção de uma aplicação que una ferramentas de comunicação síncrona, como Chat (Moraes et al., 2008), Whiteboard (Jardim et al., 2005) e Comunicador Instantâneo (Lobato et al., 2005) com áudio e vídeo (AV), provendo facilidades de uso e de configuração.

Os objetivos específicos incluem especificar uma versão da aplicação DiGaE, desenvolver protótipos de interfaces, avaliá-los e sugerir soluções que facilitem a interação do usuário com a aplicação, aproximando o modelo conceitual da aplicação do modelo mental do usuário alvo.

\subsection{Metodologia e Resultados Obtidos}

A pesquisa bibliográfica foi realizada com artigos, livros, revistas e na web, com o intuito de obter informações que contribuíssem para solução de design de interfaces para aplicações de comunicação síncrona e distribuída.

Para a modelagem dos requisitos do DiGaE foram utilizados os diagramas e casos de uso da Unified Modeling Language ou UML (OMG, 1997), identificando cenários com uma sequência de passos que descreve a interação do usuário com a aplicação (Flower e Scott, 2000). O cenário é composto por (Blaha e Rumbaugh, 2006):

- Atores, que são perfis de usuários que interagem com o programa, ou mesmo outros programas. Devem ser externos ao programa e se comunicar com ele, mas não ser parte dele; e, 
- Casos de uso, que são partes coerentes de funcionalidades que um programa pode fornecer interagindo com os atores ou outros programas externos.

Como resultado, foi desenvolvida a documentação para a primeira versão do DiGaE, composta por Levantamento de Requisitos, Relatório de Casos de Uso, Diagrama de Sequência, Fluxograma e HTA (Hierarchical Task Analysis).

Para o desenvolvimento do DiGaE foi utilizada a abordagem de design centrado no usuário, da Interação Humano-Computador (IHC), esta técnica prevê um modelo iterativo de especificação, desenvolvimento e avaliação; e visa obter alto nivel de usabilidade nas interfaces (Hix e Hartson, 1993; Preece, 2002).

Para a avaliação dos protótipos de interfaces desenvolvidos foram combinadas diferentes técnicas de IHC e diferentes perfis de avaliadores. A primeira avaliação foi realizada com sketches que simulavam a navegação no DiGaE, a segunda avaliação foi realizada exclusivamente sobre cada ferramenta que compõe a primeira versão do protótipo do DiGaE (Chat, Whiteboard e Comunicador Instantâneo), e a terceira avaliação ocorreu no ambiente instrumentado. Ao final das avaliações foi identificado um conjunto de problemas que devem ser considerados para o desenvolvimento da próxima versão do DiGaE com o objetivo de aumentar sua usabilidade, e que pode também ser utilizado para orientar o desenvolvimento de aplicações de mesma natureza.

O protótipo atual do DiGaE possibilita a realização de sessões de comunicação remota entre participantes utilizando os recursos disponiveis no ambiente: leitor de RFID para identificação do usuário, lousa eletrônica para interação via caneta, câmera, microfone de lapela e caixas de som para captura de áudio e de vídeo, todos coordenados por um conjunto de computadores.

\subsection{Estrutura da Dissertação}

Esta dissertação está organizada da seguinte maneira: No Capitulo 2 são apresentados os conceitos fundamentais que foram utilizados para o 
desenvolvimento deste projeto: da Engenharia de Software, os diagramas UML e o modelo de desenvolvimento; de Interação Humano-Computador, a abordagem de design centrado no usuário e os métodos de desenvolvimento e de avaliação de interfaces; de Computação Ubíqua foram estudados trabalhos relacionados e utilizadas a classificação e as técnicas de captura e acesso de documentos. No Capítulo 3 há uma revisão da literatura que inclui a discussão de trabalhos desenvolvidos como aplicações de captura e acesso para diversos domínios e aplicação convencionais utilizadas em comunicação síncrona distribuída. O Capítulo 4 detalha a metodologia adotada, seguida pelos resultados, discussões e contribuições obtidos ao final de cada fase do desenvolvimento. O Capítulo 5 apresenta a discussão dos resultados e das limitações da solução proposta, sumariza as contribuições obtidas e discute os trabalhos futuros. 


\section{CONCEITOS FUNDAMENTAIS}

\subsection{Considerações Iniciais}

Neste capítulo são apresentadas informações importantes para o entendimento do trabalho relatado nesta dissertação, como, por exemplo, modelos de classificação de computação ubíqua, técnicas de modelagem e de especificação de requisitos de engenharia de software, métodos para design e avaliação de interfaces da área de interação humano-computador.

\subsection{Computação Ubíqua}

A computação ubíqua prevê o enriquecimento de espaços físicos com aparatos tecnológicos para automatizar e apoiar tarefas cotidianas (Weiser, 1999). Nesses espaços, sensores capturam informações sobre o contexto ou a atividade do usuário, e aplicações adequam os recursos do ambiente às necessidades do indivíduo.

As informações de contexto se referem aos dados disponíveis no ambiente que permitem à tecnologia computacional se adequar às necessidades dos usuários e incluem a data de um evento, o local, os dispositivos em uso, as pessoas envolvidas, a temperatura (Abowd et al., 2002).

Em um contexto de sala de aula ubíqua, por exemplo, pode-se utilizar sensores de temperatura que acionam o ar condicionado, regulando-o para que a temperatura sempre esteja apropriada; sensores de presença podem ajustar a iluminação do ambiente e a captura da câmera de acordo com a movimentação do professor; sensores de áudio permitem alterar o volume nas caixas de som de acordo com o que for capturado pelo microfone.

Enfim, há vários cenários que podem ser contemplados de modo ubíquo em eventos cotidianos. No entanto, para todos eles é necessário um dispositivo de hardware (por exemplo um sensor) para capturar uma informação de contexto no ambiente, uma aplicação computacional que receba o dado do sensor e esteja programada para tratá-lo, e um outro 
dispositivo computacional (ou um conjunto destes) que reaja conforme as especificações transmitidas pela aplicação.

As aplicações de computação ubíqua exigem o trabalho de uma equipe multidisciplinar por envolver diferentes áreas da computação, como sistemas distribuídos, interação humano-computador, hipermídia e engenharia de software, com objetivo de gerar uma aplicação rica e transparente (Weiser, 1999).

A literatura de Computação Ubíqua define como aplicações de captura e acesso (Abowd et al., 2002), sistemas computacionais invisivelmente embutidos no contexto do usuário que capturam as informações geradas em um evento, armazenando-as e possibilitando que sejam posteriormente recuperadas. Aplicações de captura e acesso demandam a integração de dispositivos de hardware com softwares que disponibilizem os serviços fornecidos de modo sincronizado.

As informações de contexto estão associadas a diferentes características do ambiente ubíquo, uma delas se refere à identificação do usuário. O controle do acesso ao ambiente não só identifica o usuário como também permite que a aplicação se adapte a ele. Para a identificação, podem ser adotados diferentes tipos de abordagens, tais como o uso de um leitor de impressão digital (Sanchez-Reillo e Sanchez-Avila, 2001), ou o reconhecimento de voz ou face para autenticação de usuários em um ambiente (Lee et al., 2002; Shi et al., 2003). Uma desvantagem destes tipos de identificação é a necessidade da interação explícita do usuário.

RFID (Radio-Frequency Identification) é um método de identificação automática por sinais de rádio, composto por uma etiqueta RFID e um leitor. Uma etiqueta RFID é um transponder com microchips de silício e antenas que respondem a sinais de rádio enviados por uma base transmissora. Os microchips possuem um número de identificação. Um leitor de etiquetas RFID, ou transceiver, converte as ondas de rádio refletidas da etiqueta RFID para informação digital que pode ser usada em um computador para fins específicos (ISO 18000, 2003). 
No contexto do DiGaE foi utilizado um leitor de $\mathrm{RFID}^{3}$ com chip Mifare e um cartão USP com a etiqueta RFID ${ }^{4}$ embutida conforme ilustra a Figura 2. O leitor de RFID é um dispositivo eletrônico que pode ser utilizado para controle de acesso a um ambiente instrumentado. Ele se liga à porta serial RS232 de um computador por meio de um cabo de conexão conversor de DB15 para DB9 e usa fonte de 12 Volts. O transponder ${ }^{5}$ do cartão, que neste caso tem frequência de $13,56 \mathrm{Mhz}$, é detectado pelo transceiver $^{6}$ do leitor.

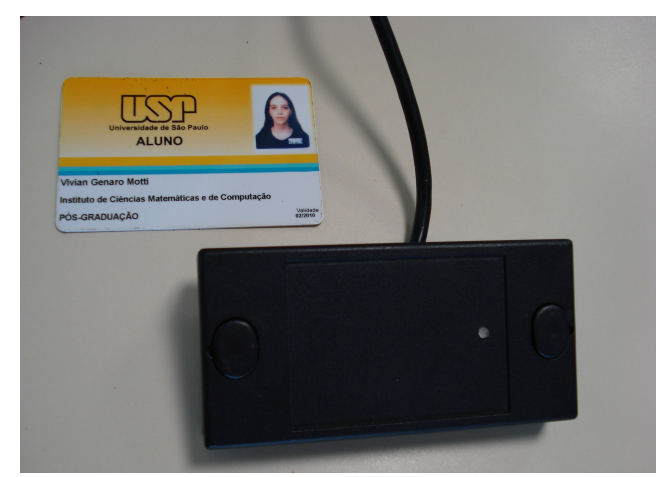

Figura 2: Cartão USP com etiqueta RFID e leitor RFID.

\subsection{Modelagem e Especificação}

Da área de Engenharia de Software utilizou-se a UML (OMG, 1997) para organizar a especificação do sistema com documentos, diagramas, técnicas e notação pré-definida, para se obter uma visão real da aplicação antes de seu desenvolvimento e para apoiá-lo.

A UML detalha a solução a ser desenvolvida na forma de uma aplicação por diferentes diagramas: diagramas de classe, diagramas de sequência e diagramas de casos de uso. Esses diagramas auxiliam o levantamento e a análise dos requisitos da aplicação, uma vez que devem ser identificados os nomes dos atores, os casos de uso e os seus relacionamentos. Assim, é possivel entender e explicitar os objetos, as tarefas e os requisitos da aplicação.

Após a descrição dos casos de uso, é possível, segundo Blaha e Rumbaugh (2006), adequar os modelos de diagramas para conceitos

\footnotetext{
${ }^{3}$ Um leitor RFID detecta uma etiqueta e identifica o código associado a ela.

${ }^{4}$ Uma etiqueta RFID permite identificar por rádio-frequência objetos ou dispositivos ao embutir um chip neles com um código de identificação.

${ }^{5}$ Transponder é um dispositivo eletrônico de comunicação que recebe um sinal em uma frequência específica.

${ }^{6}$ Transceiver é um leitor, componente de comunicação entre o sistema RFID e sistemas externos de comunicação.
} 
computacionais usando o diagrama de classes. O emprego da UML no processo de desenvolvimento da solução permitiu sua descrição com diagramas de casos de uso e de sequência, e a definição, mais clara, do modelo e da arquitetura da aplicação.

Além desses diagramas, foram elaborados um diagrama de fluxo, para ilustrar a estrutura da aplicação de modo geral, e um diagrama HTA, que decompõe as tarefas do sistema em subníveis para identificar todos os passos necessários para que o usuário conclua uma tarefa (Preece, 2002). O Capítulo 3 descreve e ilustra os diagramas desenvolvidos.

\subsection{Design e Avaliação}

Um bom design de interface de usuário provê uma interação fácil, natural e atraente com o sistema. A área da computação que estuda como as pessoas interagem com os sistemas computacionais denomina-se interação humano-computador (IHC); ela incentiva o uso de técnicas de desenvolvimento e de avaliação de interfaces para que estas alcancem alto nível de usabilidade, de modo que o usuário realize suas tarefas com segurança, eficiência, eficácia e satisfação. Esses aspectos são conhecidos como usabilidade e medem o quanto um produto é usável dentro de um contexto (ISO-9241, 1998). As medidas de usabilidade refletem os resultados da interação dos usuários com o sistema proposto (Filardi e Traina, 2008).

Em IHC diversas técnicas foram propostas para desenvolver interfaces visando a fácil interação dos usuários, assim como técnicas de avaliação para identificar quão próximas a navegação e as interfaces estão do modelo mental do usuário alvo.

O grande desafio de projetar sistemas para pessoas usarem é saber como fazer a transição do que pode ser feito (funcionalidade) para como deve ser feito (usabilidade), buscando alcançar as necessidades e os objetivos dos usuários. Deste modo, avaliações da IHC são necessárias para verificar se as idéias do projetista são realmente o que os usuários necessitam ou desejam. É essencial que os projetistas de interface saibam porque é importante avaliar, o que avaliar e quando avaliar (Preece, 2002). 
Para o desenvolvimento do projeto reportado nesta dissertação foi adotada a abordagem de design centrado no usuário, um método no qual o desenvolvedor deve concentrar seus esforços no usuário e nas tarefas, de maneira que a estrutura da interface deixe claro para o usuário o que ele pode ou não fazer com cada uma das opções disponiveis, como ele deve fazer para interagir e qual resultado irá obter do sistema (Hix e Hartson, 1993).

O projeto centrado no usuário é a união de diversos princípios de usabilidade em uma interface. Essa abordagem de design considerando fatores humanos ajuda as interfaces a tornarem-se mais fácil para o uso. Um projeto centrado no usuário é um processo iterativo que considera design, implementação e avaliação (Hix e Hartson, 1993). O projeto centrado no usuário deve, portanto, buscar a agilidade na interação aumentando a eficiência do usuário, e não reduzindo as tarefas disponíveis. Seus benefícios são claros: melhoria na usabilidade, baixa taxa de erros e tempo de aprendizado menor (Norman, 1988).

Para atingir facilidade de uso nas interfaces é necessário combinar diferentes técnicas de avaliação. Para o DiGaE foram utilizadas quatro técnicas distintas: Percurso Cognitivo, Avaliação Heurística, Think Aloud ${ }^{7}$ e Questionários.

No Percurso Cognitivo (Hom, 1998), os avaliadores incorporam o papel de usuários, simulando-os para tentar responder a perguntas sobre como o usuário tentaria realizar determinadas tarefas no sistema. Este método foca na aprendizagem do sistema por parte do usuário. Quatro perguntas devem ser usadas na fase de análise: a) Os usuários realizarão a ação correta para atingir um objetivo esperado? b) Os usuários perceberão que a ação correta está disponivel? c) Os usuários associarão a ação correta ao efeito desejado? d) Se a ação correta for executada, eles perceberão o progresso no sistema?

Se o design da interface for bom, a intenção do usuário fará com que ele selecione a opção correta e perceba isso na resposta do sistema. Para esse método deve ser identificado o perfil dos usuários contendo informações como: idade, experiência com computadores, profissão, entre outras. A descrição da tarefa e das ações necessárias para concluí-la também devem

\footnotetext{
${ }^{7}$ Na tradução literal, Think Aloud significa Pensar em Voz Alta.
} 
estar especificadas. As respostas dos avaliadores podem ser registradas em áudio e vídeo para serem analisadas e concluir a avaliação. $\mathrm{Na}$ análise dos resultados obtidos, as falhas identificadas na interação, devem ser usadas para orientar desenvolvedores a melhorar o sistema (Hom, 1998).

A Avaliação Heurística (Nielsen, 1993) é um método de inspeção de usabilidade reconhecido por não exigir muito tempo de treinamento e de avaliação. Pela inspeção sistemática das interfaces, é identificada uma série de problemas que podem impedir que um usuário interaja de maneira eficiente com o sistema. Para executá-la, um conjunto de avaliadores examina a interface, verificando se ela está de acordo com um conjunto de heurísticas, que são regras gerais para orientar a avaliação das interfaces conforme a usabilidade. É possivel que o avaliador identifique aspectos de usabilidade específicos a um determinado contexto e que relate isso na avaliação. Nielsen (1993) propôs dez heurísticas para analisar interfaces segundo critérios importantes cujas definições estão intimamente associadas. São elas:

i. Visibilidade do status do sistema: o usuário deve ter acesso ao que está acontecendo no sistema; se houve falha ou sucesso, ou seja, se a tarefa requerida pôde ser concluída ou não, e por qual motivo.

ii. Correspondência entre o sistema e o mundo real: a linguagem do sistema deve ser clara para o usuário, evitando termos técnicos. Metáforas auxiliam o usuário a interagir, desde que não falhem com facilidade e que sejam familiares.

iii. Controle e liberdade do usuário: o usuário deve ter acesso a tarefas específicas dentro de um sistema, mas para outras pode ser necessário uma autenticação. Caso o usuário acesse funções que não sejam de seu interesse, ele deve ter a opção de retornar para onde estava antes no sistema.

iv. Consistência e padrão: manter sempre um mesmo padrão de ícones, fontes, cores e de sequência de interação ajuda o usuário a executar as tarefas e a aprender a utilizar eficientemente o sistema.

v. Prevenção de erros: para usuários principiantes é comum que ocorram certos tipos de erros; durante a avaliação o especialista deve tentar identificá-los e sugerir formas de evitar que aconteçam. Evitar um erro 
previsivel é melhor do que exibir uma mensagem de erro depois que ele tenha sido cometido.

vi. Reconhecimento ao invés de lembrança: existem alguns tipos de serviços que são utilizados com pouca frequência, portanto seus objetos de interação devem ser facilmente reconhecidos a fim de diminuir o esforço cognitivo do usuário durante a utilização do sistema. Se objetos, ações e opções estiverem facilmente identificáveis na interface, o usuário não precisará de muito esforço para realizar o que pretende.

vii. Flexibilidade e eficiência de uso: permitir que usuários avançados tenham opções de interação mais eficientes, por exemplo, usando teclas de atalho para executar determinadas tarefas. As opções mais acessadas em uma interface devem estar em locais de fácil acesso e devem poder ser acessadas de diferentes formas.

viii. Design estético e minimalista: quanto maior o número de opções de tarefas para o usuário no sistema, mais difícil será para ele encontrar o que deseja. A mesma regra se aplica ao conteúdo; quanto menos palavras forem usadas para expressar um mesmo conceito, mas fácil será para o usuário compreendê-lo.

ix. Ajudar usuários a reconhecer, diagnosticar e recuperar erros: o usuário não deve perder dados ou uma sequência de tarefas realizadas, a menos que ele seja avisado sobre isso e seja possível desfazer essa ação, recuperando-os.

x. Ajuda e documentação: partindo do princípio que um sistema nunca estará de acordo com as preferências de todos os usuários, é necessário disponibilizar um manual explicativo do que o sistema pode fazer, como deve fazer e para que serve cada uma das opções de interação.

O resultado da Avaliação Heurística é uma lista de problemas de usabilidade encontrados na interface e uma justificativa bem especificada sobre eles. Assim, a Avaliação Heurística não provê sugestões sobre como corrigir os problemas encontrados, mas os próprios princípios definidos para orientar o design podem ser utilizados na solução dos problemas. Aos problemas identificados na Avaliação Heurística são atribuídos diferentes niveis de severidade. A gravidade de cada problema é dada em função de três 
fatores: a frequência na qual ele ocorre, seu impacto (se o usuário consegue superá-1o) e sua persistência (se o problema se repete) (Nielsen, 1993).

Partindo do pressuposto que um único avaliador não encontra todos os erros ao examinar uma interface, para o método de Avaliação Heurística são necessários ao menos cinco especialistas para detectar uma quantidade significativa de erros. Foi realizado um estudo para identificar qual o número mínimo de avaliadores suficiente para encontrar uma quantidade significativa de erros na interface e observou-se que, quando o número de especialistas utilizados é maior que cinco, a porcentagem de erros detectados na avaliação não aumenta significativamente, de acordo com a curva representada na Figura 3 (Nielsen e Molich, 1990).

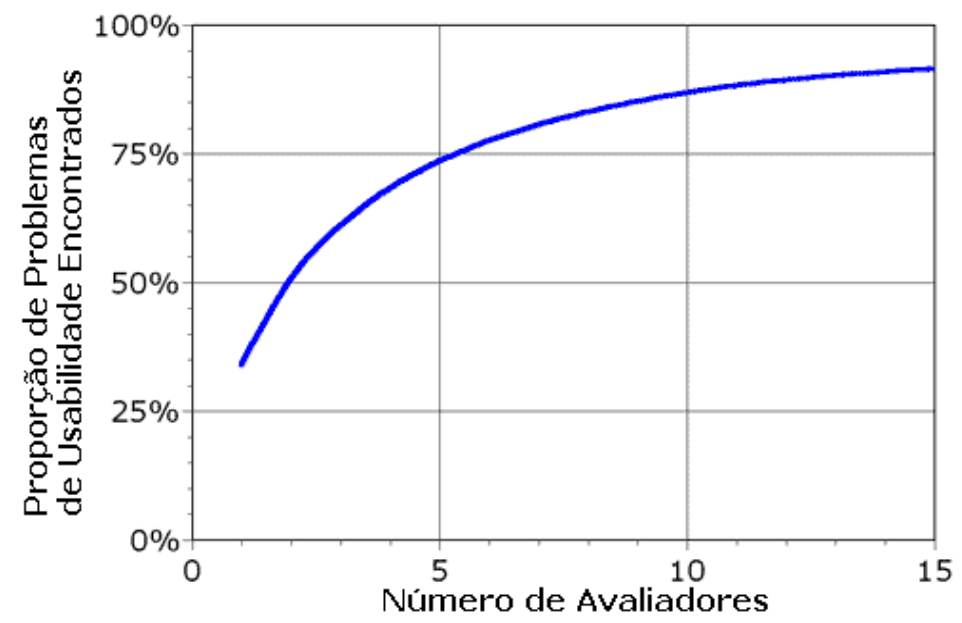

Figura 3: Relação entre número de erros e de avaliadores da Avaliação Heurística (Nielsen e Molich, 1990).

Também deve ser considerada a relação custo-beneficio para definir a avaliação que será realizada no sistema. Sistemas mais críticos, como o de controladores de vôo, por exemplo, devem ser avaliados com mais especialistas a fim de que uma porcentagem maior de erros seja detectada (Nielsen, 1992). 
Outra conclusão que esse estudo identificou é que há diferentes tipos de erros nas interfaces, uns mais fáceis de serem observados e outros mais dificeis, assim como há diferentes tipos de avaliadores, uns mais detalhistas, mais observadores, e outros menos (Nielsen, 1992). Portanto, os problemas mais dificeis de serem notados são identificados apenas por um número restrito de avaliadores, enquanto que problemas mais facilmente identificáveis são observados pela maioria dos especialistas que estão avaliando as interfaces, de acordo com o gráfico da Figura 4.

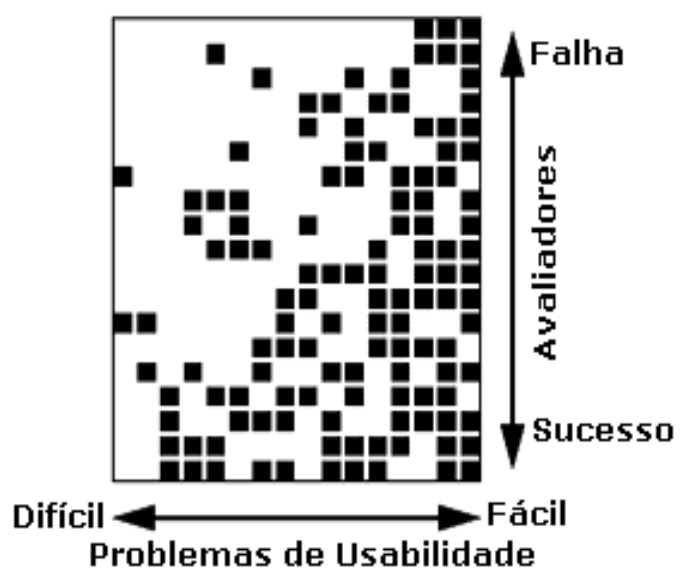

Figura 4: Dificuldade em encontrar os erros $x \mathbf{N}^{\circ}$ de avaliadores (Nielsen, 1992).

A Avaliação Heurística deve ser conduzida sobre cada interface do sistema e por cada avaliador independentemente, evitando viés nos resultados. Somente depois de concluídas todas as avaliações de modo independente por cada avaliador é que os resultados devem ser analisados e considerados para melhorias nas interfaces do sistema.

O Think Aloud (Pensar em Voz Alta) é um método de avaliação que consiste em atribuir uma tarefa bem especificada para um usuário e solicitar que ele a execute na interface (Lewis, 1982). Durante a execução, o usuário deve descrever verbalmente passo-a-passo, quais são suas intenções e o que está sendo feito. Para documentar a sessão podem ser usados gravadores de áudio e vídeo. O material documentado deve ser analisado para identificar o desempenho do sistema durante a interação, possibilitando que sejam observadas se as estratégias usadas para atingir o objetivo foram ideais e se ocorreram problemas e erros durante o processo. Todos os comentários do usuário devem ser criteriosamente analisados. 
A maior desvantagem deste método é que o participante faz duas coisas ao mesmo tempo: executa a tarefa e narra suas ações e pensamentos. A concentração do usuário no uso é de certa maneira reduzida e seu comportamento não é exatamente o mesmo se estivesse calado. Além disso, por se tratar de uma atividade pouco natural, algumas pessoas sentem dificuldade em manter um fluxo contínuo de fala enquanto usam a interface (Nielsen, 1993). Por isso às vezes é necessário interferir, incentivando o avaliador a continuar seu relato.

Questionários de Avaliação são uma técnica bem-estabelecida para coletar opinião de usuários (Preece, 2002). Embora possam parecer um método genérico de avaliação, são capazes de identificar informações valiosas para os desenvolvedores.

Questionários utilizam a metodologia top-down que consiste em avaliar tarefas amplas e depois questões mais específicas do sistema. Podem ser usadas questões abertas, para obter respostas subjetivas (como por exemplo com relação à satisfação do usuário ao interagir com o sistema) e também permitem ao usuário se expressar livremente. Embora respostas abertas exijam esforço maior para análise, elas identificam opiniões que não são descobertas com respostas restritas. Uma vantagem a ser explorada na elaboração de questionários é a possibilidade de solicitar ao usuário sugestões de melhorias para o sistema, as quais podem orientar o desenvolvedor no processo de redesign. Outra vantagem é a possibilidade de comparar a avaliação de participantes diferentes, já que todos recebem o mesmo conjunto de perguntas. Mas é necessário cuidado para criar as sentenças, escolher bem seus termos e analisar os resultados obtidos.

Questionários longos devem ter suas sentenças agrupadas tornando o seu preenchimento mais fácil e lógico. Preece (2002) sugere algumas regras que devem ser seguidas na elaboração de questionários: as sentenças devem ser claras e específicas, a opção não sei deve ser incluída como resposta, a ordem das sentenças deve ser bem pensada, sentenças complexas devem ser evitadas, escalas devem ter intervalos apropriados, ordem intuitiva e ser consistentes, deve-se evitar termos técnicos e sentenças negativas, devem-se 
fornecer instruções claras de preenchimento e manter o questionário tão compacto quanto possivel.

Conforme a sentença elaborada, há tipos diferentes de respostas que podem ser usadas: intervalos, escalas por diferencial semântico e escalas Likert, por exemplo. As respostas especificas podem ser categorizadas mais facilmente, enquanto os intervalos agrupam possiveis respostas, facilitam sua interpretação e podem ser usados, por exemplo, para solicitar a idade, já que algumas pessoas se sentem desconfortáveis ao admiti-la e podem fornecer o valor incorreto. Ao usar intervalos não se deve sobrepor valores nas opções dadas para não confundir os participantes. Por exemplo para perguntar a idade do participante não se deve usar intervalos do tipo 15-20, 20-25, pois pessoas de 20 anos não saberão qual o intervalo correto para resposta (Preece, 2002).

Escalas por diferencial semântico exploram um intervalo entre opiniões divergentes sobre um quesito de avaliação, usando adjetivos. O avaliador escolhe uma posição entre dois extremos indicando seu nível de concordância com relação ao quesito avaliado (Preece, 2002). A Tabela 1 ilustra um exemplo de escala por diferencial semântico com três critérios e sete intervalos para avaliar uma página web.

Tabela 1: Exemplo de escala por diferencial semântico para avaliação de uma página web.

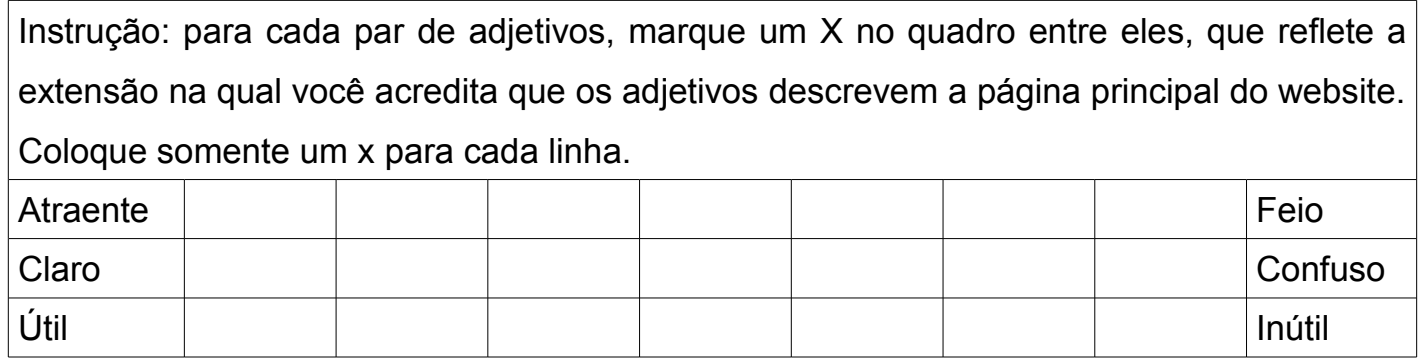

Escalas Likert são usadas para medir a opinião e avaliar a satisfação dos usuários. Para elaborá-las deve-se identificar uma série de sentenças curtas sobre as características a serem avaliadas. Preece (2002) afirma que indivíduos não diferenciam precisamente itens consecutivos em escalas longas, então escalas com mais de cinco itens são desnecessariamente dificeis para serem usadas. Escalas Likert são bastante utilizadas, por ser mais fácil identificar sentenças adequadas à compreensão dos avaliadores do que pares semânticos que os avaliadores interpretem apropriadamente. As 
Tabelas 2 e 3 mostram exemplos de escala Likert, sendo que na Tabela 2 são usados intervalos numéricos para avaliação e na Tabela 3 intervalos por diferencial semântico.

Tabela 2: Exemplo de escala Likert com intervalo numérico.

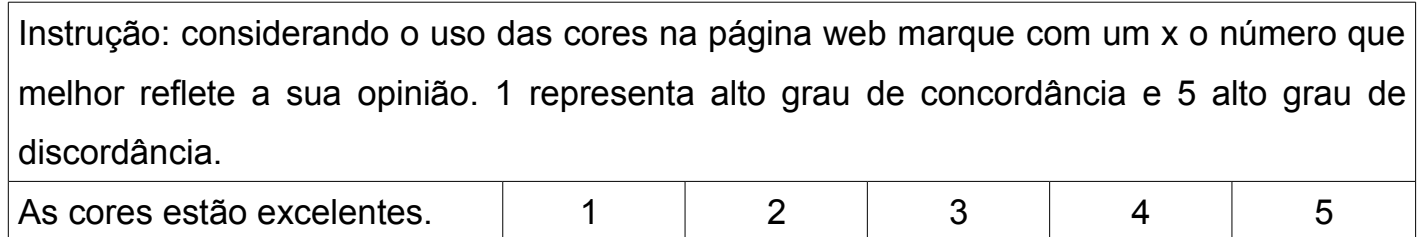

Tabela 3: Exemplo de escala Likert por diferencial semântico.

\begin{tabular}{|l|c|c|c|c|c|}
\hline & $\begin{array}{c}\text { Concordo } \\
\text { fortemente }\end{array}$ & Concordo & Ok & Discordo & $\begin{array}{c}\text { Discordo } \\
\text { fortemente }\end{array}$ \\
\hline As cores estão excelentes. & & & & & \\
\hline
\end{tabular}

A literatura reporta quatro questionários que se destacam para avaliação de usabilidade, podendo ser usados para fins acadêmicos ou comerciais: (i) QUIS ${ }^{8}$ (Questionnaire for User Interaction Satisfaction); (ii) SUMI $^{9}$ (Software Usability Measurement Inventory); (iii) WAMMI ${ }^{10}$ (Websites Analysis and Measurement Inventory) e o (iv) SUS ${ }^{11}$ (System Usability Scale).

O QUIS foi desenvolvido para avaliação da satisfação dos usuários de sistemas computacionais interativos. Muitos de seus itens são uma seleção de um checklist de avaliação por especialistas ao invés de questões para medir a satisfação de usuários. Ele engloba quatro critérios: aprendizagem, terminologia e fluxo de informação, output e características do sistema. Tem dezessete perguntas e utiliza escala por diferencial semântico (Chin et al., 1988).

O WAMMI é um questionário curto e confiável, para avaliação de websites, que extrai informações sobre o nível de usabilidade e de satisfação dos usuários. Foi elaborado pelo Human Factors Research Group.

O SUMI é um questionário de avaliação, reconhecido como padrão internacional (ISO 9241, 1998), para medir a satisfação do usuário durante a interação e a qualidade do software sob o ponto de vista do usuário (Chin et al., 1988). Ele é composto por 50 sentenças sobre as quais o usuário

\footnotetext{
${ }^{8}$ http://lap.umd.edu/QUIS/

${ }^{9}$ http://sumi.ucc.ie

${ }^{10}$ http://www.wammi.com

${ }^{11}$ http://www.mindd.com
} 
avaliador deve analisar se concorda, não concorda ou se ela não se aplica. As questões englobam aspectos de satisfação, eficiência, aprendizagem, ajuda e controle. O preenchimento do formulário SUMI leva cerca de 5 minutos e uma amostra de 5 avaliadores já provê resultados úteis para análise (Chin et al., 1988). A Tabela 4 exemplifica quatro critérios que são analisados na aplicação do SUMI.

Tabela 4: Sentenças de avaliação SUMI.

\begin{tabular}{|l|l|l|l|}
\hline & Concordo & Indeciso & Discordo \\
\hline A resposta do sistema à entrada de dados é muito lenta. & & & \\
\hline As mensagens e instruções ajudam bastante. & & & \\
\hline A forma de apresentação dos dados é clara e compreensível. & & & \\
\hline Eu não utilizaria este sistema diariamente. & & & \\
\hline
\end{tabular}

Os itens avaliados pelo SUMI estão classificados em cinco fatores: a afinidade que analisa reações emocionais do usuário ao software, como a satisfação dele ao interagir; a eficiência que avalia o nível no qual o software ajuda os usuários em seu trabalho; a eficácia que mede o quanto o software é de fácil compreensão, além do quanto a ajuda e a documentação são adequadas; o controle que avalia o quanto os usuários se sentem no comando do software, e não controlados por ele, quando executam a tarefa; e o aprendizado, que mede a velocidade e facilidade do usuário em aprender novas funções do software e se sentir hábil na sua utilização.

Para avaliação do DiGaE, o questionário SUMI original (Chin et al., 1988) foi traduzido, avaliado e então foi feito um teste piloto para identificar se os usuários teriam problemas em compreender corretamente as sentenças. Após essa avaliação, uma versão do questionário foi produzida e aplicada. O SUMI utilizado pode ser consultado no Apêndice A.

Uma versão especializada do SUMI, voltada para sistemas multimídia, o MUMMS ${ }^{12}$ (Measuring The Usability of Multimedia Systems), foi desenvolvida. Ele foca em cinco conceitos: se o produto captura respostas emocionais do usuário, o quanto o usuário tem controle sobre o software, o grau de eficácia dos usuários ao interagir, o quanto o produto ajuda o 12 http://www.ucc.ie/hfrg/questionnaires/mumms/ 
usuário e a facilidade com a qual o usuário pode aprender a usar o produto. Uma restrição do MUMMS é que seu foco é comercial (Preece, 2002).

Para obter resultados significativos com a aplicação dos questionários é necessário atingir uma amostra representativa de participantes e assegurar uma taxa de resposta razoável. Preece (2002) afirma que 40\% de retorno é em geral aceitável, mas que normalmente porcentagens bem menores são comuns. Para evitar isto sugere-se incentivar os avaliadores:

- garantindo um bom design de questionário,

- instruindo os avaliadores para o preenchimento correto,

- facilitando o envio das respostas,

- explicando a necessidade e o objetivo do questionário,

- cobrando a resposta e,

- oferecendo recompensas, por exemplo em dinheiro.

\subsection{Considerações Finais}

Muitas teorias já foram desenvolvidas para orientar desenvolvedores tanto no processo de construção quanto no processo de avaliação de interfaces. Há guias de estilo e principios que sintetizam o que um desenvolvedor deve considerar no desenvolvimento do sistema para assegurar alto nivel de usabilidade na interação.

Com relação às técnicas de avaliação, é evidente que combinar diferentes tipos de avaliadores, sejam eles especialistas em IHC ou usuários reais, provê resultados melhores e complementares, assim como a combinação de diferentes técnicas possibilita identificar problemas de diferentes tipos, fornecendo um resultado final de avaliação mais completo.

Em qualquer avaliação o usuário ou o especialista que colabora com a avaliação deve estar ciente de que é o sistema que está sendo avaliado, e não o seu desempenho ao executar tarefas no sistema.

Além de utilizar guias e princípios que orientem o desenvolvimento e técnicas de avaliação de usabilidade complementares, deve-se enfatizar que a IHC deve ser considerada durante todo o processo de desenvolvimento de um sistema, pois isto evita um esforço intensivo de avaliação e correção de erros depois que o sistema está em estágio avançado de desenvolvimento, 
além de garantir mais facilidade de uso, aliando eficiência, eficácia e satisfação do usuário na interação com o sistema. 


\section{TRABALHOS RELACIONADOS}

\subsection{Considerações Iniciais}

Este capitulo apresenta cronologicamente os trabalhos encontrados na literatura que relatam a experiência dos autores com projetos de captura e acesso em diferentes domínios de aplicação e apresenta comunicadores instantâneos que foram desenvolvidos e atualmente são utilizados. Foram analisados e discutidos especialmente os aspectos de interação apresentados pelos autores e que contribuíram com o desenvolvimento do DiGaE.

\subsection{Tivoli}

É uma aplicação do tipo Whiteboard para suporte a reuniões. No seu desenvolvimento, para identificar suas funcionalidades, 14 cenários possiveis foram especificados e alguns dos serviços necessários a eles foram desenvolvidos: interação via caneta, múltiplas páginas, armazenamento, recuperação, impressão e importação de imagens. O diferencial da Whiteboard desenvolvida (Pedersen et al., 1993) está no reconhecimento de gestos na escrita, que é mais natural para interação via caneta. Apesar disso, suas funções também podem ser acessadas via botões ou menus, uma vez que usuários novatos não conhecem os gestos pré-determinados. A lousa permite interação colaborativa, mas a princípio o gerenciamento das ações nestes casos não foi implementado. O design da ferramenta possui como principal desafio equilibrar objetivos conflitantes: simplicidade na interface e funcionalidades múltiplas. O usuário novo tende a achar a interface da lousa tão complexa que é incapaz de realizar ações básicas. A Figura 5 ilustra a interface do Tivoli para escrita, desenho e anotação usando uma lousa eletrônica com interação via caneta (Pedersen et al., 1993). 


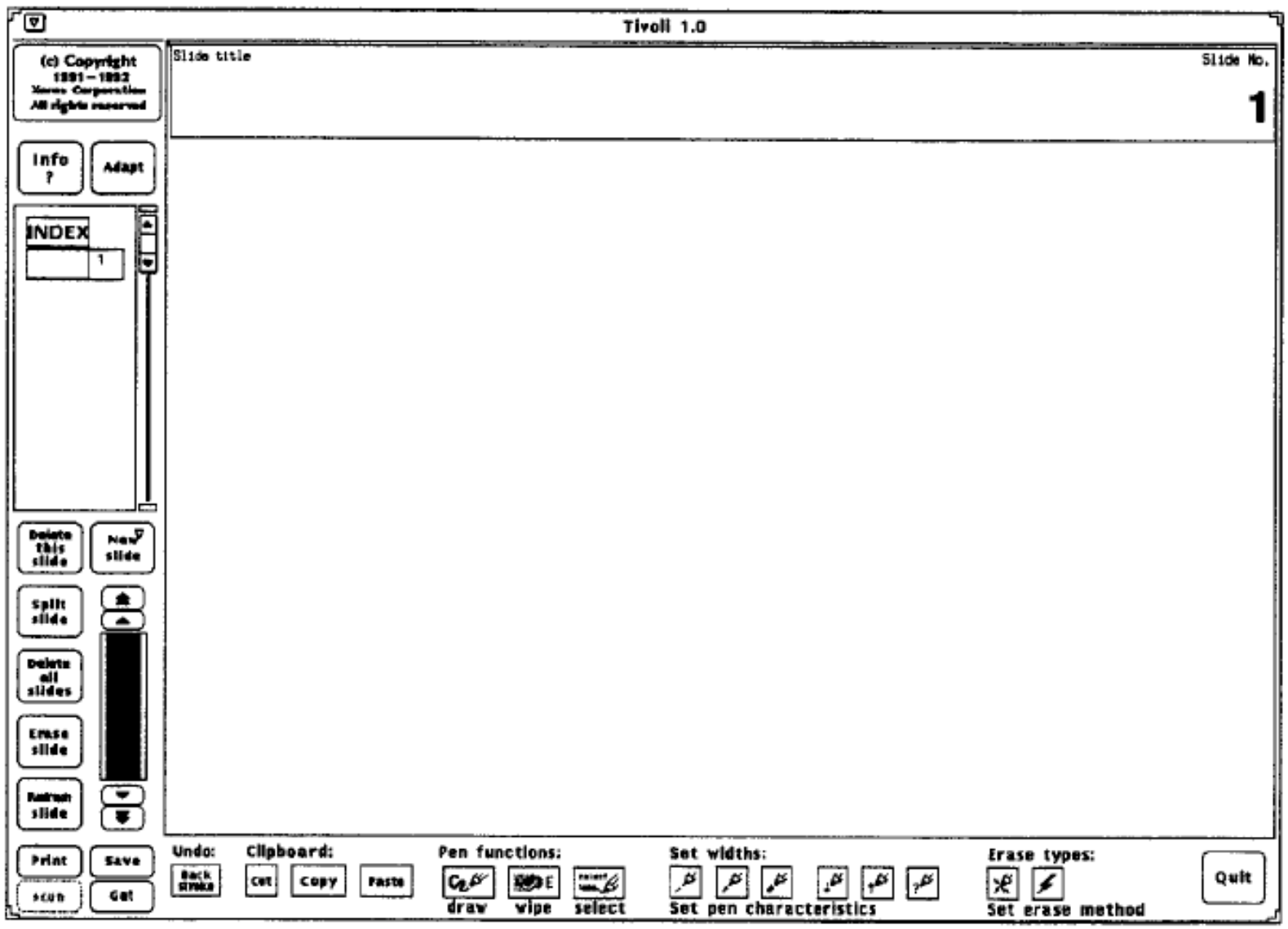

Figura 5: Janela do Tivoli com slide em branco (Pedersen et al., 1993).

\subsection{Coral}

Coral explora uma arquitetura composta por duas aplicações préexistentes, o WhereWereWe (API que facilita o compartilhamento de recursos, faz indexação e permite navegação pelo fluxo de dados) e o Tivoli (responsável pela captura de multimídia) (Pedersen et al., 1993). Coral é uma ferramenta de apoio a reuniões, com foco em ambientes de comunicação multimídia, conforme o ilustrado na Figura 6. Além de estender atividades em papel ou lousa eletrônica usando ferramentas computacionais, é capaz de registrar aspectos informais das atividades de reuniões. Neste trabalho os autores relataram que o contato próximo com os usuários facilitou a identificação das tarefas que o sistema deveria fazer. Também foi relatado que atividades de captura e acesso com registro de dados associado ao tempo têm se mostrado uma área extremamente rica, com diversas linhas de pesquisa como o reconhecimento de voz ou interfaces de usuário baseadas em caneta (Minneman et al., 1995). 


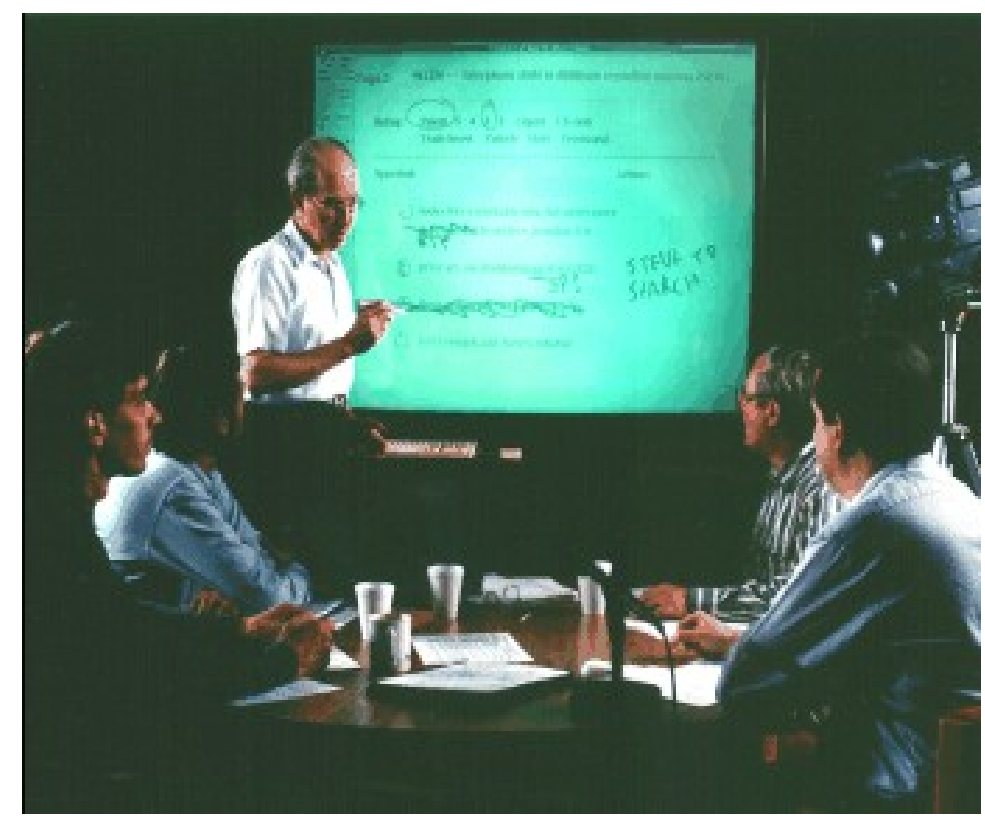

Figura 6: Uma sessão de captura. O microfone, a câmera, a LiveBoard e o laptop capturam áudio, vídeo e anotações em uma reunião (Minneman et al, 1995).

\subsection{DUMMBO}

DUMMBO (Dynamic Ubiquitous Mobile Meeting Board) é uma lousa eletrônica com superficie para escrita, conforme ilustra a Figura 7 à esquerda. Microfones e laptops armazenam o áudio de reuniões e registram as interações de escrever, desenhar e apagar, conforme ilustra a Figura 7 à direita. Essa lousa é para ser utilizada em reuniões informais e não planejadas. O áudio é capturado por dois microfones de alta qualidade enquanto a lousa estiver em uso. O computador mantém um banco de dados com todas as interações na lousa e áudio capturado. Uma página web disponibiliza as atividades registradas e para acessá-las o usuário deve indicar a data e o local do evento. A navegação pelos quadros capturados de uma sessão ocorre com a movimentação de uma barra de rolagem referente ao tempo, assim o usuário pode acessar diferentes instantes de um evento em uma busca rápida (Brotherton et al., 1999). 


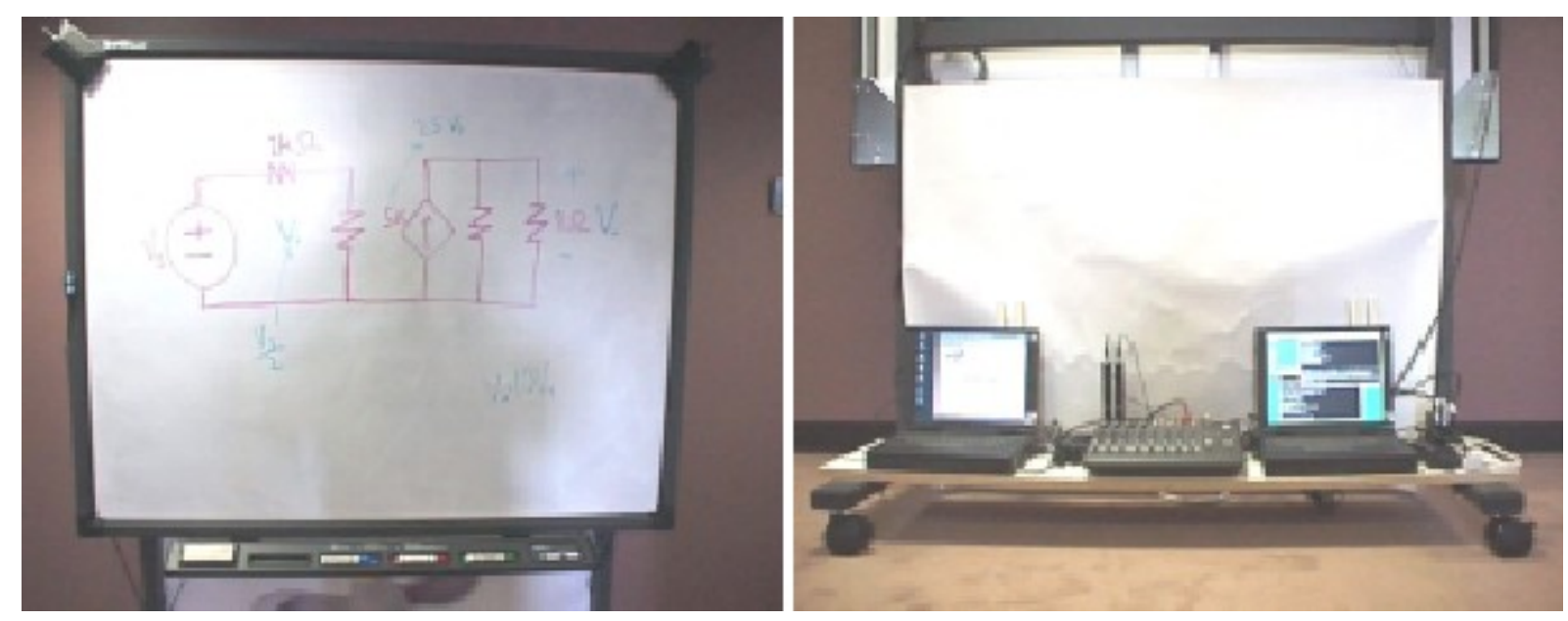

Figura 7: A vista de frente da lousa DUMMBO (à esquerda) e a de trás (à direita) com os equipamentos (Brotherton et al., 1999).

\section{5 iClass}

iClass, baseado no original eClass reportado por Abowd (1999), permite registrar informações produzidas em uma aula, os strokes e os slides de uma lousa eletrônica, áudio de microfones, vídeo de uma câmera e páginas web visitadas durante a apresentação. A Figura 8 ilustra, à esquerda, um aluno usando um Tablet PC para interagir com a ferramenta e, à direita, a professora escrevendo sobre a lousa. Ao final da aula, um documento XML integrando diferentes mídias capturadas é automaticamente produzido e armazenado em um repositório (Pimentel et al., 2005). É possivel revisitar os slides estaticamente, visualizando seu conteúdo na forma de imagens apresentadas na página web, ou dinamicamente, com o iPlayer que foi desenvolvido para sincronização dos slides contendo os strokes que foram capturados com as mídias contínuas (áudio ou vídeo). 


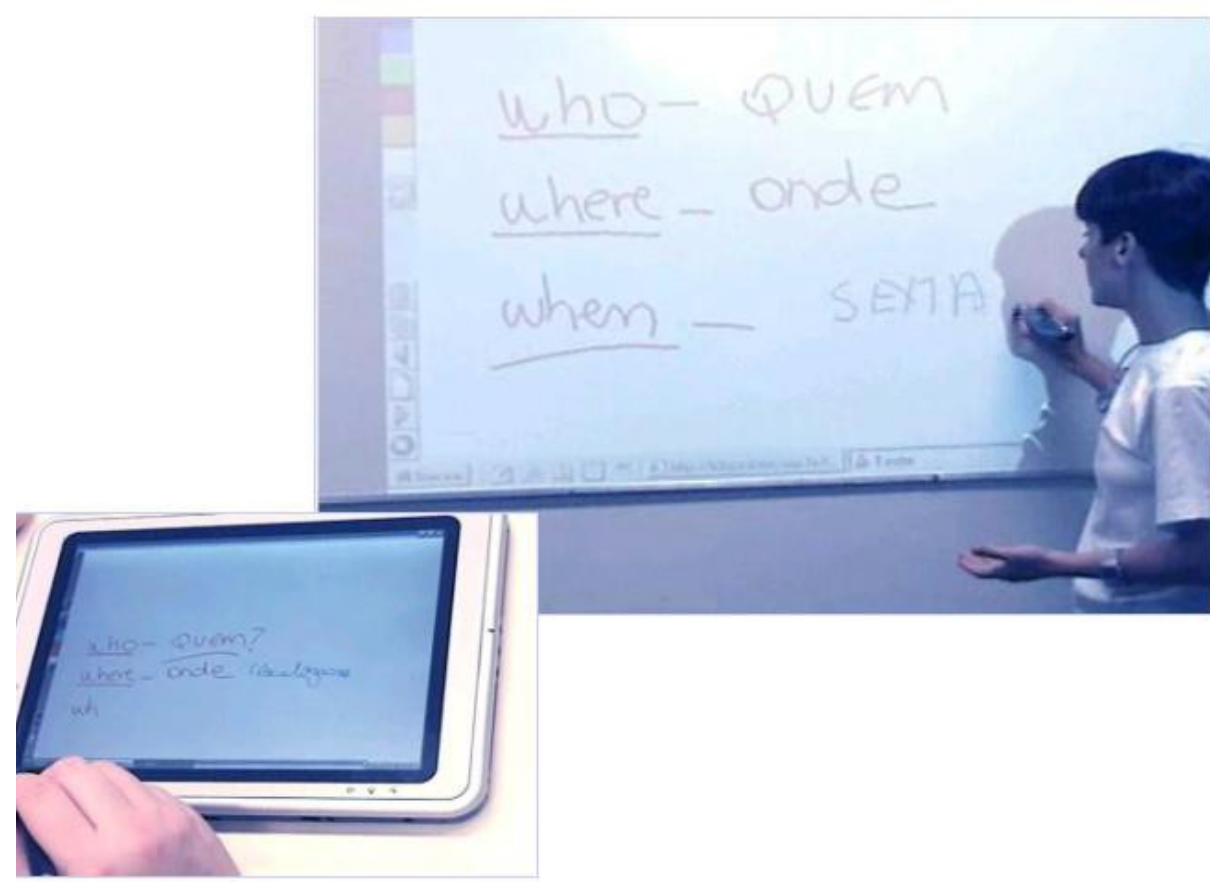

Figura 8: $O$ professor escreve na lousa usando iClass (esquerda). $O$ aluno usa o iClass em um tablet (direita) (Pimentel et al., 2005).

\subsection{LiteMinutes}

LiteMinutes (Chiu et al., 2001) é uma aplicação para automatizar a realização de anotações durante reuniões em empresas. O sistema funciona da seguinte maneira: um ou mais participantes da reunião acessam a aplicação e, enquanto participam da reunião, produzem anotações associadas. O conteúdo produzido é associado a marcações de horário para que depois seja sincronizado com o áudio e o vídeo capturados, e acessado mediante links disponiveis junto às anotações. É possivel que o redator das anotações efetue uma revisão no material produzido corrigindo possiveis imperfeições ou completando partes do texto.

O conteúdo gerado é automaticamente publicado em uma página web e enviado por email a cada um dos participantes. No contexto de ambientes CSCW, o sistema LiteMinutes foi projetado para apoiar a captura de informações em reuniões de projeto programadas, e faz uso de um conjunto de servidores integrados que capturam e apóiam as mídias suportadas (anotações, slides, áudio e vídeo). Em termos de infra-estrutura, a arquitetura do LiteMinutes utiliza servidores multimídia genéricos para 
armazenamento e acesso à informação. Outro diferencial neste sistema é o uso de metadados. A Figura 9 ilustra um ambiente para uso do LiteMinutes.

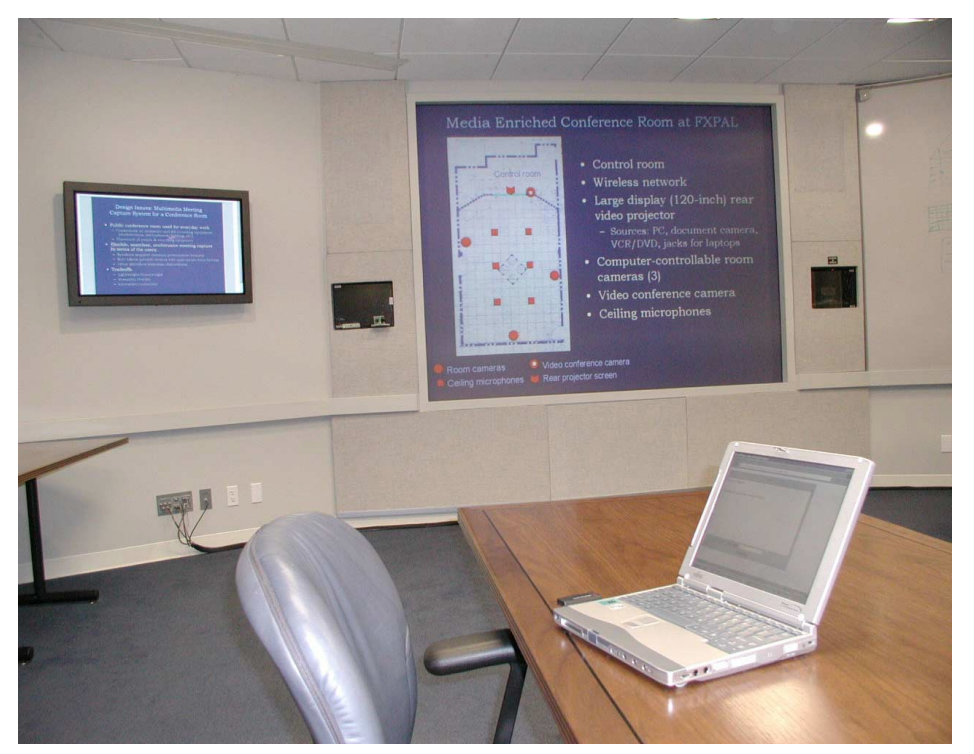

Figura 9: Sala de reuniões com um display grande, um pequeno e notebook wireless para anotações (Chiu et al., 2001).

\subsection{Portable Meeting Recorder}

Em sua pesquisa, Lee et al. (2002) enfatizam questões de acesso aos documentos gerados. A captura é realizada por um único equipamento, ao invés de um ambiente instrumentado. Uma câmera captura o vídeo panorâmico da reunião e quatro microfones registram o áudio. A interface da Figura 10 permite que os participantes acessem em tempo real o áudio e o vídeo e anotem. Para acessar o conteúdo há várias opções de navegação. No centro da interface está o vídeo (tanto em imagem panorâmica como com foco no participante que está falando), os usuários podem navegar por indices (como o da transição entre participantes que discursam), ou acessar conteúdo em áudio, imagens ou vídeos. Um transcrito ASR (automatic speech recognition), ou seja, de reconhecimento automático de discurso, é produzido, assim como, um conjunto de quadros principais que também podem ser usados para acesso. A interface permite rever qualquer nota feita ou outros dados gerados na reunião (Lee et al., 2002). 


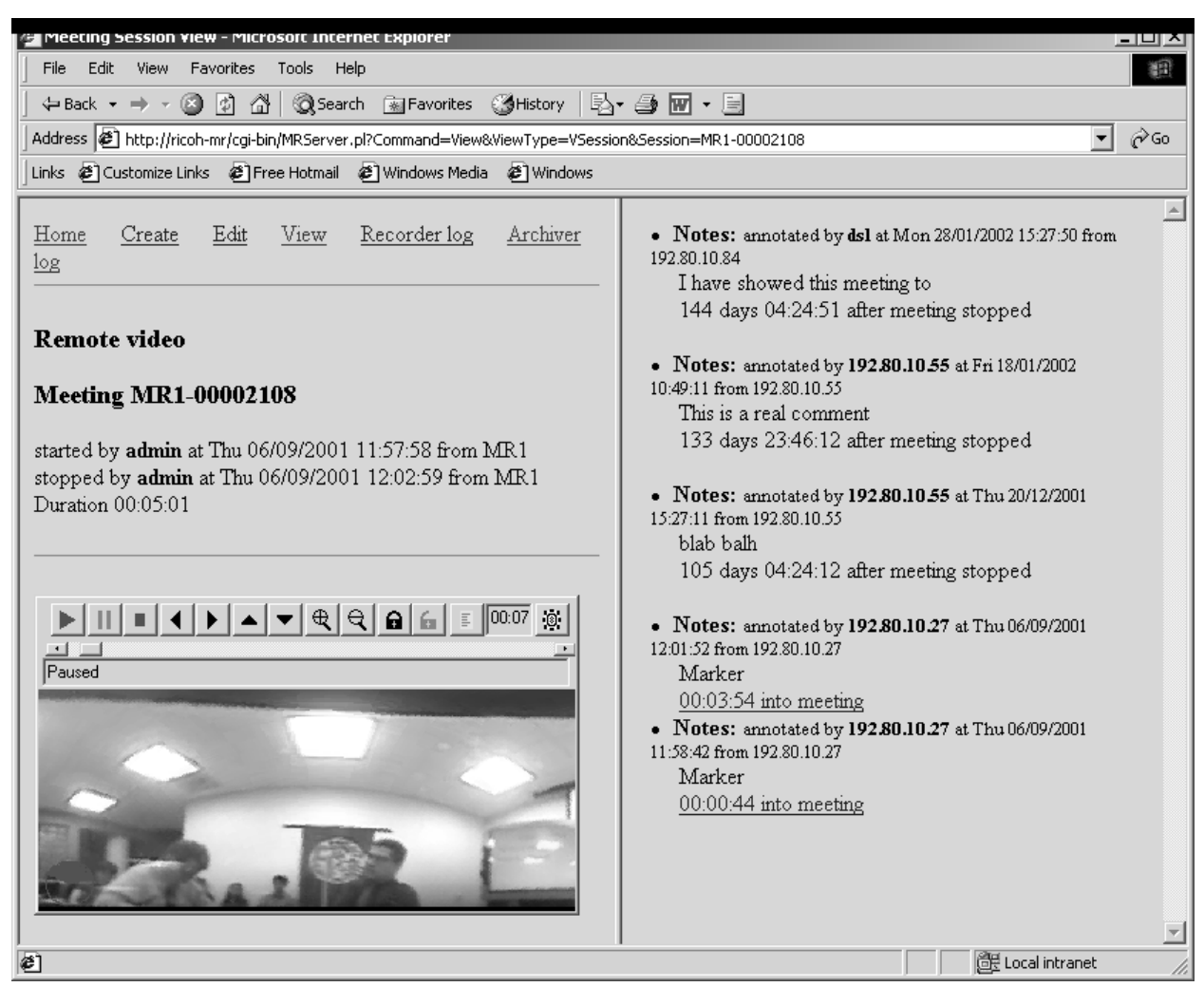

Figura 10: Interface para visualizar a reunião (Lee et al., 2002).

\subsection{Smart Classroom}

Integrando reconhecimento de voz, visão computacional e outras tecnologias, Shi et al. (2003) provêem uma experiência de educação a distância por meio de um sistema multimídia que permite a comunicação entre professores e alunos, remota e sincronamente. Os autores estendem a interface para uma sala de aula 3D, conforme ilustra a Figura 11, armazenando o conteúdo para ser revisto depois. Um assistente virtual exibe as imagens dos estudantes remotos (não foram usados vídeos por questões de desempenho e transmissão na rede). O professor usa um microfone sem fio e anota em uma SmartBoard ${ }^{13}$. Foram citados problemas de escalabilidade para agrupar todas as imagens dos estudantes na projeção lateral. Foram feitas avaliações de usabilidade de modo informal. E agentes de software foram utilizados para a elaboração do aplicativo.

"...executamos um estudo informal de usabilidade da plataforma treinando os membros do projeto Smart Classroom para utilizá-la. Os sete participantes tinham diferentes conhecimentos de pesquisa e experiências em computação distribuída. Nossas observações mostraram que a maioria deles compreendeu os princípios da plataforma e

\footnotetext{
${ }^{13}$ http://smarttech.com/
} 
poderia usar o SDK [kit para desenvolvimento de software] em menos de 1 hora. Metade dos estagiários instalou e executou a plataforma em seus próprios computadores e começou a desenvolver agentes sem ajuda extra."

Para o login uma câmera é colocada atrás de um espelho para fazer o reconhecimento facial do usuário, e essa informação é validada juntamente com a voz do usuário.

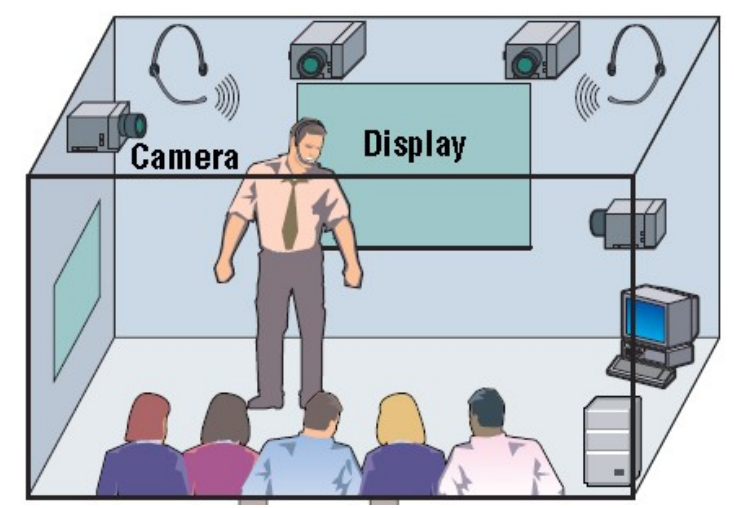

Figura 11: Sala de aula aumentada - Smart Classroom (Shi et al. 2003).

Um dos desafios relatados pelos pesquisadores diz respeito à adaptação das interfaces ao contexto, ou seja, o foco da aula de acordo com o que está acontecendo, por exemplo a câmera deve focar na lousa enquanto o professor escreve sobre ela. É um trabalho bastante completo, no entanto não estão descritos aspectos de IHC. Os autores relatam somente que receberam comentários positivos sobre as interfaces.

\subsection{CAT}

É um toolkit para geração automática de aplicações de captura e acesso pela seleção das funcionalidades desejadas. Como resultado é produzido um front-end, na forma de um applet correspondente à combinação escolhida. O CAT fornece uma página web na qual o usuário provê informação contextual e seleciona as funcionalidades desejadas para a aplicação, conforme ilustra a Figura 12. As informações de contexto consistem em: título da sessão, participantes, local, tipo e controle de acesso. As funcionalidades a serem escolhidas são: texto (chat), Whiteboard, áudio, vídeo e web logging. Como resposta o usuário recebe um applet pronto para execução conforme suas solicitações. Não foi reportada avaliação de uso (Cattelan, 2004). 


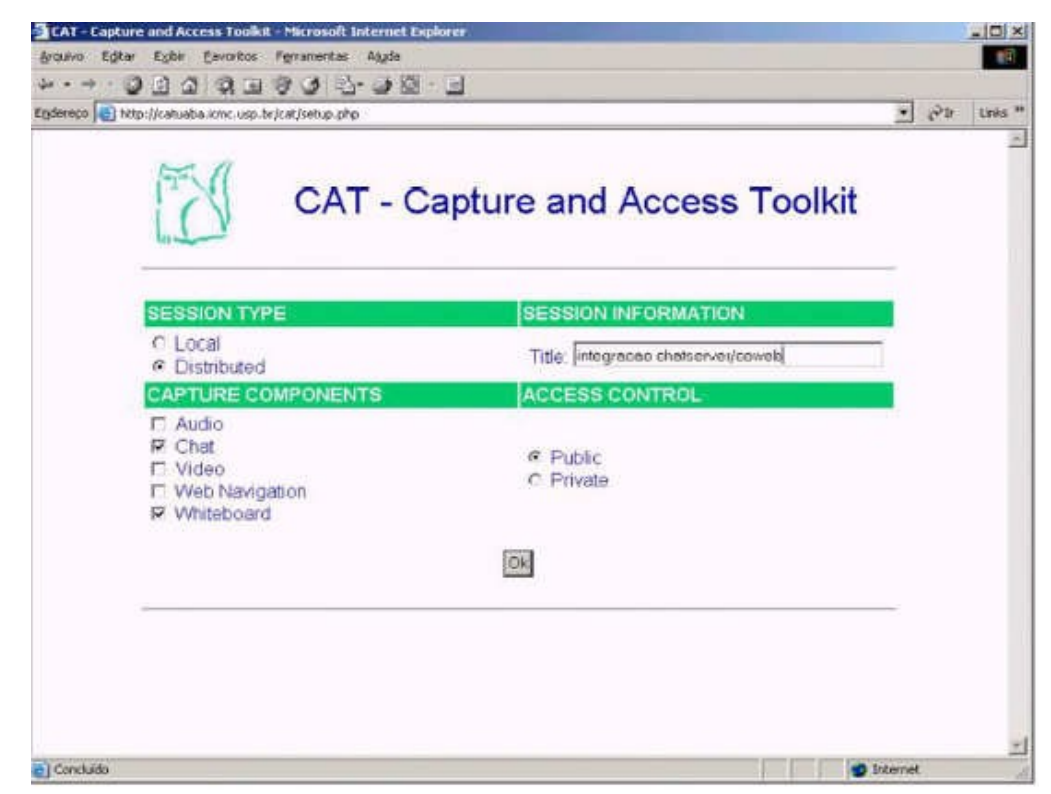

Figura 12: Interface CAT para criação de sessões (Cattelan, 2004).

\subsection{Abaris}

Abaris é uma aplicação de captura e acesso projetada para auxiliar terapeutas na coleta de dados relativos à observação de crianças com autismo. Para indexar uma sessão de vídeo capturado, a aplicação utiliza reconhecimento de voz e, com interação via caneta, os terapeutas preenchem um formulário de anotações. Esses dados são então eletronicamente gravados em um banco de dados e utilizados na geração de relatórios, conforme ilustra a Figura 13 à direita. As vantagens destacadas foram (Kientz et al., 2005): facilidade em interagir com os formulários, que eram bastante similares aos utilizados anteriormente; diminuição no tempo de coleta de dados; e discussões mais eficientes entre os profissionais devido à facilidade no acesso aos dados.

O sistema Abaris explora o uso de procedimentos estruturados por parte de seus usuários. Considerando o material que os terapeutas estão acostumados a manipular, o ambiente permite o uso de Anoto $^{14}$ para captura de informações customizadas às necessidades desses usuários, conforme ilustra a Figura 13 à esquerda. A ênfase está em prover, para as sessões de revisão do conteúdo capturado, interfaces especializadas para

\footnotetext{
${ }^{14}$ Caneta digital que registra tudo o que for escrito em um papel especialmente marcado.
} 
que os terapeutas possam manipular grandes quantidades de informações adquiridas de diversas sessões de captura (Kientz et al., 2005).

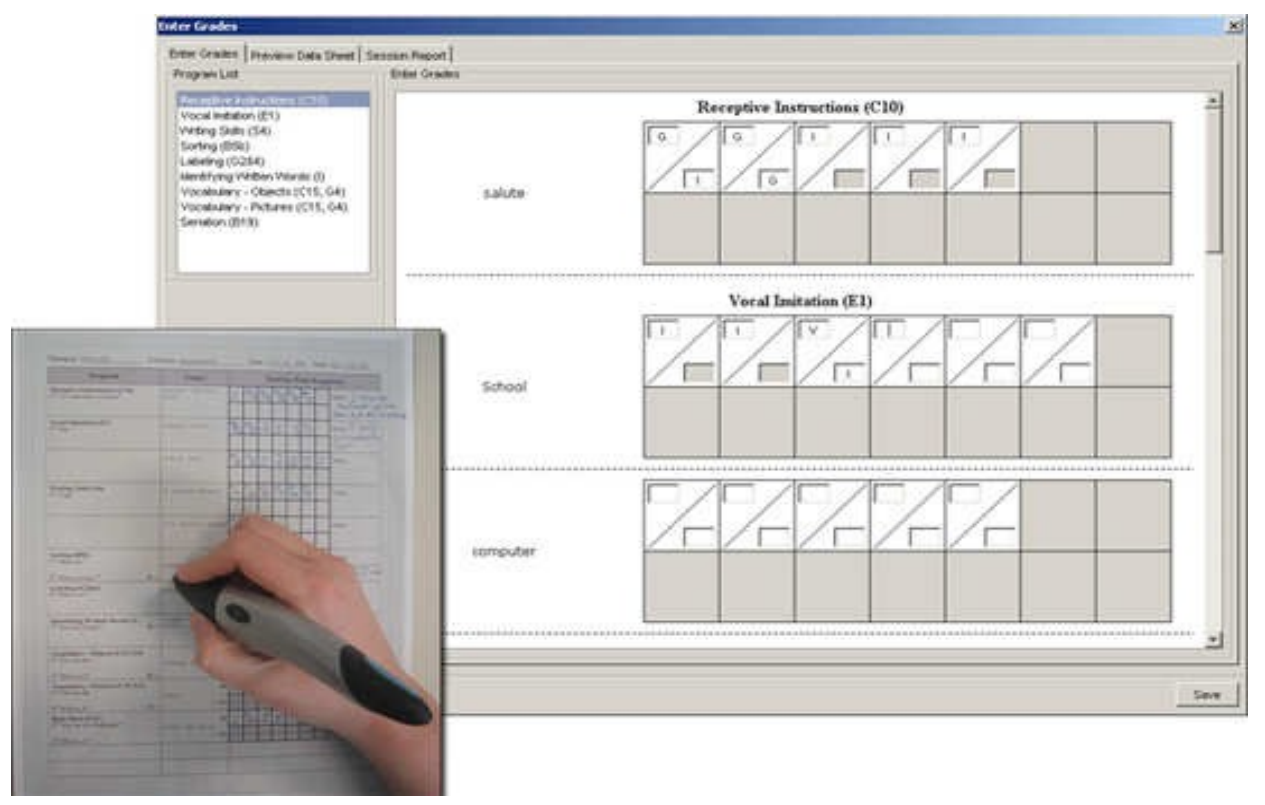

Figura 13: Interface de captura do Abaris (Kientz et al., 2005).

\subsection{ActiveTheatre}

Projetado para dar apoio à captura de informação em ambientes de centros cirúrgicos, o ActiveTheatre explora as tecnologias baseadas em interação com caneta eletrônica e câmeras para captura de informações com base em eventos. A abordagem é associar a captura a eventos disparados propositadamente pelos usuários, em contrapartida à gravação de toda informação como os sistemas citados anteriormente. A Figura 14 ilustra especialistas consultando as informações capturadas durante uma cirurgia. A infra-estrutura do ambiente se integra aos sistemas corporativos do hospital, e faz reúso de componentes de armazenamento e recuperação de informações de contexto (Hansen e Bardram, 2005). 


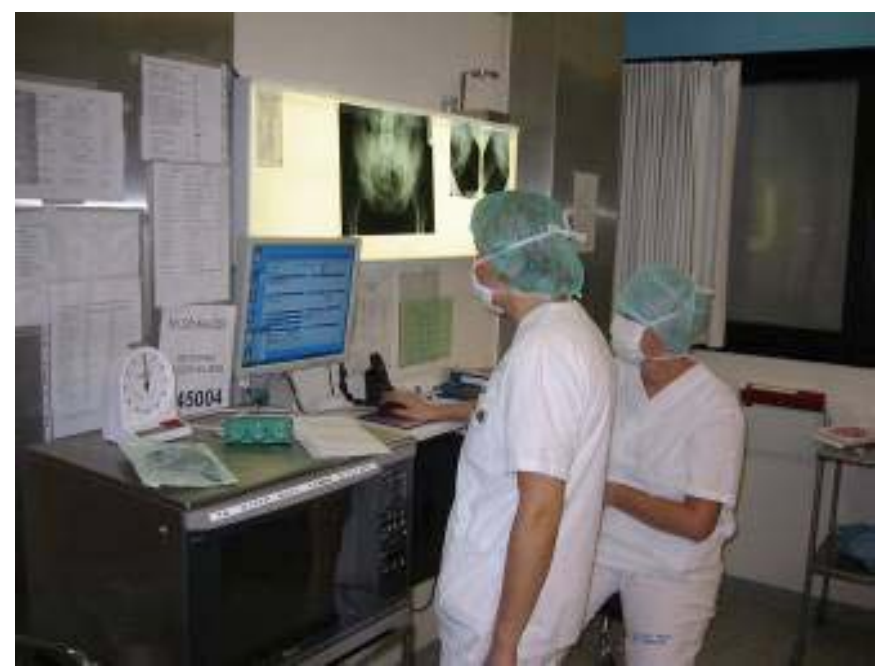

Figura 14: Acesso a imagens e registros eletrônicos médicos durante a cirurgia (Hansen e Bardram, 2005).

\subsection{CAS (Serviço de Captura e Acesso)}

É uma arquitetura para suporte de Captura e Acesso em ambientes de computação ubíqua, como salas de aula inteligentes e salas colaborativas. Essa arquitetura possui componentes para captura de mídias, áudio, vídeo e apresentações de slides, e a sincronia dos fluxos é mantida pela geração automática de um documento hipermídia NCL, padrão para TV digital brasileira. O foco do trabalho é a separação em modelos conceitual, navegacional e de apresentação, e a proposta é investigar documentos interativos que permitam ao usuário optar por alternativas de navegação, consulta e apresentação. Para o armazenamento de meta-informação sobre um evento, os usuários podem informá-la manualmente (como o assunto e o tipo do evento) ou elas são obtidas automaticamente (como a data e o usuário) (Portella e Cerqueira, 2007). Uma página web permite o agendamento dos eventos, controle de eventos armazenados, visualização de eventos e buscas. Utilizando a interface ilustrada na Figura 15 o usuário pode especificar quais slides iniciam novos contextos de informação. Foram realizados três estudos de caso em uma sala de aula inteligente (com 4 câmeras e microfones de mesa), uma sala multifuncional (equipada com câmeras), e uma sala de visualização (com preparação acústica e microfones de lapela). Os testes demonstraram que a solução proposta era viável e 
necessitava de algumas adequações (como o suporte à captura de tela e de webcams) (Portella e Cerqueira, 2007).

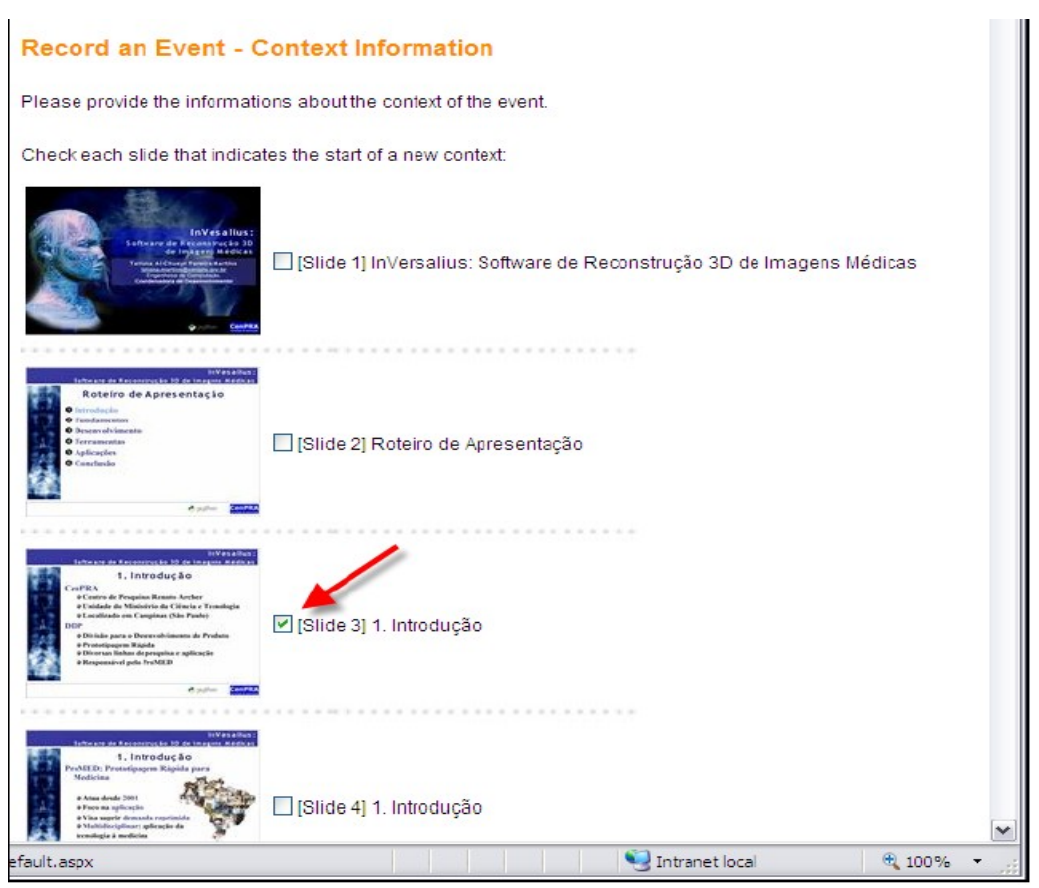

Figura 15: Interface para edição manual de informação de contexto do CAS (Portella, 2008).

\subsection{Filochat}

Filochat combina a captura de áudio com um tablet para anotações gerando assim o registro de reuniões. As anotações são indexadas com áudio, de modo que ao serem clicadas elas possibilitem o acesso ao áudio capturado naquele instante. Todas as informações capturadas da sessão são disponibilizadas por um navegador, cuja interface está ilustrada pela Figura 16. O tablet permite aos usuários armazenar muitas páginas de anotações e organizá-las em seções. Os usuários podem então utilizar as anotações para acessar partes relevantes do áudio. O uso do sistema foi bem sucedido tanto em experimentos em laboratório como no campo, pois aumentou a qualidade e a quantidade das anotações produzidas após reuniões (Whittaker et al., 2008). 


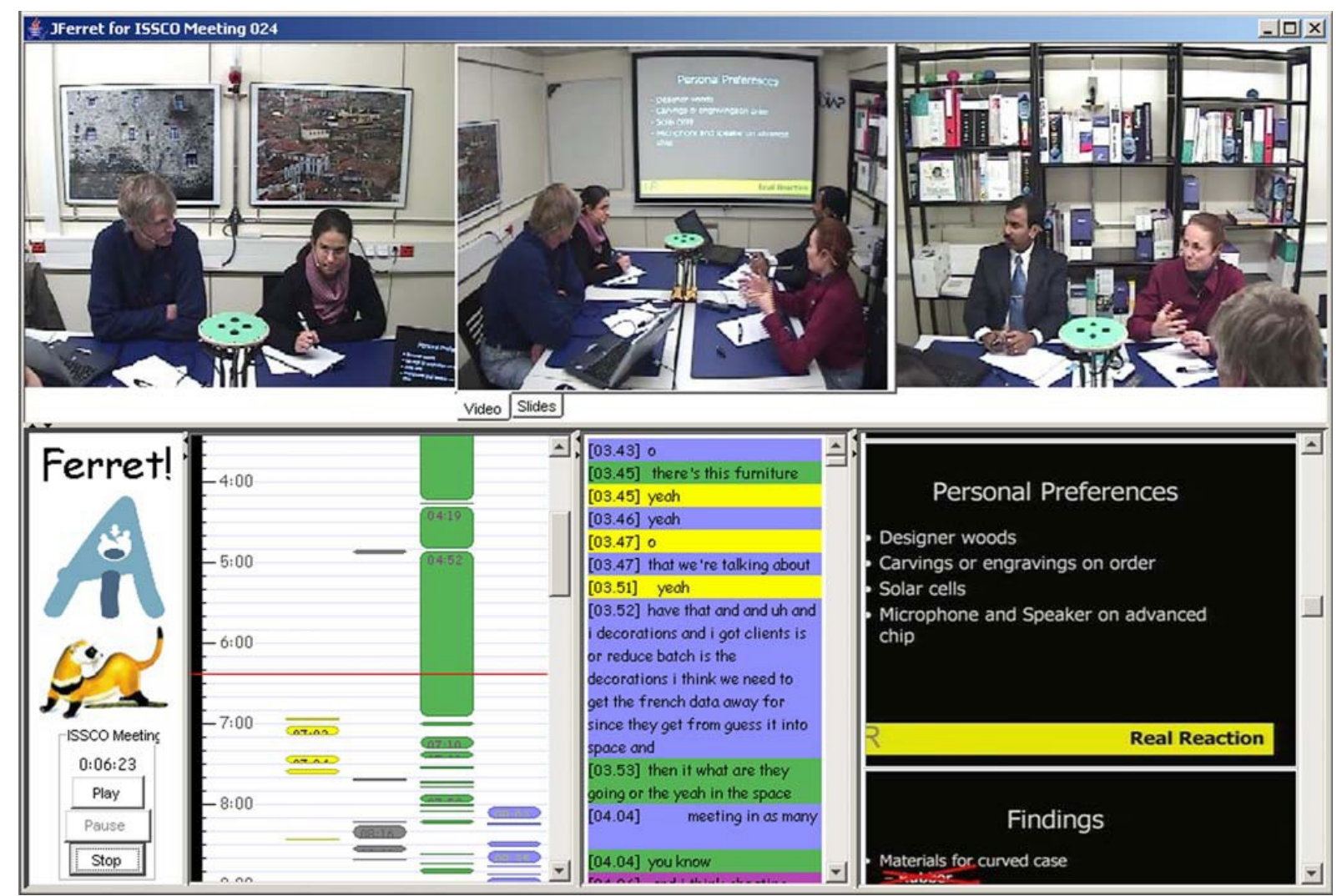

Figura 16: Interface para navegação pelas informações capturadas de uma reunião (Whittaker et al., 2008).

\subsection{Aplicações convencionais para reunião distribuída}

O Microsoft Netmeeting ${ }^{15}$, lançado em 1996, é uma ferramenta para compartilhar arquivos, imagens ou aplicações. Em sua interface, ilustrada na Figura 17, há opções para realizar vídeo-conferências e sessões de chat ou whiteboard. O sistema tem suporte a microfones e configuração de áudio e vídeo. É suportada do Windows 95 ao XP. Para o Windows Vista, foi substituída por uma nova versão o Windows Meeting Space.

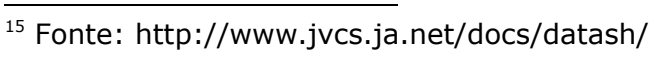




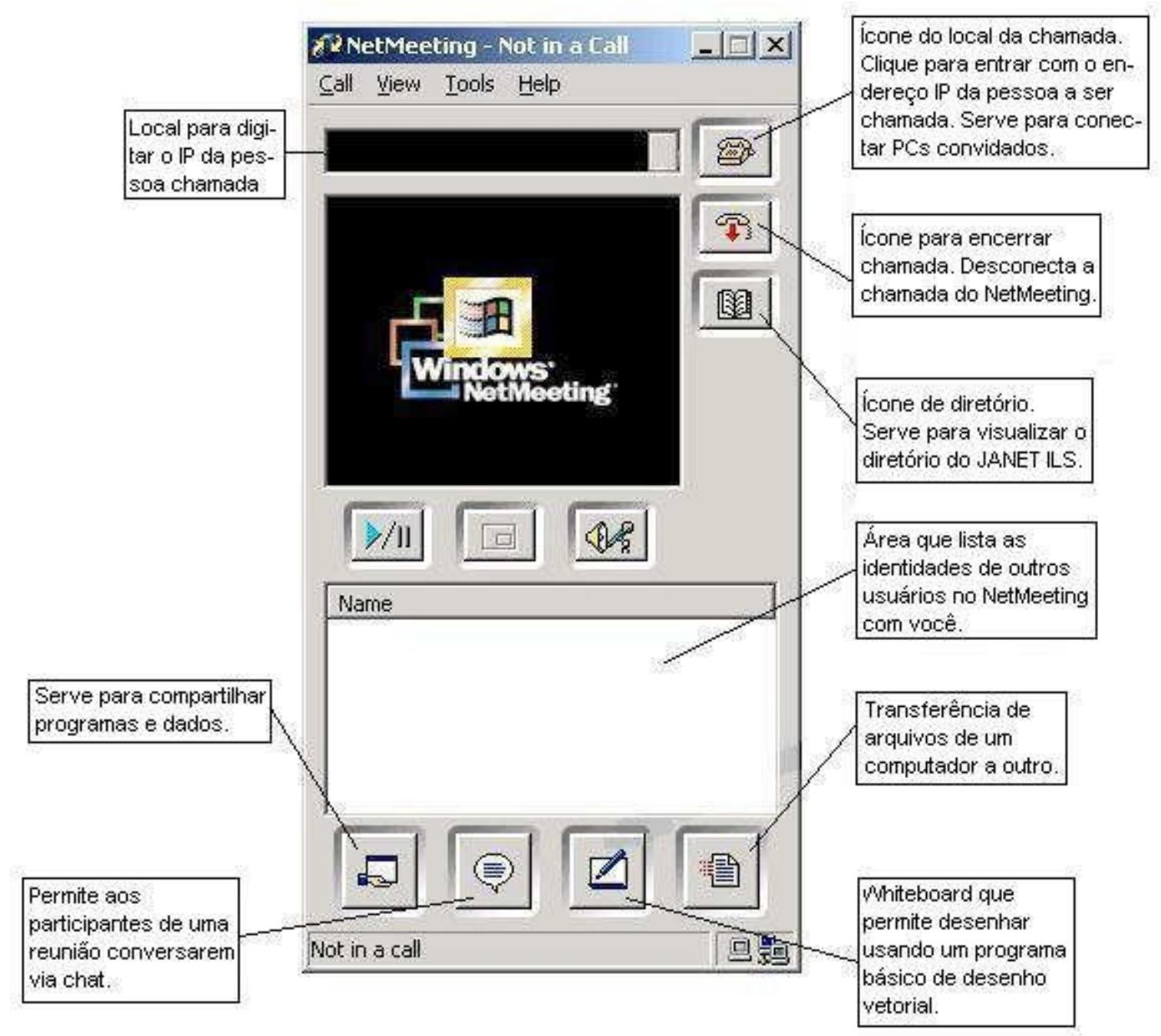

Figura 17: Interface do NetMeeting comentada.

O Windows Meeting Space ${ }^{16}$ é um programa de colaboração ponto-aponto, para sessões de 2 a 10 participantes. A Figura 18 ilustra sua interface. Esta nova versão suporta reuniões, compartilhamento de programas, transferência de arquivos, e troca de mensagens via rede. Os usuários podem participar de uma sessão existente ou iniciar uma sessão e convidar participantes. Para o gerenciamento de sessões as opções são: iniciar uma sessão, participar de uma sessão existente, convidar alguém para a sessão e aceitar um convite recebido. Quando uma aplicação é compartilhada, o Meeting Space muda para o modo de apresentação para que os participantes vejam o que está sendo apresentado e possam editar ou

\footnotetext{
${ }^{16}$ Fonte: http://www.microsoft.com/library/media/1033/windows/images/products/windowsvista/features /details/screenshot_Meeting_SpaceNote.jpg
} 
rever a aplicação colaborativamente. Para que o participante apresente, um projetor multimídia deve estar conectado à rede (Windows, 2008).

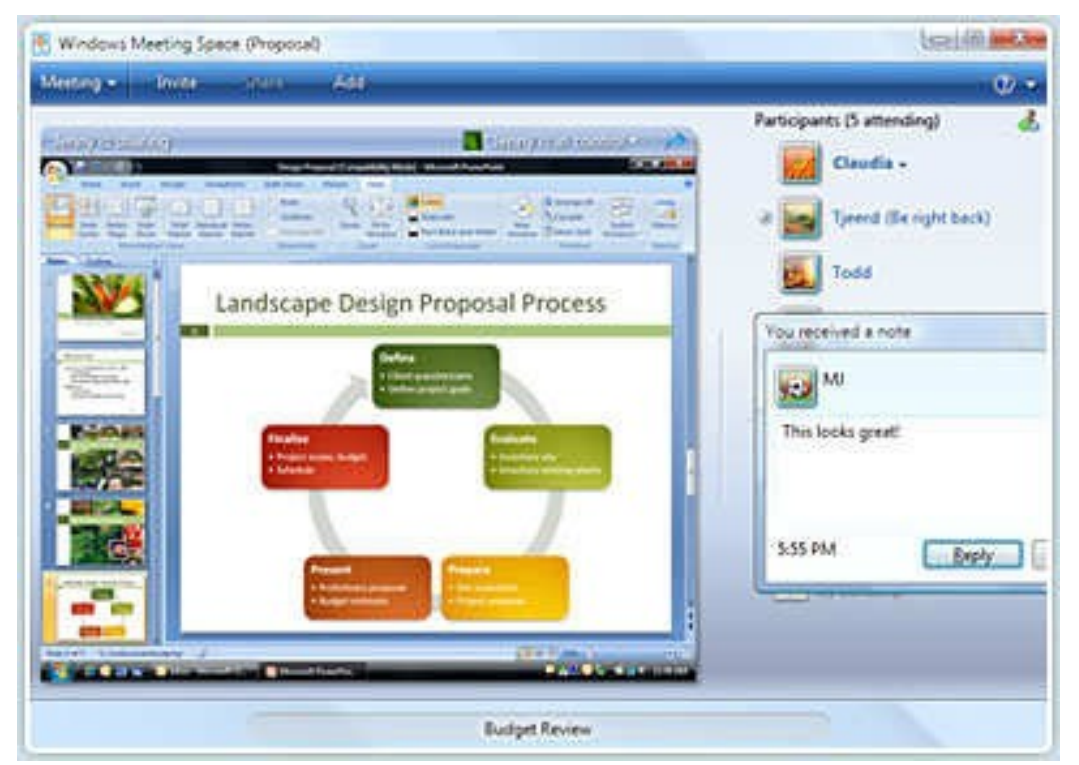

Figura 18: Interface do Windows Meeting Space (Windows, 2008).

O MS Conference $\mathrm{XP}^{17}$ é uma plataforma de vídeo-conferência de baixa latência e alta fidelidade, dentro dos padrões atuais, para utilização no ensino a distância em cenários de colaboração. Como ferramenta para o usuário final, ele tem suporte ao reconhecimento de escrita via Tablet PC, ao compartilhamento de vídeo de alta definição e a câmeras (Conference XP, 2008).

A Figura 19 ilustra uma reunião entre 3 participantes utilizando a ferramenta, uma palestra, um cenário de aula e um sketche criado com a whiteboard da aplicação.

\footnotetext{
${ }^{17}$ Fonte: research.microsoft.com/workshops/FS2007/presentations/Anderson_R_Oka_P_Faculty_Summit _071707.ppt
} 

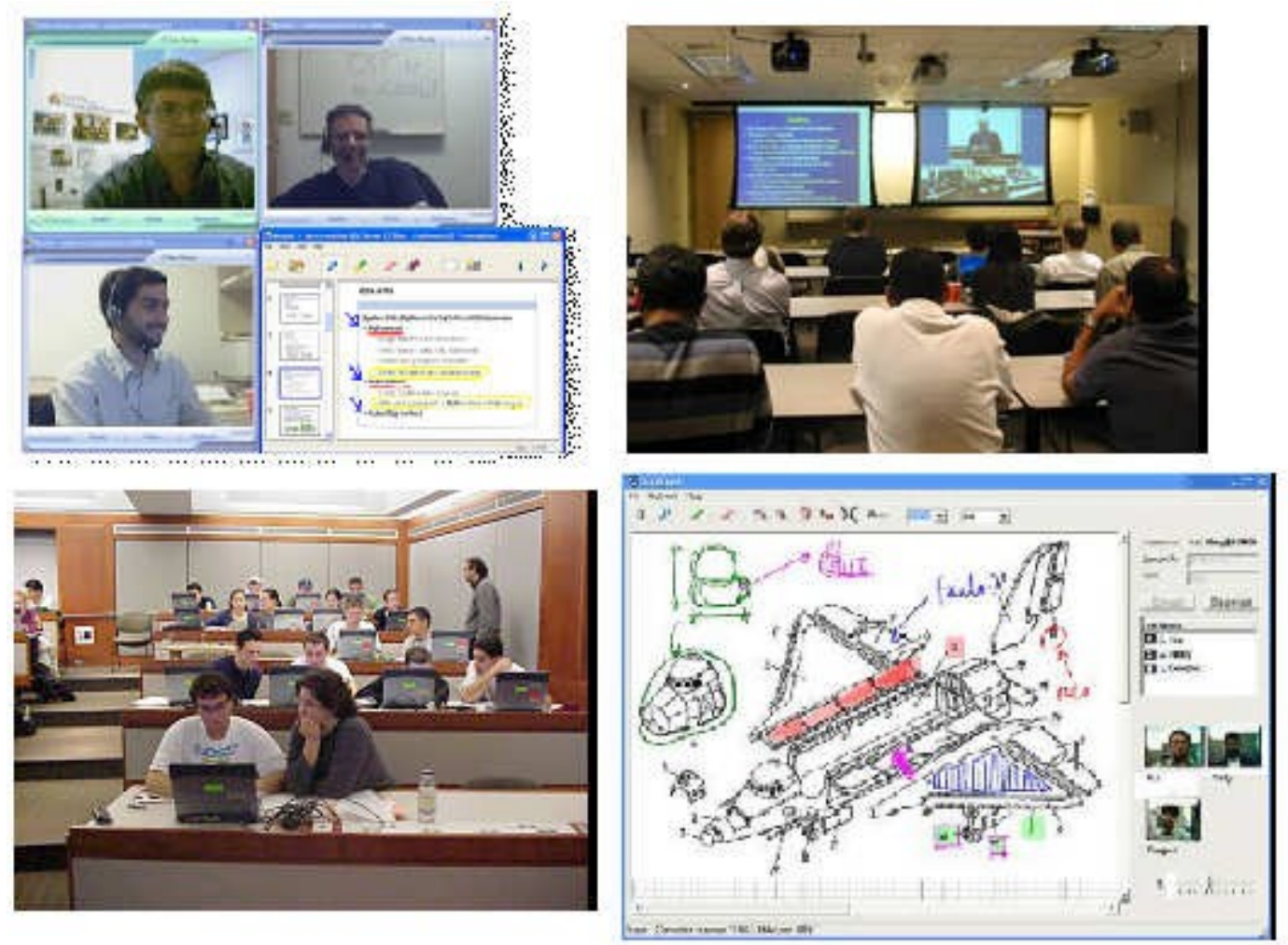

Figura 19: Quatro cenários de uso para o MS Conference XP (Conference XP, 2008).

O Adobe Acrobat Connect ${ }^{18}$ é um produto para comunicação via web para treinamento, marketing, conferências, reuniões e colaboração online. Os usuários podem configurar ambientes virtuais de reunião conforme seu estilo de apresentação, os layouts escolhidos e os conteúdos das reuniões são salvos automaticamente e estão sempre disponíveis, o que reduz o tempo de preparação para novas reuniões. A Figura 20 ilustra a versão básica, com ferramentas de colaboração como, compartilhamento de tela, whiteboard, chat, vídeo e áudio-conferência (Connect, 2008).

\footnotetext{
${ }^{18}$ Fonte: http://www.aecbytes.com/review/2007/Acrobat8Pro-images/fig6small.jpg
} 


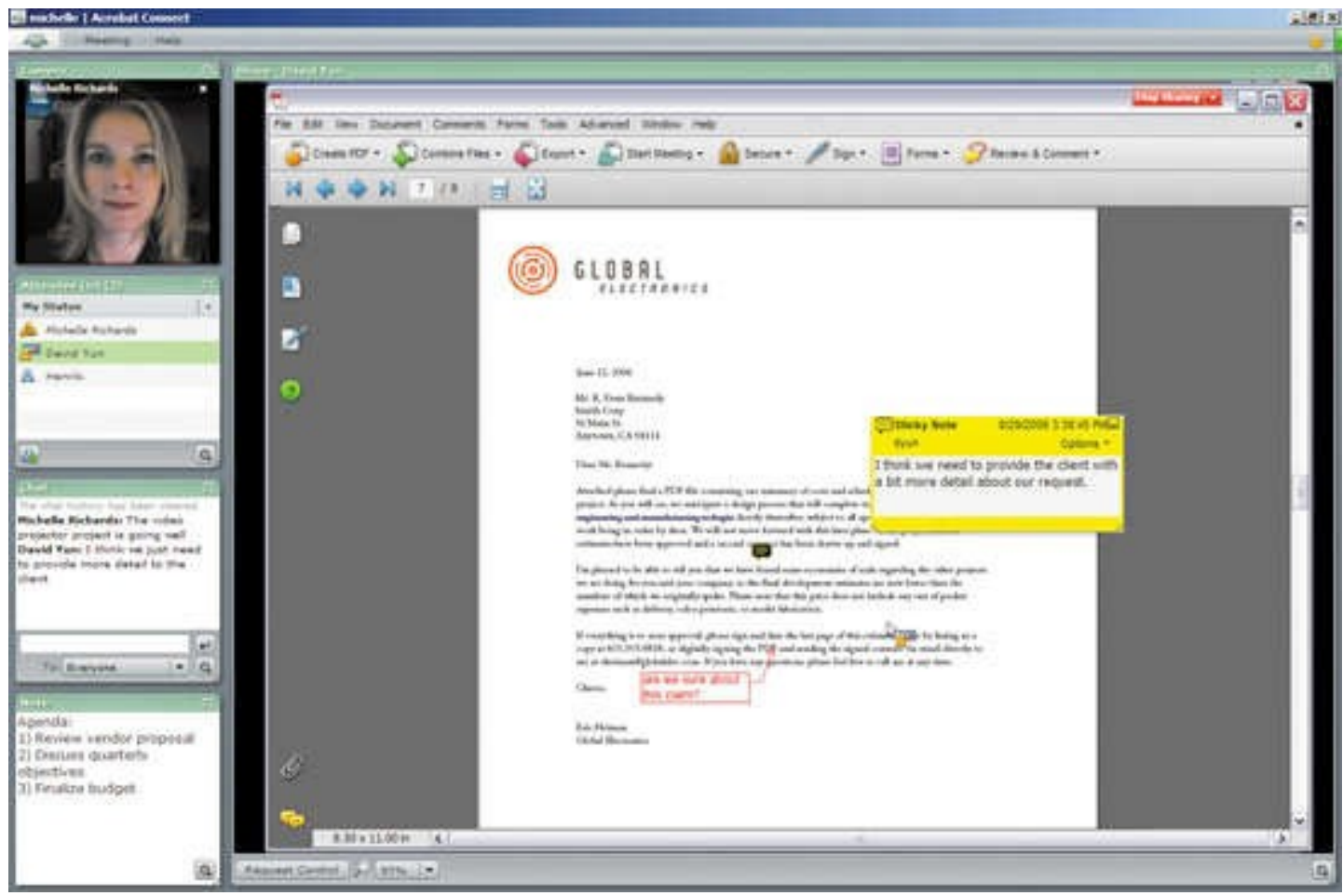

Figura 20: Interface do Adobe Acrobat Connect (Connect, 2008).

$\mathrm{O} \mathrm{Evo}^{19}$ é um sistema que permite a troca de mensagens instantâneas, incluindo informações de presença ou ausência do usuário, chat privado ou em grupo durante reuniões, reuniões agendadas, envio de convites para reuniões, funções de captura e acesso (de vídeo, áudio, whiteboard, mensagens instantâneas e chat) e compartilhamento de arquivos (Evo, 2008). A Figura 21 ilustra um cenário de utilização do EVO. 


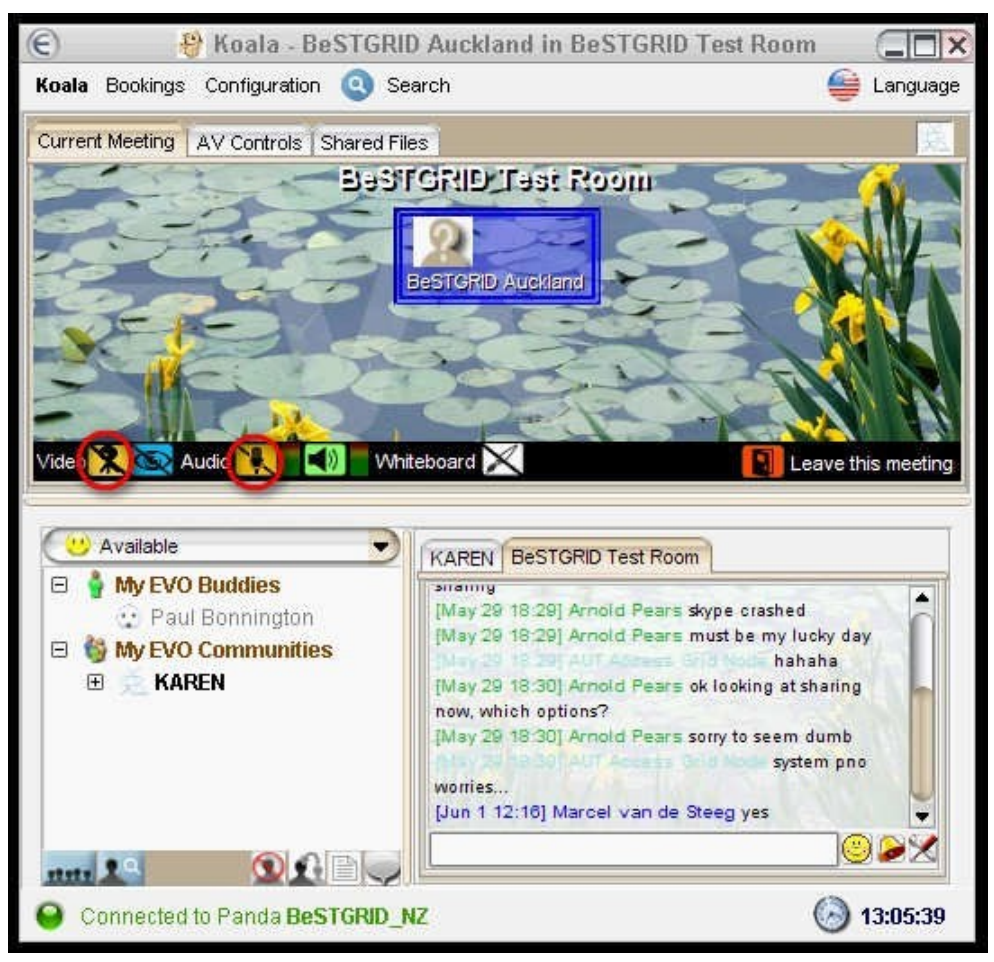

Figura 21: Interface de uso do EVO (Evo, 2008).

A Google lançou o OpenMeeting ${ }^{20}$, como uma plataforma customizável para vídeo conferência e colaboração. A aplicação possui suporte a áudio e vídeo, e permite visualização da área de trabalho de todos os participantes, customização, uso de multi-linguagens, acesso à whiteboard (para desenhos, escrita, edição, escala), realização de conferências (incluindo desenhos), armazenamento de arquivos para serem acessados e editados posteriormente, envio de convites para reuniões, sistema de moderador, módulo de backup e criação de salas de reunião pública ou privada (OpenMeeting, 2008).

A Figura 22 ilustra quatro cenários de uso do OpenMeeting, em sentido horário, estão apresentadas: a aplicação no modo de audiência, a ferramenta de apresentação, a aplicação em modo de conferência e a interface da aplicação.

\footnotetext{
${ }^{20}$ Fonte: http://code.google.com/p/openmeetings/
} 

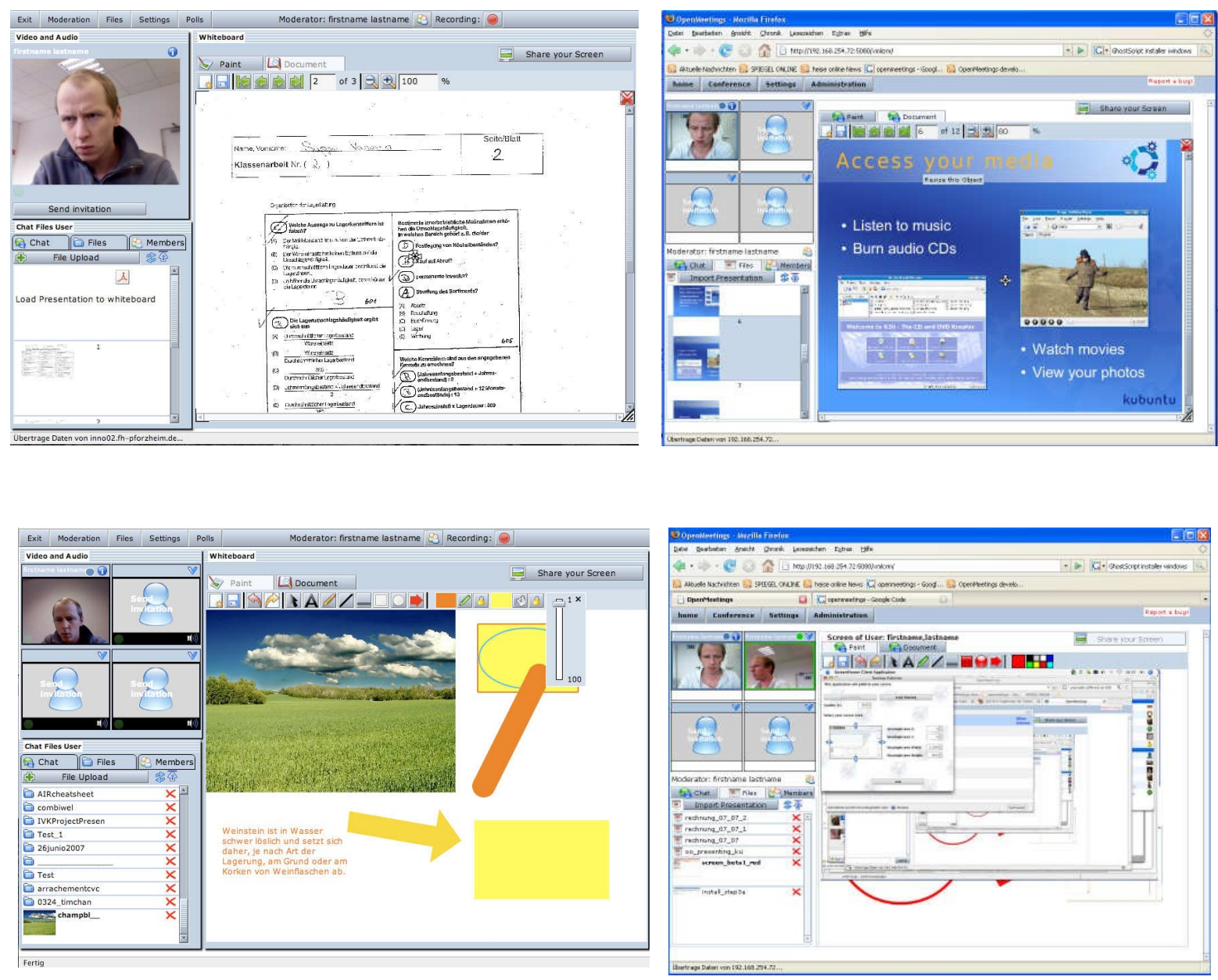

Figura 22: Interfaces do OpenMeeting (OpenMeeting, 2008).

O TalkAndWrite ${ }^{21}$ é um software de interação em tempo real para usuários interagirem sobre um mesmo documento. Com ele é possível desenhar, escrever, apagar, digitar e selecionar textos e conversar com outros usuários. As informações são transmitidas de forma criptografada. O sistema suporta até 10 pessoas interagindo simultaneamente. Pode ser usado para treinamentos, apresentação, reuniões de negócios, geração de idéias e relacionamento com clientes. A Figura 23 ilustra quatro contextos onde o TalkAndWrite pode ser usado, para advocacia, medicina, educação e para arquitetura e engenharia (TalkAndWrite, 2008). 


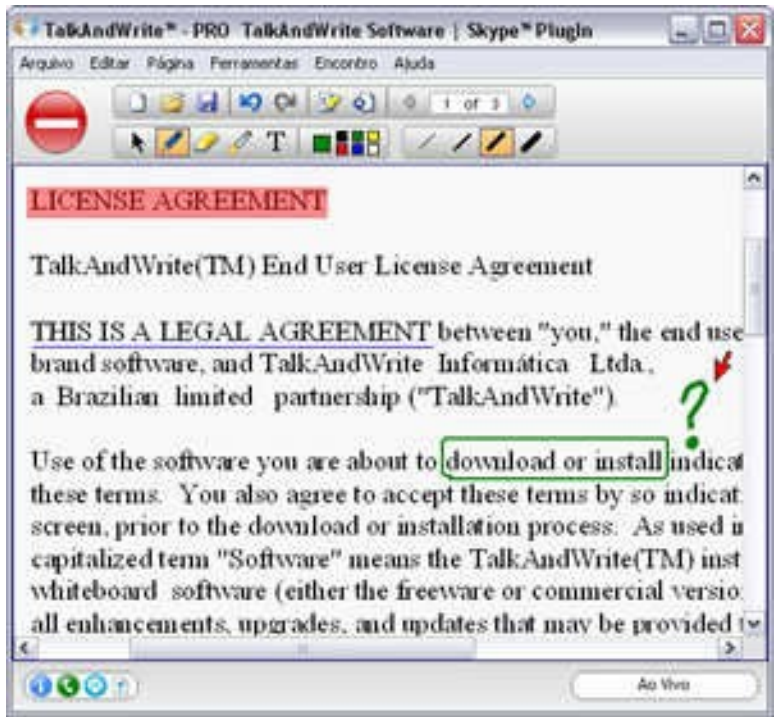
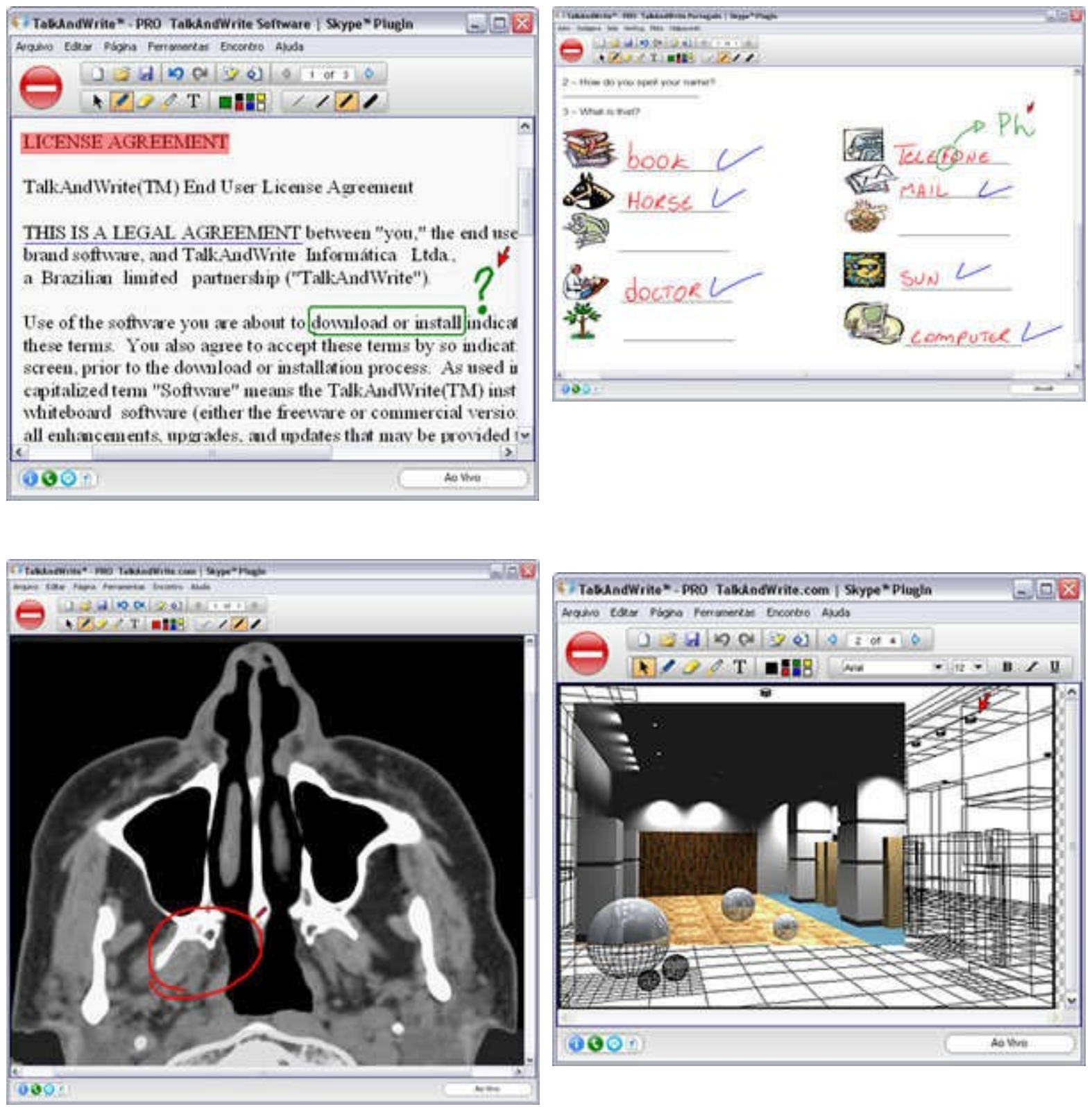

Figura 23: Quatro opções de uso para o TalkAndWrite (TalkAndWrite, 2008).

\subsection{Discussão}

Abowd et al. (1996) identificaram quatro fases indispensáveis para aplicação de captura e acesso: a pré-produção, o registro ao vivo, a pósprodução e o acesso à informação capturada. No caso do DiGaE a fase de pré-produção se caracteriza pelo agendamento prévio da sessão, com o cadastro de dados sobre ela, e preparação de material caso seja necessário; o registro ocorre de modo automático, capturando áudio, vídeo, informações textuais geradas durante a sessão e também as interações com a lousa eletrônica; a pós-produção fica a critério dos participantes, caso eles 
desejem, podem alterar tanto os dados como o conteúdo da sessão capturada, que por sua vez estará integralmente disponível para acesso na página do DiGaE.

A princípio as informações geradas estão apenas publicadas no repositório web, mas há outras questões que podem ser consideradas para facilitar a sua recuperação, como sincronização, busca e metadados.

O SmartClassroom utiliza computação ubíqua para prover educação à distância de modo tão similar quanto possivel a uma sala de aula real. Shi et al. (2003) defendem que o professor deve estar ciente da presença do aluno remoto no ambiente, mas pondera que a transmissão de vídeo de todos os participantes remotos da sessão exige muito da rede e de CPU. Para a utilização do DiGaE, a escalabilidade no ambiente também deve ser considerada, ainda que se pretenda usar a rede KyaTera, de alta velocidade, grande largura de banda e de baixa latência, a rede está sendo implantada no contexto do Projeto TIDIA, e participantes em computadores remotos, que não estejam no ambiente instrumentado devem poder participar de uma sessão do DiGaE.

A avaliação do SmartClassroom com usuários foi planejada para depois do término dos protótipos da ferramenta, o que pode ser crítico e exigir esforços duplicados de desenvolvimento. A autenticação do professor é via reconhecimento de voz e para solicitá-la foi implementado um assistente virtual (Shi et al., 2003).

O CAT define como informações de contexto relevantes à sessão: título, participantes, local, tipo e controle de acesso. Já as funcionalidades possiveis de serem escolhidas são: texto (chat), Whiteboard, áudio, vídeo e web logging. Como resposta o usuário recebe um applet, pronto para execução conforme suas solicitações (Cattelan, 2004). O objetivo do sistema é permitir que o usuário configure quais funcionalidades serão utilizadas na sessão para visualizá-las posteriormente, não foram relatadas avaliações com usuário para elaboração das interfaces.

No eClass, o foco da avaliação do trabalho é sobre o impacto da tecnologia no ensino-aprendizagem. Para realizar a avaliação, a ferramenta foi incorporada no contexto de salas de aula. Os autores concluíram com a 
avaliação que para $53 \%$ dos alunos a captura de áudio melhora o entendimento das anotações. Ainda observaram que, o uso dos dados capturados se dava por duas razões: rever as aulas e estudar para provas (Abowd, 1999). Tanto no SmartClassroom como no eClass o processo de avaliação com o usuário é realizado ao final da elaboração da ferramenta, o que pode gerar trabalhos extras caso sejam identificados problemas graves na interação.

No DUMMBO a navegação pelos quadros capturados de uma sessão ocorre com a movimentação de uma barra de rolagem referente ao tempo, assim o usuário pode acessar diferentes instantes de um evento em uma busca (Brotherton et al., 1999). O CAS, que foca em engenharia de documentos, relata a utilização de NCL, linguagem para TV digital e interativa, para visualização do conteúdo capturado na sessão (Portella e Cerqueira, 2007). Para o DiGaE pretende-se implementar um player que execute de modo síncrono os dados de áudio, vídeo e texto capturados de uma sessão.

Com relação às aplicações convencionais para suporte a reuniões, em geral elas permitem trabalho colaborativo, acesso ao ambiente de trabalho alheio, compartilhamento de programas e dados, edição simultânea de documentos, captura de áudio, vídeo e interação. As adequações nas interfaces se limitam a diferentes opções de cores, fontes e layouts.

\subsection{Considerações Finais}

Embora muitas aplicações de captura e acesso tenham sido desenvolvidas, as técnicas mais comuns de interação utilizadas em reuniões ainda são canetas, notebooks e laptops. Whittaker et al. (2008) acreditam que as aplicações podem falhar por três razões: (i) por capturar as informações mas não conseguir fazer com que elas estejam significativamente acessiveis aos usuários, (ii) por não atenderem exatamente às necessidades de usuários, ou ainda (iii) por fornecerem apenas suporte básico à captura, sendo necessário aprimorá-las para que atendam às exigências dos usuários. 
Em geral, os sistemas que capturam eventos não focam em como torná-los significativamente acessiveis para seus usuários. Poucas pesquisas investigam as necessidades dos usuários e a interação destes com sistemas de captura e acesso $\left(\mathrm{ICR}^{22}\right)$. Pedersen et al. (1993) consideraram o uso da lousa eletrônica por usuários novatos e Kientz et al. (2005) fizeram a avaliação do Abaris com usuários reais.

Ainda em aplicações ubíquas é necessária uma pré-produção do ambiente, todos os dispositivos devem estar devidamente instalados, configurados e acionados para interação. Isto pode exigir um esforço de especialistas e o ideal ubíquo seria que uma vez estruturado, o ambiente reagisse automaticamente.

Whittaker et al. (2008) estudaram as necessidades do usuário em um estudo exploratório e concluíram que, enquanto grandes esforços são dispensados no desenvolvimento de novas tecnologias ICR, pouco trabalho tem sido feito para determinar as necessidades do usuário ou para avaliar sistematicamente essas tecnologias. No CAS os autores afirmam que a avaliação foi apenas subjetiva, e reconhecem a necessidade de se realizar avaliações mais profundas e qualitativas para considerar aspectos de usabilidade (Portella, 2008).

No SmartClassroom, Shi et al. (2003) informam que foi realizada uma avaliação informal de usabilidade, mas os resultados expostos indicam que os usuários conseguiram instalar e desenvolver usando a plataforma.

Não foram informadas as teorias de IHC que embasaram as avaliações e os resultados apresentados parecem distantes da definição formal de avaliação de usabilidade.

Considerar o perfil de usuários leigos para desenvolver interfaces provê benefícios na interação de modo geral, contribuindo para a eficiência da interação. Tendo em vista essas características, este projeto tem por objetivo prover a usuários diversos um ambiente instrumentado com uma aplicação que permita comunicação remota, capturando os dados gerados para serem recuperados posteriormente, de maneira fácil e intuitiva.

${ }^{22}$ ICR (Information Capture and Retrieval) significa captura e recuperação de informações. 
Para o desenvolvimento do DiGaE, descrito no capítulo seguinte, a abordagem de design centrado no usuário visou conciliar os requisitos da aplicação com os recursos do ambiente instrumentado e com o perfil do usuário alvo. Almejando o objetivo de disponibilizar as funcionalidades das interfaces com alto nível de usabilidade. 


\section{METODOLOGIA E DESENVOLVIMENTO}

\subsection{Considerações Iniciais}

Este capítulo apresenta parte do material que foi desenvolvido como resultado deste projeto de mestrado seguindo a abordagem de design centrado no usuário.

A primeira etapa consistiu na definição do (Distributed Gathering Environment) DiGaE, para tal foi feita a documentação do projeto contendo o levantamento de requisitos, o relatório de casos de uso, o diagrama de sequência, o diagrama de fluxo e um diagrama de análise hierárquica de tarefas (HTA).

Uma vez identificadas as funções da aplicação, foram estruturados sketches que ilustram e simulam possiveis interfaces do DiGaE para uso em computador pessoal. Os sketches foram avaliados em um protótipo que simulava a interação com a aplicação com o objetivo de obter feedback de usuários reais do DiGaE e direcionar a sequência do desenvolvimento. Fezse então a avaliação das três ferramentas que compõem a versão inicial do DiGaE: Whiteboard, Comunicador Instantâneo e Chat. Por fim foi avaliada a aplicação em seu ambiente real, uma sala instrumentada. Os resultados das avaliações foram analisados e discutidos.

A documentação completa do DiGaE incluindo requisitos não funcionais, de interface, de licença, a ajuda online e informações para suporte, os diagramas de casos de uso, seu relatório, o diagrama de sequência, e os protótipos de interface que foram utilizados para a primeira avaliação da ferramenta podem ser consultados em seus documentos originais disponiveis online no SVN do Projeto TIDIA em http://incaserve.icmc.usp.br:8111/svn/Tidia-intermidia/trunk/docs/tools/ digae. Neste capítulo é apresentada parte da documentação, considerada essencial para a compreensão do DiGaE, e parte dela está nos Apêndices. 


\subsection{Especificação do DiGaE}

Para especificar o DiGaE e elaborar sua documentação, foram desenvolvidos o Levantamento de Requisitos, o Relatório de Casos de Uso, o Diagrama de Sequência, o Diagrama de Fluxo e o Diagrama HTA.

\subsubsection{Levantamento dos Requisitos}

Foi utilizada UML (OMG, 1997) para fazer o levantamento de requisitos do DiGaE, os diagramas e o relatório de casos de uso. Os requisitos da aplicação foram identificados após o estudo de trabalhos relacionados à área (que foram descritos no capítulo anterior) e reuniões com a equipe de desenvolvimento. Nesta seção serão apresentadas informações essenciais para compreensão do DiGaE que foram extraídas do documento com o Levantamento de Requisitos da aplicação.

\subsubsection{Visão Geral do Sistema}

A idéia do ambiente DiGaE é que o usuário não tenha sempre que agendar uma sessão para se comunicar com outro(s) usuário(s), mas que a sessão possa acontecer de modo natural, estando os usuários online, eles podem compartilhar seus fluxos de áudio, vídeo, interagir via Whiteboard e ainda trocar informações textuais via Chat. Essas interações são então capturadas e salvas, de modo que possam ser acessadas posteriormente. $\mathrm{O}$ usuário configura quais funcionalidades do ambiente ele deseja utilizar na sessão.

O DiGaE detecta a presença do usuário assim que ele acessa o ambiente, através do leitor de RFID, e suas funcionalidades estão então disponiveis para que ele as use se assim desejar.

\subsubsection{Requisitos}

Para especificar o DiGaE foram identificados seus requisitos funcionais e não funcionais. Os requisitos funcionais estão na Tabela 5 , se referem ao acesso do usuário ao ambiente, e compreendem: fornecimento de dados de áudio, vídeo, texto e a interação com as ferramentas de Whiteboard, para desenho e Chat, para troca de mensagens. No ambiente DiGaE, o usuário pode configurar seu status (online, offline, invisivel e ocupado). O sistema lista as sessões que foram agendadas e que o incluem 
como participante. Ele pode então acessar uma sessão em andamento: compartilhando canais de áudio-vídeo e texto e recebendo dados de outros usuários, sendo o uso de texto na ferramenta de Chat, e também acessar a Whiteboard e ver as interações que estejam ocorrendo nela.

Tabela 5: Requisitos Funcionais do DiGaE

\begin{tabular}{|l|}
\hline$[R 01]$ acesso ao ambiente \\
\hline$[R 02]$ lista de sessões agendadas \\
\hline$[R 03]$ início de sessão \\
\hline$[R 04]$ acesso à sessão atual \\
\hline$[R 05]$ configuração do status \\
\hline$[R 06]$ criação da lista de participantes da sessão \\
\hline$[R 07]$ exibição da lista de participantes da sessão \\
\hline$[R 08]$ atualização da lista de participantes da sessão \\
\hline$[R 09]$ uso da whiteboard \\
\hline$[R 10]$ uso do chat \\
\hline$[R 11]$ captura de áudio e vídeo \\
\hline$[R 12]$ compartilhamento de áudio e vídeo \\
\hline$[R 13]$ visualização de vídeo dos outros participantes \\
\hline$[R 14]$ execução de áudio dos outros participantes \\
\hline$[R 15]$ ajuste de volume de áudio \\
\hline$[R 16]$ movimento das janelas \\
\hline$[R 17]$ redimensionamento das janelas \\
\hline$[R 18]$ opção de salvar sessão \\
\hline$[R 19]$ finalização de sessão \\
\hline$[R 20]$ cadastro de sessão \\
\hline$[R 21]$ edição de sessão \\
\hline$[R 22]$ exclusão de sessão \\
\hline$[R 23]$ consulta de sessão \\
\hline$[R 24]$ lista de sessões retornadas \\
\hline$[R 25]$ visualização de dados da sessão \\
\hline$[R 26]$ navegação whiteboard da sessão \\
\hline$[R 27]$ navegação no comunicador instantâneo da sessão \\
\hline$[R 28]$ navegação áudio e vídeo da sessão \\
\hline$[R 29]$ acesso à ajuda \\
\hline$[R 30]$ saída do ambiente \\
\hline
\end{tabular}

Uma vez terminado o evento, o usuário pode finalizar a sessão e editar ou manter os dados referentes a ela (assunto e descrição); outros dados são gerados automaticamente (data e duração). O DiGaE identifica e lista os 
usuários participantes e as ferramentas utilizadas. Para o cadastro de uma nova sessão, o usuário especifica seu tema, descrição, data, hora, local, usuários que participarão e também quais ferramentas serão usadas. Há também a opção de consultar sessões agendadas para editá-las ou excluílas. Para consultar sessões o usuário pode optar por colocar o tema associado a ela, a data na qual ela ocorreu, ou ambos. Retornados os resultados, o usuário pode escolher a sessão de interesse para acessar seus dados (inclusive informações geradas com Chat, Whiteboard e Comunicador Instantâneo, no caso de sessões já finalizadas), ou ainda editar os dados da sessão ou excluíla. No DiGaE a opção de Ajuda, contendo informações descritivas sobre cada uma das funcionalidades implementadas, auxiliará o usuário por meio de textos e imagens a utilizar o ambiente.

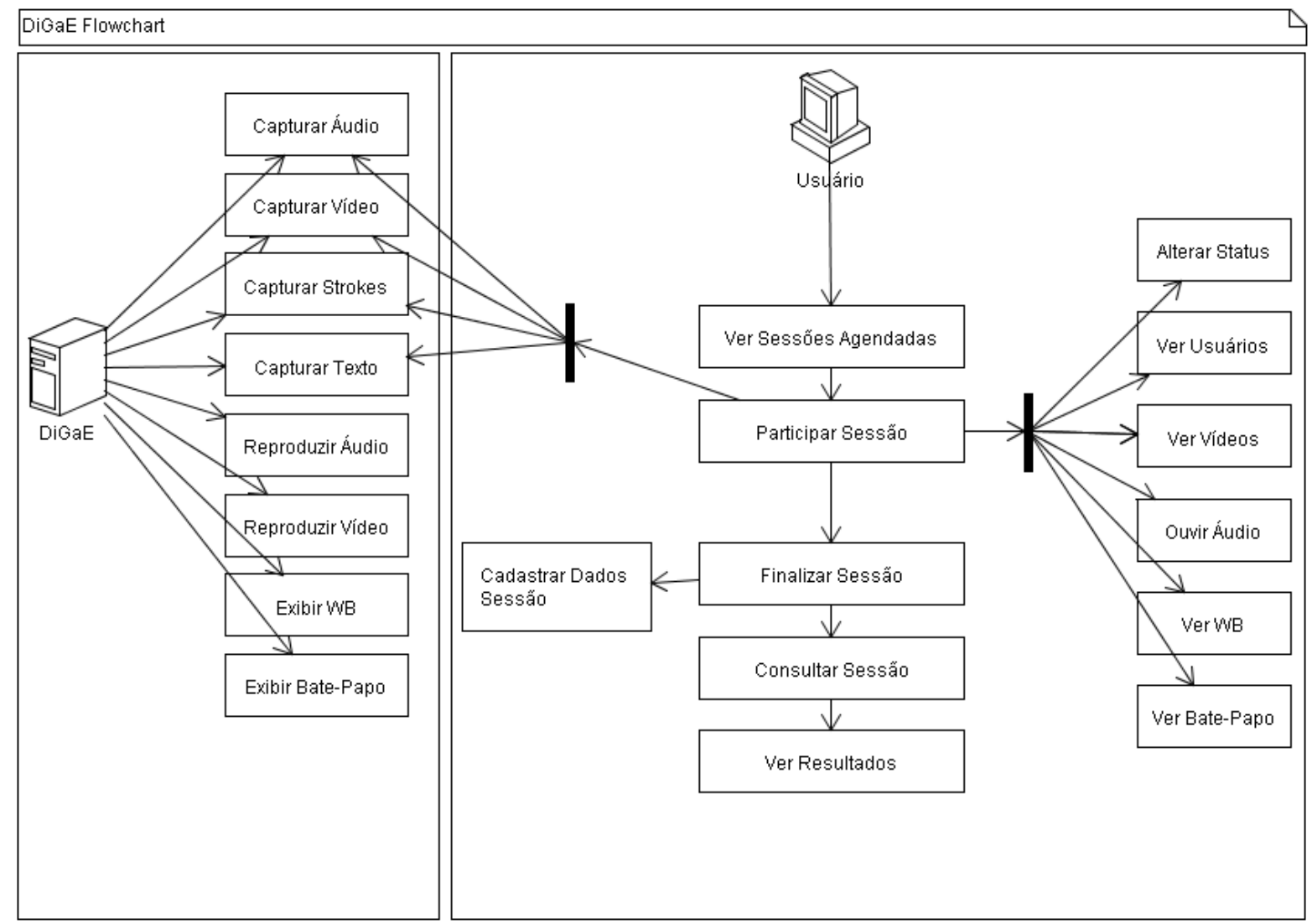

Figura 24: Diagrama de Fluxos do DiGaE.

Após a especificação dos requisitos foi elaborado o relatório contendo o diagrama de casos de uso. Foi elaborado também um Diagrama de Fluxos (FlowChart), que sintetiza os casos de uso do DiGaE, e mostra a estrutura de funcionamento da aplicação conforme ilustra a Figura 24. O usuário tem 6 
opções de tarefas disponiveis no DiGaE, que por sua vez é responsável por capturar os dados de um usuário online e exibi-los aos outros participantes da sessão.

\subsubsection{Casos de Uso}

Para complementação do material de levantamento de requisitos da aplicação e identificação das tarefas que os usuários poderiam desempenhar no sistema, foram identificados e ilustrados por meio de diagrama, os casos de uso do DiGaE. A especificação completa está disponível no $\mathrm{SVN}^{23}$ do Projeto TIDIA. A Figura 25 ilustra o Diagrama de Casos de Uso do DiGaE, sendo que nele estão incluídas as principais funções da aplicação, totalizando 25 casos de uso, que estão descritos em detalhes no Apêndice C. Foi utilizado um único papel de ator pois a aplicação TIDIA-Sakai permite criar papéis, especificando qual o nivel de acesso às funções disponiveis, e atribuí-los aos participantes. Para as ferramentas de Whiteboard, Comunicador Instantâneo e Chat foram criados três casos de uso que, por definição, incluem todos os casos de uso destas ferramentas.

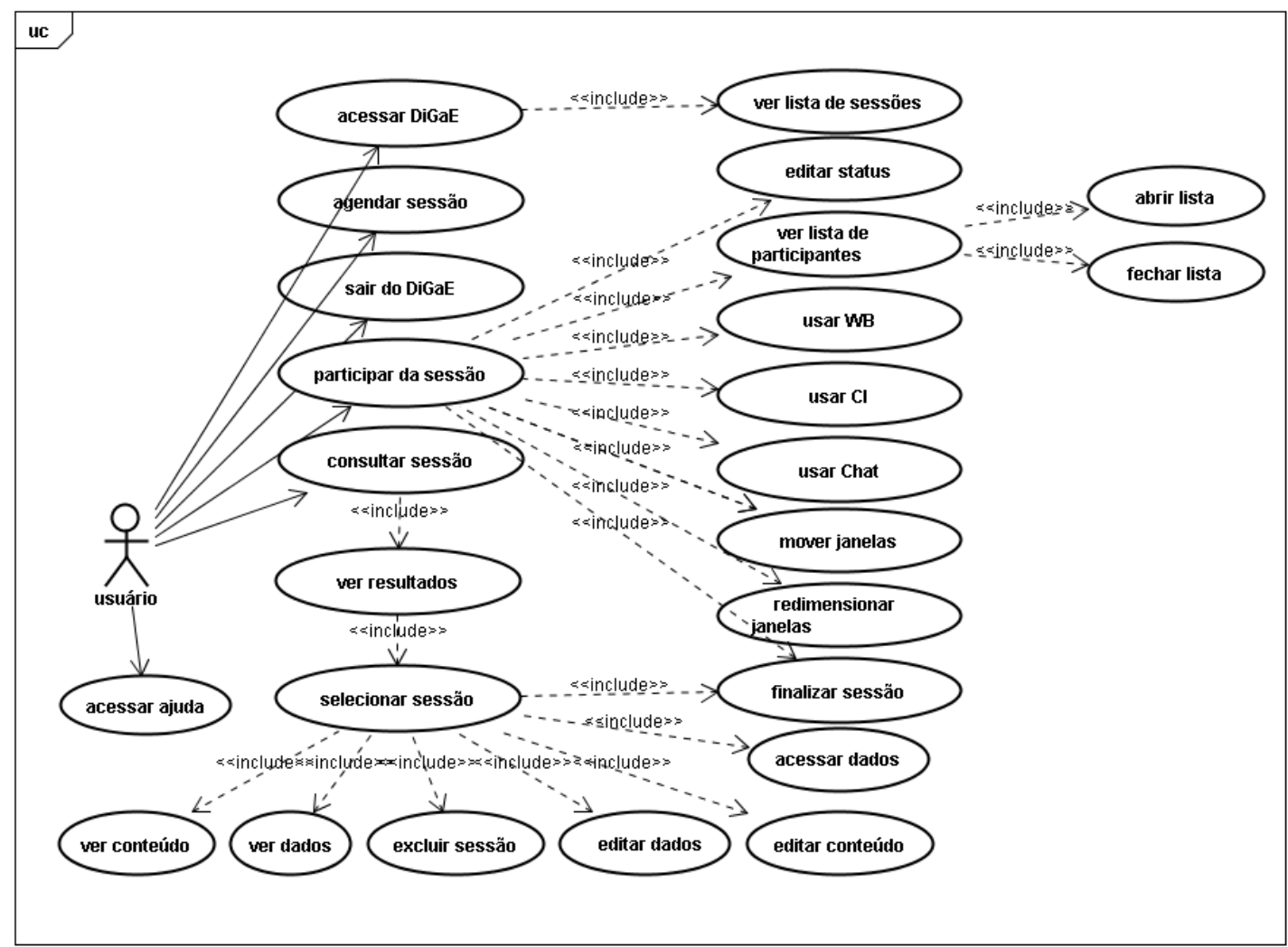

Figura 25: Diagrama de Casos de Uso do DiGaE.

${ }^{23}$ http://incaserve.icmc.usp.br:8111/svn/Tidia-intermidia/trunk/docs/tools/digae 


\subsubsection{HTA (Hierarchical Task Analysis)}

O diagrama HTA identifica os passos necessários para completar cada uma das tarefas disponiveis em um sistema. Para elaborá-lo é necessária a decomposição do sistema em niveis hierárquicos de modo que as subtarefas sejam agrupadas em tarefas mais complexas. Para o DiGaE foi desenvolvido um HTA ilustrado pela Figura 26.

Foram identificados cinco níveis hierárquicos necessários para acessar as funcionalidades do DiGaE e, sequências compostas por até cinco passos de interação. O diagrama especificado engloba quatro fases da interação: a pré-produção (caracterizada pelo agendamento da sessão), a captura (durante a sessão), a pós-produção (caracterizada pela edição dos dados da sessão ou exclusão de dados capturados) e o acesso (onde o usuário consulta e recupera informações da sessão).

O diagrama HTA tem estreita relação com questões de IHC. Por exemplo, para a execução de tarefas e composição de menus, deve-se procurar equilibrar as tarefas descritas na hierarquia, evitando desde uma sequência de passos muito longa para conclusão de uma tarefa até o excesso de opções de tarefas curtas que podem confundir o usuário e sobrecarregar a interface. O usuário deve ser capaz de identificar a tarefa que ele procura entre as categorias disponiveis na interface, e deve seguir o menor número de passos possiveis para concluí-la.

No entanto para que o mapeamento das tarefas esteja mais próximo ao modelo mental do usuário é recomendado desenvolver o diagrama junto com usuários, seja com suas sugestões ou avaliações de modelos de navegação propostos.

Para este projeto a avaliação do modelo de navegação foi iniciada após o desenvolvimento dos sketches, que já foram elaborados com base na estrutura proposta pelo HTA. 


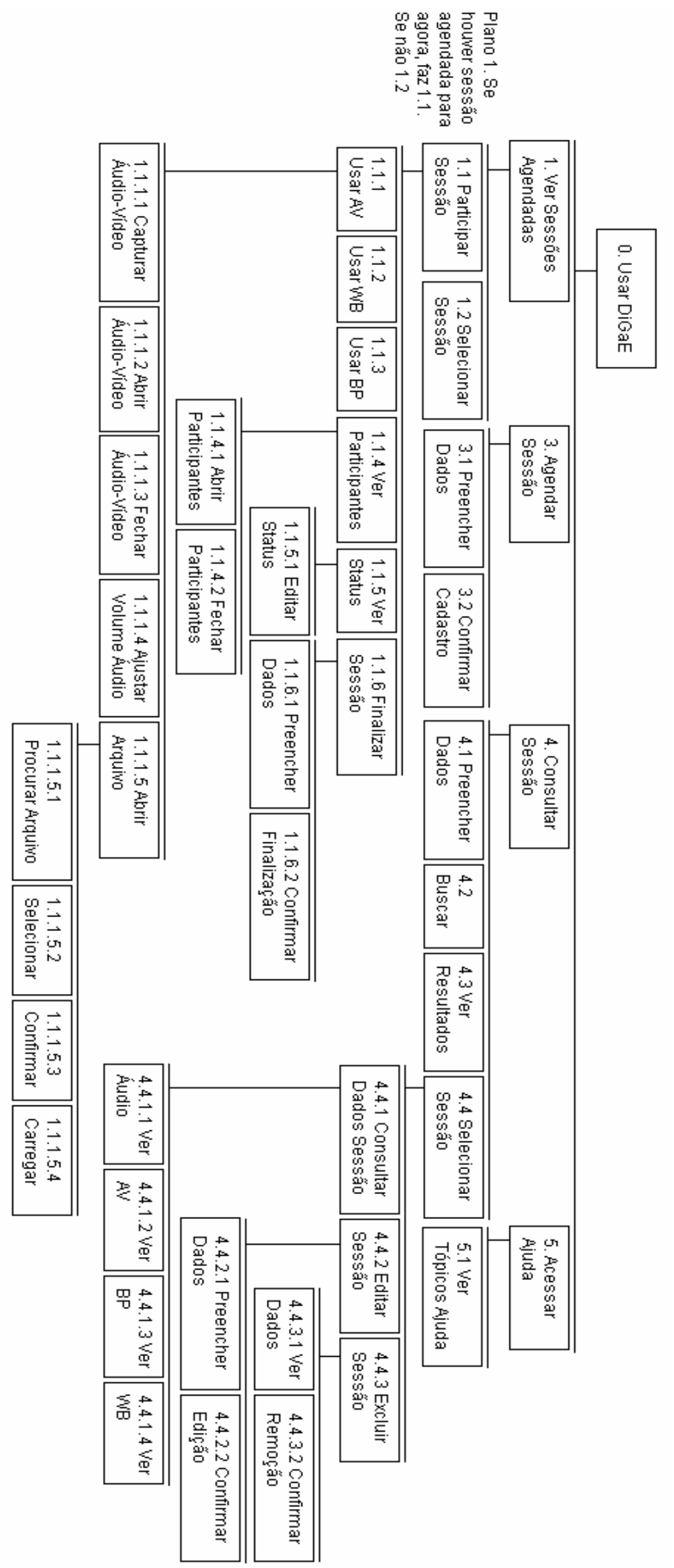

Figura 26: Diagrama HTA do DiGaE. 
Para os sketches, protótipos não funcionais das interfaces gráficas desenvolvidos, todas as fases foram consideradas. Já a implementação funcional conta com a pré-produção e a captura desenvolvidas até o momento pela equipe de desenvolvimento do Projeto TIDIA. As funções de recuperação da informação capturada encontram-se em estágio inicial de desenvolvimento. Ainda não foram implementados nem funções de recuperação semântica, nem o player com sincronização dos dados da sessão, mas está disponível a recuperação das sessões agendadas e de seus dados.

\subsection{Prototipação}

Para avaliação da primeira fase do protótipo da aplicação foram desenvolvidos protótipos de baixa fidelidade do sistema, simulando a navegação entre as páginas. Os protótipos foram desenvolvidos em HTML e publicados na web para que a primeira avaliação pudesse ser conduzida.

\subsubsection{Sketches}

Os sketches são uma maneira simplificada de representar uma aplicação ubíqua, pois não possuem os mesmos recursos que um ambiente instrumentado fornece. Entretanto, a versão produzida representa uma versão da aplicação que pode ser utilizada por um usuário remoto que participa de uma sessão de DiGaE com seu computador convencional.

O objetivo de utilizar sketches para uma primeira avaliação é observar a reação dos avaliadores, potenciais usuários do DiGaE, à aplicação, à interface, à estrutura de navegação, sendo que os resultados obtidos nesta fase são de fundamental importância para orientar as fases seguintes do desenvolvimento.

A Figura 27 ilustra a página principal da sessão, contendo todas as ferramentas possiveis em uma sessão (à esquerda a ferramenta Whiteboard, ao centro a ferramenta Bate-Papo ${ }^{24}$ e à direita a ferramenta de áudio e vídeo juntamente com a lista de participantes e o status do usuário).

\footnotetext{
${ }^{24}$ A ferramenta de comunicação por texto original do Projeto TIDIA era chamada de Bate-Papo, depois ela foi substituída pelo Chat, que também permite configurar a fonte, enviar emoticons e arquivos.
} 


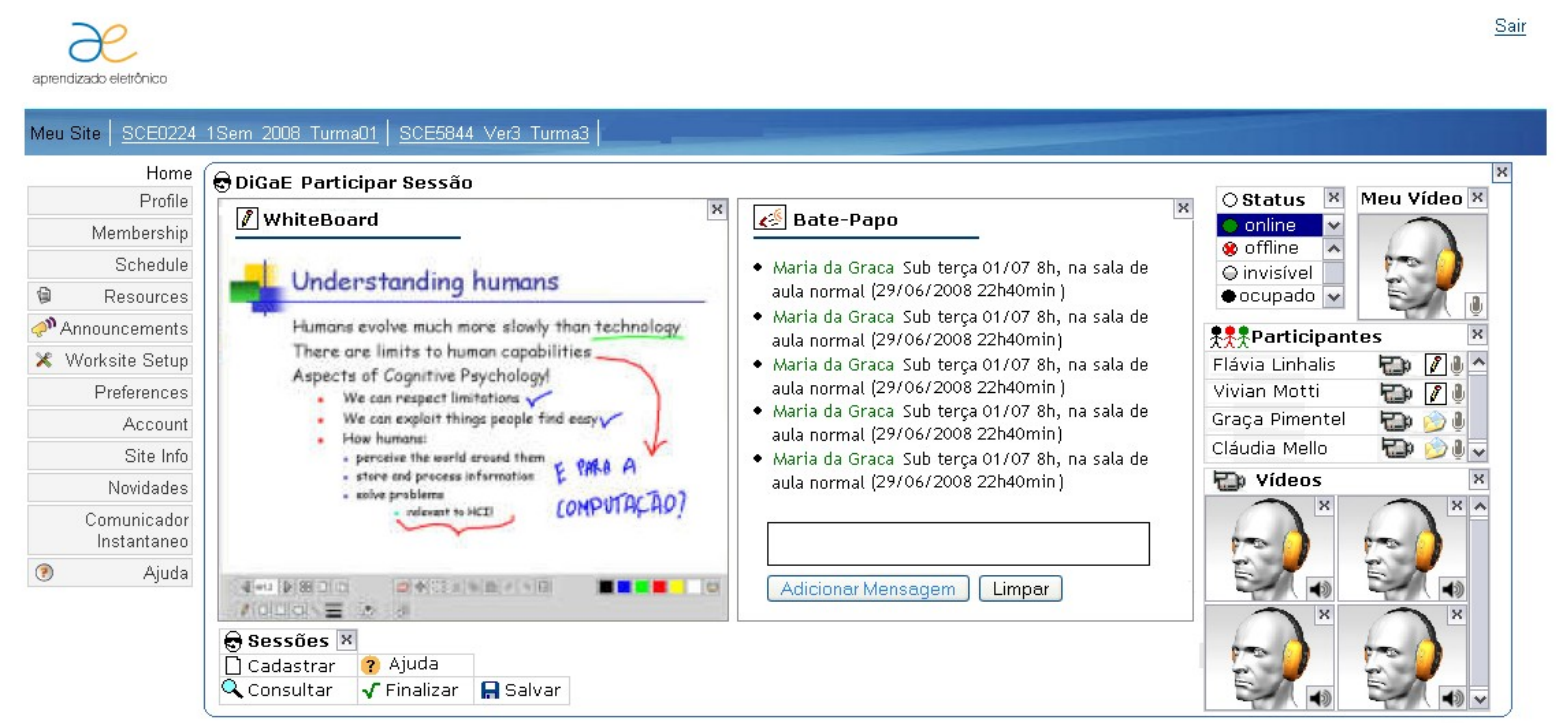

Figura 27: Protótipo de Interface da Sessão DiGaE.

À primeira vista a interface parece bastante carregada, por conter todos os componentes possiveis, mas ao mesmo tempo o usuário pode acessar diretamente as ferramentas, sem exigir passos adicionais para sua utilização. Para simplificar as opções disponíveis na tela o usuário pode minimizar ou até mesmo fechar as janelas com as ferramentas que ele desejar ou que não estiver utilizando no momento, acessando os botões disponíveis na parte superior direita das janelas.

Deve-se atentar também ao fato de que usuários que não estejam no ambiente instrumentado não terão acesso a uma rede de alta velocidade e enfrentarão restrições no processamento; deste modo, é fundamental que ele escolha qual ferramenta ele de fato deseja acompanhar na sessão: para que isto seja possível a interface deve oferecer opção de customização.

Foram desenvolvidos 43 protótipos não-funcionais das interfaces (sketches) para avaliação preliminar, eles podem ser acessados na $\mathrm{SVN}^{25}$ do Projeto TIDIA. Todos os requisitos levantados na fase anterior foram compreendidos pelas interfaces. Além das operações previstas para o DiGaE, as interfaces de Ajuda também foram elaboradas assim como mensagens de confirmação ou erro. Com isso foi possivel construir um mapa de navegação do DiGaE para elaboração de protótipos semifuncionais (storyboards). Uma avaliação crítica preliminar e informal das interfaces permitiu atualizar o

\footnotetext{
${ }^{25}$ http://incaserve.icmc.usp.br:8111/svn/Tidia-intermidia/trunk/docs/tools/digae
} 
documento de requisitos e casos de usos, tornando-o mais fiel às funcionalidades esperadas do DiGaE.

O objetivo desta fase era definir a disposição dos objetos de interação na interface, bem como os termos a serem usados, as cores, as fontes, a sequência de diálogo da interação e um mapa navegacional que especificasse os possiveis percursos do usuário no DiGaE.

\subsubsection{Avaliação dos Sketches}

O plano de avaliação foi composto por técnicas de Avaliação Heurística e de Percurso Cognitivo. Ambas as técnicas foram aplicadas com quatro avaliadores, especialistas na área de Interação Humano-Computador, para identificar aspectos das interfaces que deveriam ser reconsiderados na segunda fase do desenvolvimento. É recomendado aplicar a Avaliação Heurística utilizando de três a cinco avaliadores (conforme descreve a Seção 2.4), a utilização de quatro avaliadores neste caso se justifica pela aplicação desenvolvida até este momento estar em fase inicial. Além dessas técnicas, o protótipo foi apresentado e amplamente discutido em uma reunião da equipe de desenvolvimento, que sugeriu alterações nas interfaces.

\subsubsection{Avaliação Heurística}

As Heurísticas de Nielsen (1993) avaliam 10 características de aplicações: (i). Visibilidade do Status do Sistema; (ii.) Correspondência entre o Sistema e o Mundo Real; (iii.) Controle e Liberdade do Usuário; (iv.) Consistência e Padrão; (v.) Prevenção de Erros; (vi.) Reconhecimento ao invés de Lembrança; (vii.) Flexibilidade e Eficiência de Uso; (viii.) Design Estético e Minimalista; (ix.) Ajudar Usuários a Reconhecer, Diagnosticar e Recuperar Erros e; (x.) Ajuda e Documentação.

Os resultados da análise da Avaliação Heurística apontaram falhas na interface que foram classificadas em sete categorias conforme apresenta a Tabela 6 na qual há também sugestões provenientes da análise dos resultados da Avaliação Heurística. As categorias se referem à apresentação ou visualização da informação na interface, aos ícones utilizados, à estrutura de navegação da aplicação, ao feedback ou resposta que o usuário recebe da aplicação, às instruções fornecidas na interface, às alternativas ou 
opções que o usuário possui para interagir, e à linguagem utilizada na aplicação.

Parte das sugestões feitas está associada às limitações do protótipo, como as opções alternativas para organizar as janelas ou personalizar a interface. Entretanto, de modo geral as avaliações tiveram resultados positivos uma vez que identificaram um número bastante significativo de critérios a serem considerados no desenvolvimento das fases seguintes.

A apresentação ou visualização da informação na interface foi a categoria que mais teve recomendações dos avaliadores (9 recomendações), o que pode ser justificado pelas várias informações que estavam sendo apresentadas; seguida pelas alternativas de navegação do sistema (8 recomendações), que por ser um protótipo de baixa fidelidade, simulando a interação, não fornecia muitas opções alternativas de navegação. Por outro lado, o fato de a estrutura de navegação ter sido desenvolvida .

As outras categorias tiveram quantidades menores de recomendações, sendo que 6 recomendações faziam referência aos ícones utilizados, 5 recomendações da estrutura da navegação, 4 recomendações ao feedback e para as instruções também, e 3 recomendações à linguagem utilizada. É provável que poucas recomendações estejam associadas à linguagem pois as técnicas de avaliação aplicadas utilizaram avaliadores especialistas no domínio da computação, de modo que os termos utilizados, ainda que técnicos, estavam claros para eles. 
Tabela 6: Resultados da Avaliação Heurística sobre os Sketches (problemas e recomendações).

\begin{tabular}{|c|c|}
\hline Apresentação & $\begin{array}{l}\text { Usar chunks de informação para agrupar os dados (bordas) } \\
\text { Excesso de informação na tela } \\
\text { Padronizar a posição de objetos na interface } \\
\text { Marcar claramente campos de entrada de dados } \\
\text { Usar cores com informações redundantes } \\
\text { Eliminar o scroll horizontal } \\
\text { Destacar informações importantes na interface } \\
\text { Apresentar quantidade de sessões listadas } \\
\text { Exibir o nome da sessão atual }\end{array}$ \\
\hline Ícones & $\begin{array}{l}\text { Há inconsistências no design } \\
\text { Aumentar o contraste } \\
\text { Indicar status } \\
\text { Afastar os ícones } \\
\text { Indicar quando houver seleção } \\
\text { Desabilitar opções indisponíveis }\end{array}$ \\
\hline Navegação & $\begin{array}{l}\text { Incluir guias } \\
\text { Indicar posição atual } \\
\text { Especificar melhor os itens do menu } \\
\text { Agrupar itens relacionados } \\
\text { Afastar excluir do editar }\end{array}$ \\
\hline Feedback & $\begin{array}{l}\text { Incluir em algumas tarefas } \\
\text { Fornecer opções seguintes de interação } \\
\text { Posicionar em local melhor } \\
\text { Confirmar tarefas drásticas }\end{array}$ \\
\hline Instruções & $\begin{array}{l}\text { Estão pouco representativas } \\
\text { Aumentar quantidade } \\
\text { Advertir usuários para não cometer erros } \\
\text { Indicar tamanho de campo }\end{array}$ \\
\hline Alternativas & $\begin{array}{l}\text { Fornecer opção para: reorganizar as janelas, personalizar a interface e desfazer tarefas } \\
\text { Confirmar a exclusão de itens } \\
\text { Melhorar opções de retorno do menu } \\
\text { Adequar a interação ao nível do usuário } \\
\text { Flexibilizar o nível de detalhes da ajuda } \\
\text { Fornecer acesso à tarefa na ajuda }\end{array}$ \\
\hline Linguagem & Esclarecer melhor: consultar, finalizar e salvar \\
\hline
\end{tabular}

\subsubsection{Percurso Cognitivo}

O Percurso Cognitivo (Hom, 1998) avalia a facilidade de aprendizagem do usuário ao interagir com o sistema, aspecto fundamental para o DiGaE, cujo usuário alvo não é necessariamente experiente em computação.

A primeira etapa desse método de avaliação consiste em fornecer aos avaliadores descrições sobre o usuário e o sistema. O perfil do usuário do DiGaE, dentro do contexto deste projeto, se caracteriza por alunos, professores ou funcionários, vinculados a instituições de ensino ou pesquisa, em diferentes áreas de atuação, que realizem reuniões ou apresentações, e em geral são maiores de 18 anos. 
O DiGaE se caracteriza por um ambiente instrumentado com câmera, microfone, lousa eletrônica e computadores, para reuniões entre participantes remotos, com compartilhamento de áudio, vídeo, texto, tinta eletrônica e imagens.

Após conhecer o sistema e o perfil de seus usuários, algumas tarefas são propostas ao avaliador para que ele as execute, analise e responda a quatro perguntas: (i) Se os usuários atingirão a meta correta; (ii) Se os usuários perceberão que a opção da tarefa está disponivel na interface; (iii) Se os usuários reconhecerão que o objeto de interação, disponível na interface, produzirá o efeito que ele deseja; e (iv) Se após a execução da tarefa, o usuário perceberá que o sistema progrediu em direção à solução da tarefa.

Para avaliação por percurso cognitivo, oito tarefas, que englobavam as principais tarefas disponiveis na interface, foram propostas para que quatro avaliadores avaliassem:

1. Listar todas as sessões

2. Participar de uma sessão em andamento

3. Finalizar a sessão

4. Consultar

5. Consultar dados específicos (Whiteboard, Áudio-Vídeo e Chat)

6. Editar

7. Excluir

8. Acessar tópicos da Ajuda

Como resultados da análise foram encontrados problemas na interface e sugeridas melhorias no protótipo (descritos em seguida). Doze comentários foram extraídos da análise dos relatórios do percurso cognitivo; esses comentários foram analisados e agrupados em três níveis conforme seu impacto e sua severidade na interação e sua prioridade de correção.

Problemas catastróficos impedem que o usuário conclua a tarefa e devem ser prioritários para correção; problemas graves dificultam a execução da tarefa mas não a impossibilitam; já problemas cosméticos, quando solucionados, tornam a interação mais eficiente. Essa classificação foi adaptada da classificação de severidade original da Avaliação Heurística, 
que engloba cinco classes. Ela foi utilizada também para as outras avaliações deste projeto.

Problemas Catastróficos: a opção de acesso, DiGaE, no menu inicial, pode não ser clara para usuários novatos; o botão para entrar na sessão deve ser destacado (por exemplo com o nome da sessão); a necessidade de rolagem pode impedir a visualização direta da opção finalizar no menu; para edição de sessões o usuário deve estender os detalhes delas, isto chegou a impossibilitar a conclusão da tarefa por dois avaliadores.

Problemas Graves: a posição do botão entrar (próximo à lista de participantes) pode confundir o usuário; as sessões já encerradas devem ser diferenciadas na listagem das sessões; na listagem de sessões que sejam referentes ao resultado de uma busca deve-se identificar que houve a busca; a exigência de dois passos para consultar dados específicos pode dificultar a conclusão desta tarefa; não há confirmação na exclusão de sessões.

Problemas Cosméticos: deve ser exibida a quantidade de sessões listadas; deve ser exibido o nome da seção atual, para que o usuário identifique onde ele se encontra; deve-se facilitar o acesso à opção de exclusão de sessões (pois eram exigidos dois passos).

Em geral, o resultado da análise dos relatórios do percurso cognitivo mostraram que os avaliadores não tiveram muitas dificuldades em cumprir as tarefas, mas foram detectadas falhas importante, classificadas como problemas catastróficos, que podem impedir que o usuário conclua a tarefa e que portanto, devem ser solucionados. Foram também sugeridas melhorias que deverão ser consideradas na implementação da próxima versão do protótipo.

Alguns problemas foram comuns às duas técnicas de avaliação aplicada, mas os métodos se mostraram complementares, pois a avaliação heurística avalia mais aspectos, de modo mais superficial, enquanto que o percurso cognitivo, foca no aprendizado do usuário, mas possibilita analisar mais profundamente a execução de tarefas específicas.

\subsubsection{Reuniões com Desenvolvedores e Projetistas}

A avaliação formal descrita nas seções anteriores realizadas de acordo com o plano de avaliação, visou obter o feedback de usuários reais e de 
especialistas no domínio para aprimorar as interfaces que foram criadas para o protótipo. Além delas, o protótipo foi discutido em uma reunião da equipe de desenvolvimento, que opinou sobre as interfaces e sugeriu modificações. Nove comentários foram extraídos na reunião. Eles estão listados e discutidos abaixo.

Foi sugerido que, quando o usuário acessa a lista de sessões agendadas, em uma sessão atual, o status dos participantes deve ser exibido, de modo que o usuário que visualiza a sessão saiba quem está atualmente presente nela. Não é interessante que o local seja especificado para o agendamento da sessão, uma vez que a reunião é distribuída, então ele deve ser personalizado conforme o participante. A questão do local foi tratada na nova versão do agendamento, para o cadastro da sessão há três opções de local (conforme especificação original do DiGaE) de modo que as ferramentas selecionadas para a sessão possam ser iniciadas nos três locais.

A Whiteboard exige um espaço maior na interface, portanto deve-se retirá-la da interface principal, e redistribuir as outras ferramentas. Esta versão foi adotada na fase seguinte de desenvolvimento, considerando o acesso a cada ferramenta por um dispositivo diferente (Whiteboard na lousa eletrônica com interação via caneta, monitores com exibição do áudio e vídeo e computador tradicional para utilização do Chat). Uma outra versão para usuários com computador pessoal (e não no ambiente instrumentado) está sendo implementada, pois conforme os sketches todas as ferramentas devem estar disponiveis para que o usuário possa escolher qual ele deseja acompanhar ou como deve estar a estrutura da interface. Deve-se ter em mente que usuários nessas condições podem ter restrições quanto ao processamento e à velocidade da conexão de rede, e é improvável que optem por visualizar todas as ferramentas da sessão ao mesmo tempo, todo o tempo.

Uma opção para simplificação da interface do DiGaE é a utilização de abas, de modo que o usuário selecione a aba com a ferramenta de interesse quando for interagir com ela. O ideal é que o DiGaE já inicie com a interface da sessão (e não com a lista de sessões agendadas como previsto no protótipo): embora todos os dispositivos tenham que ser carregados quando 
o usuário entra no ambiente, ele não tem que realizar nenhum passo adicional para iniciar a sessão de captura, pois ela já está disponivel simplesmente com o acesso ao DiGaE.

Um dos problemas de acesso instantâneo à Whiteboard é que, em caso de apresentação de slides, o usuário pode selecionar o arquivo com os slides antes, exigindo interação explícita (uma maneira de contornar este problema seria o usuário, ao agendar a sessão, já inserir seu conjunto de slides, o que funcionaria bem desde que sua apresentação já estivesse em versão final antes do início da apresentação). Essa questão foi resolvida na interface de agendamento, na qual usuários que incluam entre as ferramentas o uso da Whiteboard têm a opção de seleção de arquivo. Não está em uso uma versão DiGaE sem que a sessão tenha sido agendada anteriormente.

Para versões futuras da aplicação, pode-se tratar em diferentes tipos de arquivos, por exemplo contemplando um cenário no qual se deseje tocar uma música ou exibir um vídeo: esses arquivos poderiam ser incluídos no Comunicador Instantâneo, que durante o andamento da sessão DiGaE disponibilizaria o arquivo incluído para ser compartilhado ou executado.

Foi proposta, também, uma sessão de DiGaE na qual não fosse necessário agendamento prévio, ou seja, uma sessão padrão, com ferramentas pré-determinadas e participação livre de usuários. Esse modelo, próximo ao utilizado no sistema DUMMBO (Brotherton et al., 1999), facilita o início de uma sessão de captura, mas pode exigir esforço superestimado do ambiente (caso o padrão seja incluir todas as ferramentas na sessão) e dificultar a recuperação da sessão (pela inclusão de um título padronizado na sessão), além de questões de privacidade e segurança, pois o conteúdo gerado no evento estaria disponivel a todos os usuários. Essas sessões foram chamadas de live sessions, mas não foram consideradas na primeira fase da implementação.

\subsection{Ferramentas Utilizadas}

O projeto do DiGaE, em sua versão atual, prevê a utilização de três ferramentas que foram desenvolvidas no contexto do Projeto TIDIA-Ae. Para uma sessão DiGaE, algumas adaptações são necessárias. Por exemplo, a 
lista de participantes está presente em todas as ferramentas originais e, no caso de uma sessão de DiGaE com mais de uma ferramenta cadastrada, este dado se repetiria em todas elas. Além disso, a versão original do Comunicador Instantâneo comporta também troca de mensagens de texto e, como o Chat já possui essa funcionalidade, ela também se repetiria. As ferramentas Comunicador Instantâneo e Chat se complementam oferecendo, juntas, funcionalidades de compartilhamento de áudio, vídeo, texto e gráficos, conforme descrição a seguir.

\subsubsection{Whiteboard}

A Whiteboard (Jardim et al., 2005) é uma ferramenta colaborativa para desenho baseado em caneta eletrônica. A Figura 28 ilustra, no menu na parte inferior da figura, as funcionalidades disponiveis: botões com opção para percorrer os slides, visualizá-los de modo agrupado, inserir, duplicar ou excluir slide, borracha para apagar anotação, opções para mover uma seleção, selecionar, recortar, duplicar ou colar uma seleção, refazer ou desfazer ação, inserir grade, configurar a cor da anotação, selecionar caneta para fazer traço, desenhar polígonos (círculo, quadrilátero, livre) ou retas,

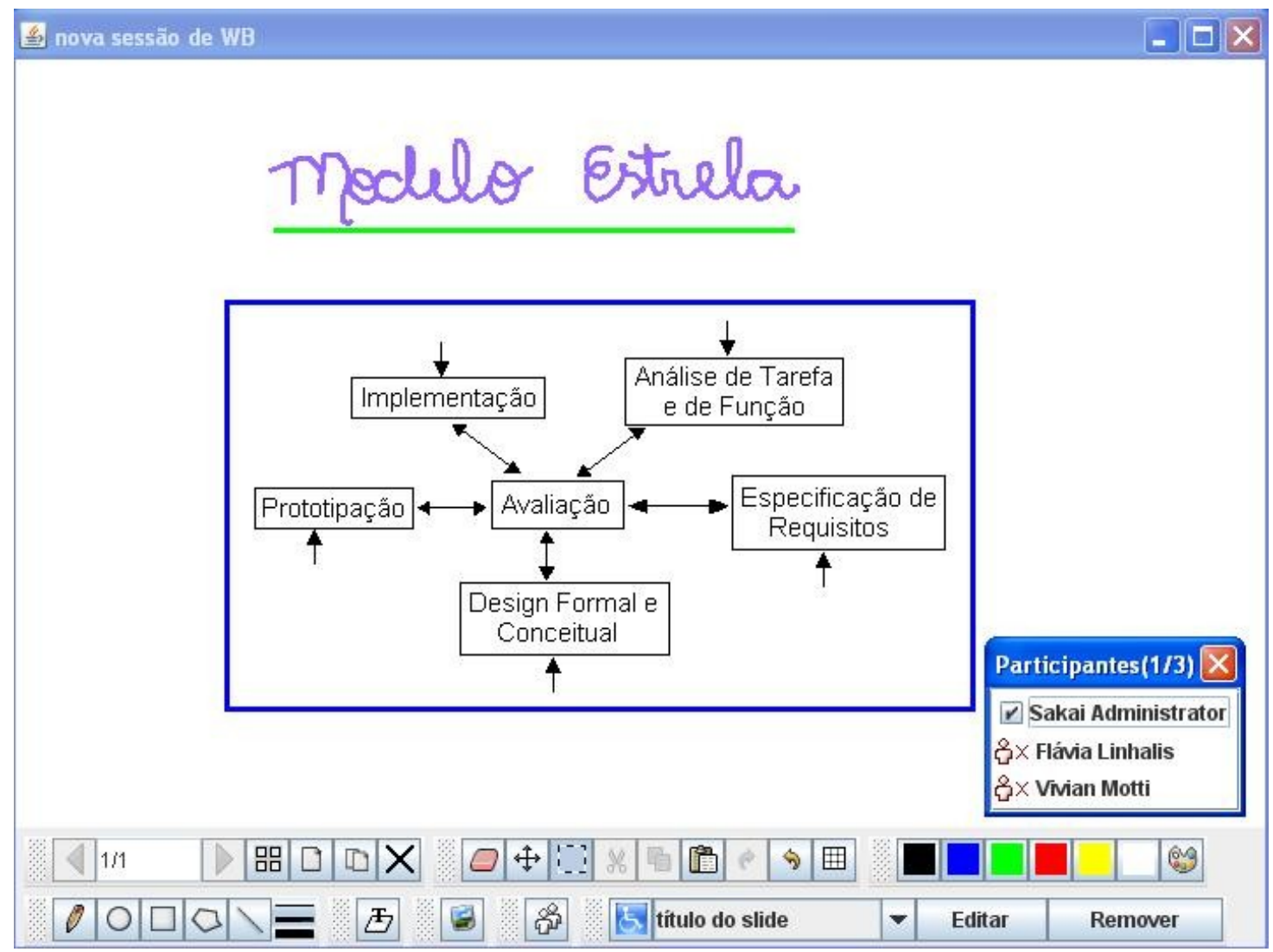

Figura 28: Interface da Ferramenta Whiteboard. 
definir espessura da tinta da caneta, inserir texto usando teclado, inserir imagem. A Figura 28 apresenta também uma janela com a lista de participantes da sessão (na parte inferior direita da figura). A Whiteboard pode ser utilizada para apresentações que fazem uso de um conjunto de slides preparados com antecedência, pois, além de exibir os slides, permite ao usuário anotar sobre ele usando uma caneta eletrônica (ou teclado e mouse convencional). A versão utilizada da Whiteboard possui função de acessibilidade, considerando deficientes visuais ou usuários com leitor de tela, disponível para usuários com perfil de administrador, para incluir uma descrição sobre os gráficos desenhados, permitindo que um usuário com leitor de tela possa ter acesso ao conteúdo do slide. O participante seleciona um conteúdo na tela, clica sobre o botão com o ícone de acessibilidade, digita uma descrição para o conteúdo e especifica a posição do conteúdo na tela, as descrições cadastradas ficam em uma lista, na parte inferior do menu na interface (por exemplo, na Figura 28, 'título do slide' é a descrição que foi incluída para Modelo Estrela), seguida pelas opções de editar ou remover descrições.

\subsubsection{Comunicador Instantâneo}

O Comunicador Instantâneo (Lobato et al., 2005) é a ferramenta para compartilhamento de áudio e vídeo, desenvolvida em Adobe Flex ${ }^{26}$, por pesquisadores do Lince (Laboratório de Inovação em Computação e Engenharia) da UFSCar (Universidade Federal de São Carlos). Essa ferramenta permite a captura de vídeo e é compativel com diversos navegadores devido ao uso de plugin instalado no cliente. Na interface, conforme ilustra a Figura 29, está disponivel a lista de participantes (Figura 29 - esquerda), e as janelas para vídeo (Figura 29 - direita) e envio de mensagens textuais (Figura 29 - centro). Acima da área de escrita de texto ao centro, há três ícones cujas funções são: captura de câmera de vídeo, convite de contatos que estejam online na lista de participantes e exibição do histórico de conversas anteriores (de 1, 15, 30 dias ou todas). As janelas do Comunicador Instantâneo podem ser movidas na interface conforme

\footnotetext{
${ }^{26}$ Adobe Flex é um framework open source para implementar aplicações web com suporte à multimídia (http://www.adobe.com/products/flex/).
} 
interesse do usuário e as sessões podem ser realizadas entre dois ou mais participantes. O Comunicador Instantâneo permite configurar a qualidade do vídeo (Figura 29 - parte superior esquerda), o que é útil para ajustar a transmissão conforme a velocidade da conexão do usuário. Essa janela possui também a aba de captura, para autorizar a solicitação de uma transmissão de vídeo (Lobato et al., 2005).

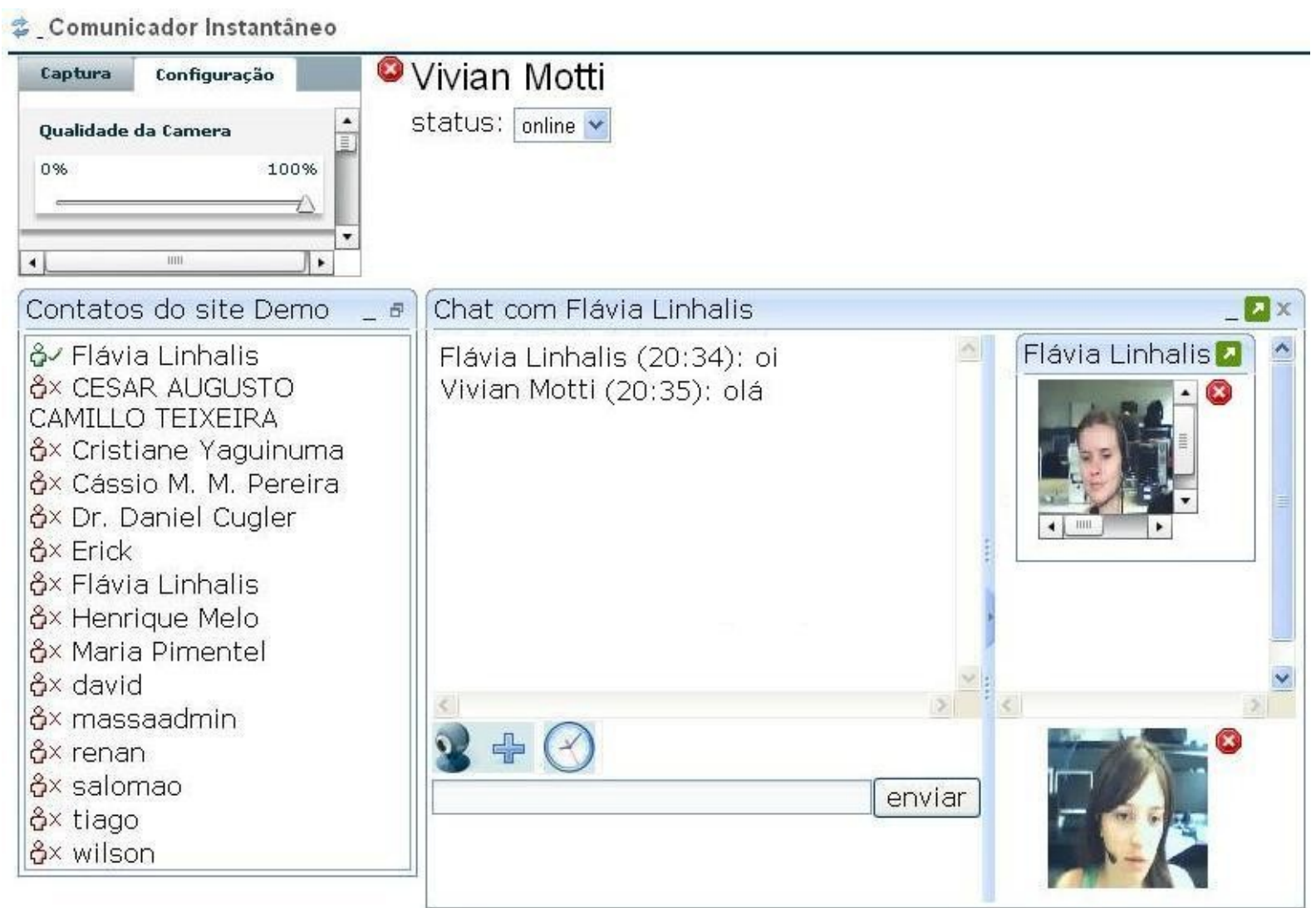

Figura 29: Interface da Ferramenta Comunicador Instantâneo.

\subsubsection{Chat}

O Chat (Moraes et al., 2008) é uma ferramenta para comunicação textual entre participantes de uma sessão. A Figura 30 ilustra sua interface: na parte maior (esquerda) estão as mensagens que foram trocadas, com a indicação do participante que a enviou e em qual horário; à direita há a lista de participantes, com ícones indicando se eles estão online ou não; na parte inferior é possivel configurar para quem se deseja enviar a mensagem, se é em modo reservado ou não, há a caixa de edição da mensagem, seguida pelo botão para enviá-la, há botões para editar a fonte do texto da mensagem, para inserir emoticons e para selecionar um arquivo a ser enviado - além disso há a opção de manter a janela de mensagens fixa ou com rolagem 
ativada automaticamente conforme as mensagens forem postadas. Essas funções estão implementadas no Chat e está sendo feita uma extensão para que um mediador possa filtrar as mensagens durante a sessão: caso a mensagem seja autorizada ela é publicada, caso contrário seu autor recebe um aviso notificando a não autorização.

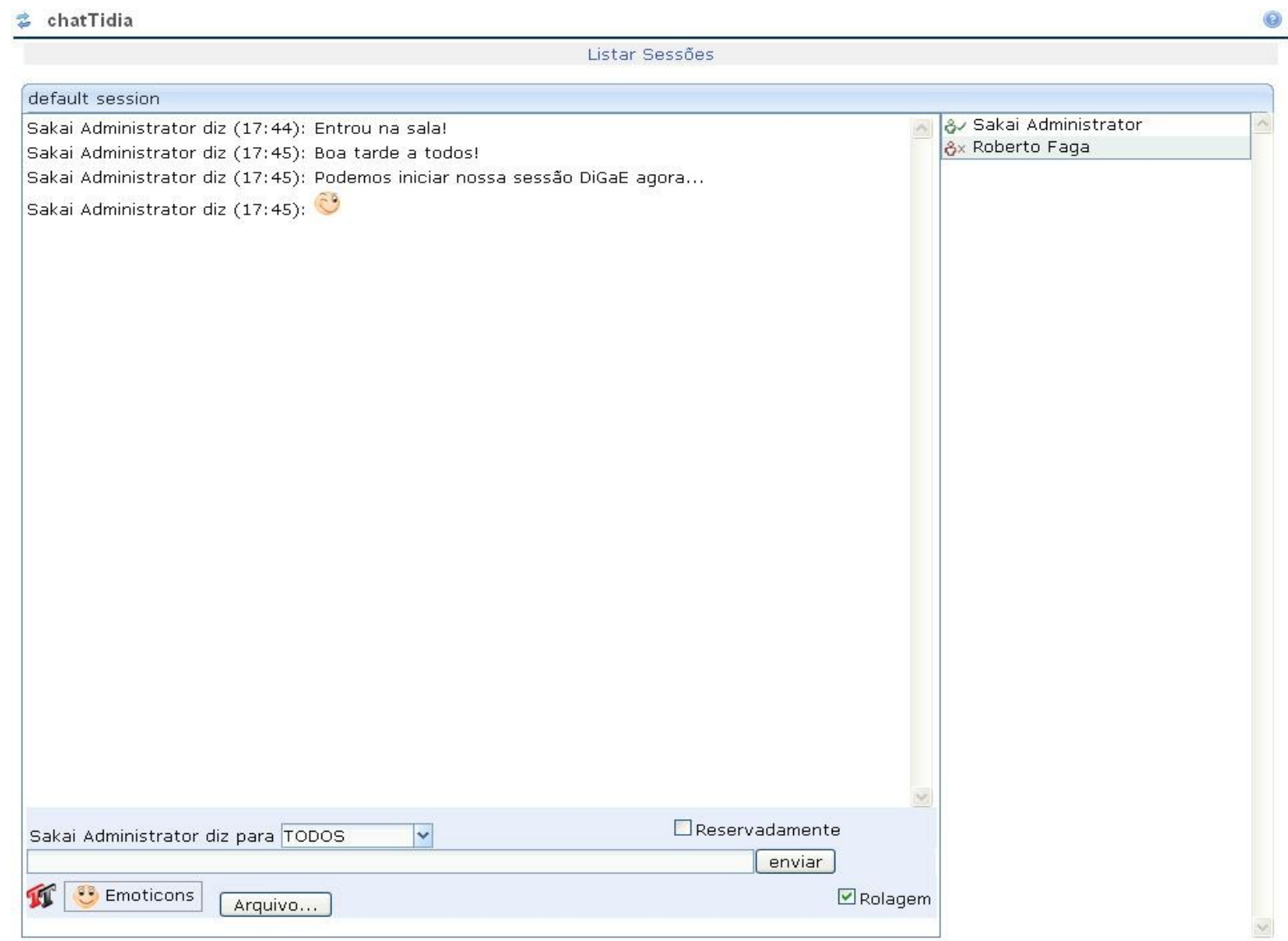

Figura 30: Interface da Ferramenta Chat.

\subsection{Avaliação das Ferramentas Utilizadas}

Antes de conduzir uma avaliação formal no ambiente do DiGaE foram realizadas avaliações específicas para as ferramentas que o compõe, para identificar o nivel de usabilidade destas. Para avaliar a ferramenta Whiteboard foi utilizado o Percurso Cognitivo, englobando as tarefas possiveis de serem executadas na ferramenta e descrevendo os passos necessários para concluí-las. Já a ferramenta Comunicador Instantâneo e a ferramenta Chat foram avaliadas com questionários. O processo de avaliação e os resultados obtidos foram discutidos e estão descritos nas seções seguintes. 


\subsubsection{Avaliação da Ferramenta Whiteboard (WB)}

Para avaliar a Whiteboard foi solicitado a quatro avaliadores que executassem a avaliação por percurso cognitivo das seguintes tarefas:

1 - Criar uma nova sessão de Whiteboard (Inserir título, descrição, objetivo, selecionar 5 participantes, fazer upload de arquivo)

2 - Listar sessões

3 - Entrar na sessão criada

a - Adicionar slide

b - Fazer um traço roxo na maior espessura

c - Duplicar slide

d - Exibir participantes

e - Inserir uma imagem

f - Inserir texto

g - Inserir cada um dos polígonos (círculo, quadrado, polígono)

h - Apagar o círculo

i - Abrir os slides

j - Selecionar o primeiro

k - Mostrar grade de 40 por 20

1 - Desenhar 2 traços, um de espessura média e um de espessura mínima

m - Mover o traço menor

n - Desfazer a ação

o - Selecionar um traço

p - Recortar

q - Colar

r - Copiar uma seleção qualquer

4 - Fechar sessão

5 - Editar a descrição da sessão

6 - Visualizar sessão

7 - Voltar para lista de sessões

8 - Finalizar a sessão

9 - Visualizar dados da sessão

10 - Listar sessões 


\section{1 - Apagar sessão}

Essas tarefas visavam a avaliação de todas as funcionalidades disponiveis na ferramenta Whiteboard e eram compostas por subtarefas que os avaliadores tiveram que concluir para responder às quatro perguntas do percurso cognitivo. Ao final da avaliação um documento foi elaborado e uma análise dos resultados obtidos foi feita.

Os avaliadores concluíram que, para todas as tarefas, os usuários tentariam atingir a meta corretamente. No entanto algumas observações foram feitas sobre a ferramenta, como detalhado a seguir.

Para a criação da nova sessão da Whiteboard, foi observado que o feedback do sistema só está disponivel após a conclusão de todos os passos da tarefa, ou seja, a mensagem de erro (caso não seja inserido o título da sessão por exemplo) só é exibida após a inserção de todos os dados no formulário e a submissão do mesmo no sistema. Esse fato causa aborrecimento nos usuários, pois exige retrabalho em caso de erro, uma vez que quando ele retorna ao formulário para correção do erro (via botão voltar do navegador, pois não há opção na ferramenta) ele deve inserir os mesmos dados novamente, pois eles não estão sendo armazenados.

Foi observado que algumas tarefas, como por exemplo a 3 (entrar na sessão e utilizar as funções da ferramenta Whiteboard) só estão disponíveis para usuários com perfil de administrador, usuários com outro perfil, neste caso, só podem assistir à sessão, sem interagir com ela.

Esta avaliação foi insuficiente pois não identificou parte dos problemas encontrados na interface. Em uma análise mais apurada, incluindo os comentários da avaliação no ambiente, observaram-se outros detalhes que devem ser corrigidos para uma nova versão da ferramenta Whiteboard.

A opção de paleta de cores, para selecionar cores específicas, tem sua descrição em inglês (swatches e preview) ou com termos muito técnicos para usuários não especialistas (HSV e RGB). O mesmo ocorre na inserção de grade, a janela aparece com todos os termos em inglês (grid, width, height), exceto os botões ( $\mathrm{Ok}$ e Cancelar). Este tipo de erro é considerado catastrófico, pois pode impedir o usuário de completar sua tarefa. 
Os itens do menu poderiam estar em uma sequência mais lógica para o usuário (primeiro ele faz a seleção, e depois ele pode movê-la, recortá-la ou duplicá-la). Os botões na janela de inserção de descrição acessivel estão inconsistentes (poderiam ter o mesmo tamanho). A lista de descrições acessivieis não comporta descrições muito grandes; que aparecem incompletas. O título da janela de fechar (fechar whiteboard) também aparece incompleto pois a largura da janela é insuficiente para sua visualização completa (uma opção seria usar 'fechar Whiteboard' como título, por exemplo).

Além disso, a organização das funções no menu poderia ser mais clara, por exemplo aproximando a borracha da função do lápis, e a seleção da função de recortar (já que é estritamente necessário que algo esteja selecionado para poder ser recortado). A opção de fechar, sinalizada por um ícone de $\mathrm{X}$ no menu confundiu os avaliadores, eles acharam que o botão apagaria um slide, não é claro a opção de fechar agrupada com as funções de slides (novo, duplicar), foi sugerido manter a opção de fechar na extremidade direita do menu.

\subsubsection{Avaliação da Ferramenta Comunicador Instantâneo}

A ferramenta Comunicador Instantâneo foi utilizada para compartilhamento de áudio e vídeo entre participantes da sessão de DiGaE. A lista de participantes, exibida na interface da ferramenta, indica por meio de ícones e cores se eles estão online ou não. Para iniciar a transmissão deve-se clicar sobre o nome do participante e uma janela com os vídeos e caixa de texto para edição de mensagens é exibida na interface. Para esta ferramenta foi solicitado a seis usuários, que já haviam utilizado ferramentas de comunicação instantânea, que analisassem cinco itens, considerados fundamentais para interação, e classificassem-os de acordo com a escala Likert de cinco pontos, por diferencial semântico. A Tabela 7 ilustra o questionário como foi aplicado: 
Tabela 7: Questionário para avaliação da ferramenta Comunicador Instantâneo.

\begin{tabular}{|l|l|}
\hline Facilidade de Uso & Muito Fácil O O O O O Muito Difícil \\
\hline Aparência do Comunicador Instantâneo & Muito Boa O O O O O Muito Ruim \\
\hline Navegação no Comunicador Instantâneo & Muito Clara O O O O O Muito Complexa \\
\hline Design de Ícones & Muito Bom O O O O O Muito Ruim \\
\hline Funções do Sistema & Muito Úteis O O O O O Muito Inúteis \\
\hline
\end{tabular}

Optou-se por este método de avaliação pela utilização de uma linguagem clara para usuários reais, que não fosse muito técnica e que englobasse um conjunto de itens importantes para identificar o nível de usabilidade do sistema. Foi também fornecida uma descrição sobre cada item a ser avaliado, conforme detalhado a seguir.

A facilidade de uso do sistema avalia se as funções estão claras, se o acesso a elas é fácil, se os termos utilizados favorecem à compreensão. A aparência do sistema avalia se o contraste entre as cores usadas é ideal (os itens estão bem visíveis), se a disposição dos menus e botões favorece a utilização do sistema, se o tamanho e a posição das janelas é adequado. A navegação do sistema avalia se as funções que estão previstas para serem implementadas no protótipo podem ser facilmente encontradas na interface da aplicação. O design dos ícones avalia se os formatos dos botões e as imagens utilizadas para os ícones torna a interpretação de suas funções claras, se é necessária uma descrição textual sobre a função do botão, ou se a imagem não é significativa para compreensão de sua utilidade no sistema. A opção Funções do sistema visa avaliar se o participante julga útil a tarefa apoiada pela ferramenta.

Também foi solicitado aos avaliadores que enviassem comentários, sugestões ou críticas sobre a interação com a ferramenta, com o propósito de identificar suas opiniões sobre ela.

Como resultados, em linhas gerais, o uso da ferramenta Comunicador Instantâneo foi considerado fácil (exceto por um avaliador que classificou-o como dificil), a navegação do sistema foi apontada como clara, o design de ícones como muito bom (exceto por um avaliador que classificou-o como regular), as funções do sistema como úteis, e aparência do sistema foi classificada como boa. 
A Tabela 8 apresenta a distribuição das atribuições feitas aos critérios de avaliação. O critério melhor avaliado foi o design dos ícones e o de pior avaliação se refere à aparência da ferramenta Comunicador Instantâneo. De modo geral as atribuições feitas aos critérios avaliados foi positiva, nenhum critério recebeu avaliação negativa ou muito negativa.

Tabela 8: Resultados da avaliação da ferramenta Comunicador Instantâneo.

\begin{tabular}{|l|c|c|c|c|c|}
\hline Critério / Atribuição & $\begin{array}{c}\text { Muito } \\
\text { Positiva }\end{array}$ & Positiva & Regular & Negativa & $\begin{array}{c}\text { Muito } \\
\text { Negativa }\end{array}$ \\
\hline Facilidade de Uso & 3 & 2 & 1 & 0 & 0 \\
\hline Aparência do Comunicador Instantâneo & 1 & 4 & 1 & 0 & 0 \\
\hline Navegação no Comunicador Instantâneo & 2 & 4 & 0 & 0 & 0 \\
\hline Design de Ícones & 3 & 3 & 1 & 0 & 0 \\
\hline Funções do Sistema & 2 & 4 & 0 & 0 & 0 \\
\hline
\end{tabular}

Com essa avaliação foram observadas diversas falhas nas interfaces, como detalhado a seguir. Essas observações foram também inicialmente classificadas de acordo com seu impacto, severidade e prioridade de correção, em três grupos: problemas catastróficos (7), graves (6) e cosméticos (5).

Problemas Catastróficos: algumas mensagens aparecem em inglês na interface (exemplo: confirmação da configuração do vídeo); termos técnicos estão sendo usados para configuração de vídeo (frames por segundo); as janelas, quando movidas, às vezes são sobrepostas por outros componentes da interface e podem ser movidas para fora da janela, o que impede sua visualização; para mover a janela pela interface seu título se mantém em fonte preta mas o fundo passa a ser azul escuro, o que pode dificultar ou até mesmo impedir sua visualização; não há opção de ajuda na interface; e o ícone com o relógio não é claro (corresponde à função de exibir o histórico da conversa) e há inconsistências no posicionamento dos botões (exemplo: Ok e Cancelar).

Problemas Graves: mensagens com caracteres especiais estão sendo exibidas incorretamente; no formato das janelas de mensagens, a opção de deslocar a janela nem sempre está disponivel; e a transmissão do áudio deveria estar desvinculada da do vídeo. 
Problemas Cosméticos: as mensagens estão inconsistentes quanto ao uso de maiúsculas e minúsculas; há falta de acentuação em alguns termos, nem sempre é necessário exibir a barra de rolagem; quando a janela estiver minimizada, essa opção deveria estar desabilitada ou não estar visível na interface.

Um dos avaliadores sugeriu a opção de alterar a fonte do texto das mensagens do Comunicador Instantâneo. No entanto, esta sugestão não será necessária para o DiGaE, pois a ferramenta de Chat já possui essa opção e o objetivo do Comunicador Instantâneo e ser utilizado para compartilhar AV.

"Uma sugestão que eu gostaria de dar seria uma ferramenta em que nós pudéssemos mudar a fonte da letra para facilitar a comunicação entre os usuários facilitando assim a ênfase de cada palavra em determinado assunto."

A maioria dos erros detectados na avaliação tem alto impacto na interação do usuário, sendo classificados como catastróficos e podem até mesmo impedir o usuário de interagir com a ferramenta. Esses erros devem ter alta prioridade de correção na implementação de uma nova versão do Comunicador Instantâneo.

\subsubsection{Avaliação da Ferramenta Chat}

Para avaliação da ferramenta Chat foi utilizada a mesma abordagem do Comunicador Instantâneo. Sete avaliadores analisaram cinco critérios de usabilidade na interação com a ferramenta e classificaram-os de acordo com a escala Likert de cinco pontos por diferencial semântico. A Tabela 9 mostra as atribuições dadas pelos avaliadores aos critérios avaliados.

A maior dificuldade dos avaliadores foi com relação à navegação na ferramenta, o que pode ser justificado pelas limitações que foram encontradas na interação com a ferramenta Chat. As funções da ferramenta Chat também receberam maior parte das avaliações como regular, isto pode ser também justificado pelas limitações encontradas na ferramenta. $O$ critério melhor avaliado foi o design de ícones, o que indica que as imagens estão claras para o entendimento do usuário. De modo geral a ferramenta teve três critérios (aparência, navegação e funções) que obtiveram a maioria das avaliações como regular, portanto será necessário um intensificar 
esforços para produzir uma nova versão da ferramenta Chat que tenha maior grau de usabilidade considerando esses aspectos.

Tabela 9: Resultados da avaliação da ferramenta Chat.

\begin{tabular}{|l|c|c|c|c|c|}
\hline Critério / Atribuição & Muito Positiva & Positiva & Regular & Negativa & Muito Negativa \\
\hline Facilidade de Uso & 1 & 5 & 1 & 0 & 0 \\
\hline Aparência do Chat & 2 & 2 & 3 & 0 & 0 \\
\hline Navegação no Chat & 0 & 2 & 5 & 0 & 0 \\
\hline Design de Ícones & 2 & 5 & 0 & 0 & 0 \\
\hline Funções do Sistema & 2 & 1 & 4 & 0 & 0 \\
\hline
\end{tabular}

Os problemas identificados foram também classificados em catastróficos, graves ou cosméticos de acordo com sua severidade, impacto e prioridade de correção.

Problemas Catastróficos: a opção de rolar a tela automaticamente deveria estar checada por padrão ou ser uma opção para usuários avançados (da maneira que está, é provável que usuários novatos não entendam sua função); não há opção de ajuda; a opção de formatação da fonte não foi implementada, no entanto aparece na interface; a mensagem de erro ao acessar essa função é muito técnica e não compreensivel para os usuários; não é possível receber um arquivo enviado.

Problemas Graves: o nome da sessão não está sendo usado como título da janela de mensagens; o tamanho da janela de mensagens poderia ser menor, ou configurável; a barra de rolagem deveria aparecer somente quando fosse necessária; os rótulos dos botões não estão padronizados quanto ao uso de maiúsculas; as formas dos botões não estão consistentes; os emoticons não estão aparecendo como imagem para quem os recebe, mas como os caracteres ASCII correspondentes.

Problemas Cosméticos: a lista de participantes poderia ter a opção de ser fechada; as mensagens estão inconsistentes quanto ao uso de maiúsculas e minúsculas; as posições das funções no menu, se estivessem agrupadas em chunks por meio de quadros, estariam mais claras para o usuário e melhorariam a aparência da ferramenta.

Alguns dos problemas identificados se referiam diretamente a limitações na ferramenta (configuração da fonte), mas a mensagem de erro 
exibida ("exceção desconhecida") não informa o usuário sobre a causa e definição do erro. Essa opção deveria estar desabilitada ou ausente na interface. A ausência de ajuda ou instruções é um problema catastrófico na ferramenta porque nem sempre o usuário entende os termos e ícones usados ("reservadamente", "rolagem" ou o ícone de "alteração de fonte"). O uso de texto alternativo ajuda mas não é suficiente para que o usuário compreenda a função disponível.

O resultado da análise da ferramenta Chat foi entregue à equipe de desenvolvimento e parte dos problemas que foram detectados já foram solucionados. Atualmente, a rolagem da caixa de mensagens fica ativada por padrão; há ajuda online; e as funções de formatação do texto da mensagem e de envio de arquivo já foram implementadas. Ao agendar uma nova sessão, o seu título é solicitado e está sendo usado tanto na lista de sessões como na interface da sessão para identificá-la. A barra de rolagem fica desabilitada e está sendo ativada somente quando necessária. As imagens dos emoticons estão aparecendo também para quem os recebe. A lista com os participantes está fixa na interface e as funções do menu estão sendo agrupadas. A nova versão da ferramenta Chat será disponibilizada para os desenvolvedores do Projeto TIDIA-Ae.

\subsection{Estudo de Caso: Ambiente Instrumentado}

Um ambiente instrumentado, ilustrado na Figura 31, foi preparado para executar a aplicação do DiGaE desenvolvida, conforme detalhado a seguir. 


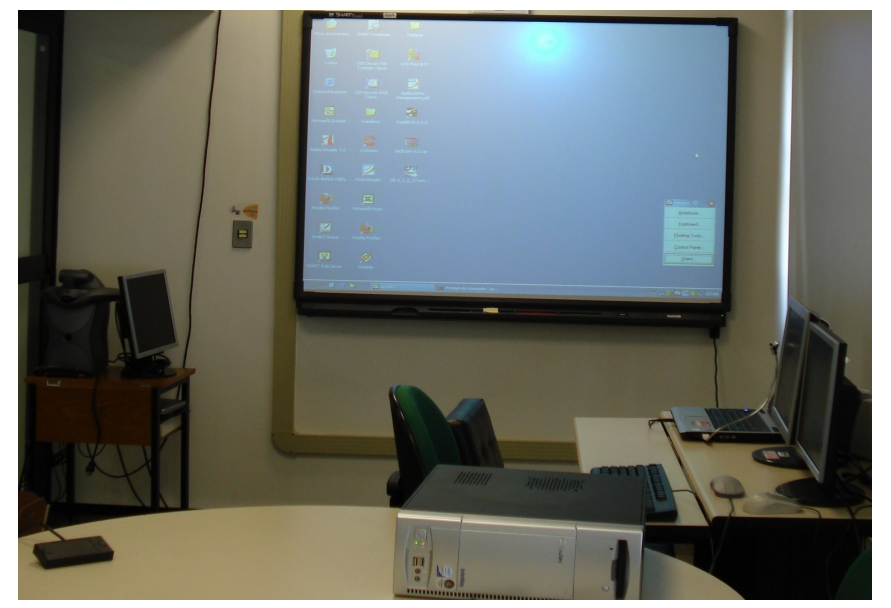

Figura 31: Ambiente instrumentado: DiGaE. À esquerda, sobre a mesa há o leitor de RFID. Ao fundo há a lousa eletrônica (Smartboard). À direita há três monitores, dois para áudio e vídeo, com câmera entre eles e o monitor à frente executa o Chat e o programa que lê a tag RFID.

\subsubsection{Descrição}

A sala do DiGaE possui: uma lousa eletrônica (SmartBoard ${ }^{27}$ ) com interação via caneta, ligada a um computador com Windows 2000, para utilização da ferramenta Whiteboard; um notebook com monitor estendido para execução da ferramenta Comunicador Instantâneo e um computador Intel core 2 duo com Windows Vista instalado para execução do programa de leitura do RFID e execução da ferramenta Chat. O dispositivo físico do leitor de RFID está conectado a esse computador e permanece próximo à entrada da sala, para que o usuário quando entrar na sala passe seu cartão pelo leitor, se identificando. No notebook estão a câmera de vídeo, microfone de lapela e um monitor adicional de 17 polegadas. O notebook executa a ferramenta Comunicador Instantâneo, que é a ferramenta de compartilhamento de áudio e vídeo do DiGaE. A Figura 31 apresenta uma fotografia do ambiente conforme descrição acima. À esquerda, sobre a mesa, está o leitor RFID. Ao fundo está a lousa eletrônica. Na mesa à direita está o notebook com monitor estendido, a câmera, o computador para execução da ferramenta Chat e do aplicativo que responsável pelo login do usuário. A câmera está estrategicamente posicionada entre dois monitores que transmitem o vídeo, para o usuário ser capturado de frente, simulando uma conversa real. Além disso, caso o usuário vá se dirigir à lousa, ele pode 
manualmente direcionar a câmera para capturar sua interação com a lousa eletrônica.

A disposição física dos equipamentos no ambiente primou pela proximidade, evitando que o usuário tivesse que se deslocar excessivamente para utilizar as ferramentas. Entretanto, a configuração atual é limitada pelos dispositivos físicos disponíveis no momento da instalação. As limitações do ambiente estão discutidas no Capítulo 5 .

\subsubsection{Configuração e Uso}

Para utilizar o ambiente instrumentado com o DiGaE, o primeiro passo deve ser agendar a sessão. Essa etapa permite cadastrar o local, a data e hora da sessão, seu assunto, selecionar seus participantes e quais ferramentas serão utilizadas, atribuir uma frequência para a sessão e fornecer descrição detalhada. O formulário de agendamento da sessão DiGaE está ilustrado na Figura 32.

Para executar a aplicação devem estar ativos agentes nos três equipamentos e o programa do leitor de RFID deve estar em execução, o projetor deve estar acionado e as máquinas devem estar ligadas.

Agentes correspondem a uma entidade de software com uma identidade, estado e comportamento bem definidos. O usuário de um agente corresponde a alguma entidade bem definida e reconhecida pelo sistema, podendo corresponder a um ser humano ou a um serviço de uma dada organização (Silva, 2000). Existem três agentes de software que estão sendo usados no DiGaE, eles são executados em dispositivos específicos conforme a ferramenta que será utilizada neles, assim na lousa eletrônica deve estar executando o agente da ferramenta Whiteboard, no notebook o agente da ferramenta Comunicador Instantâneo e no outro computador o agente da ferramenta Chat. Os agentes são acionados assim que o programa do leitor RFID envia uma mensagem a eles comunicando a identificação do usuário. 


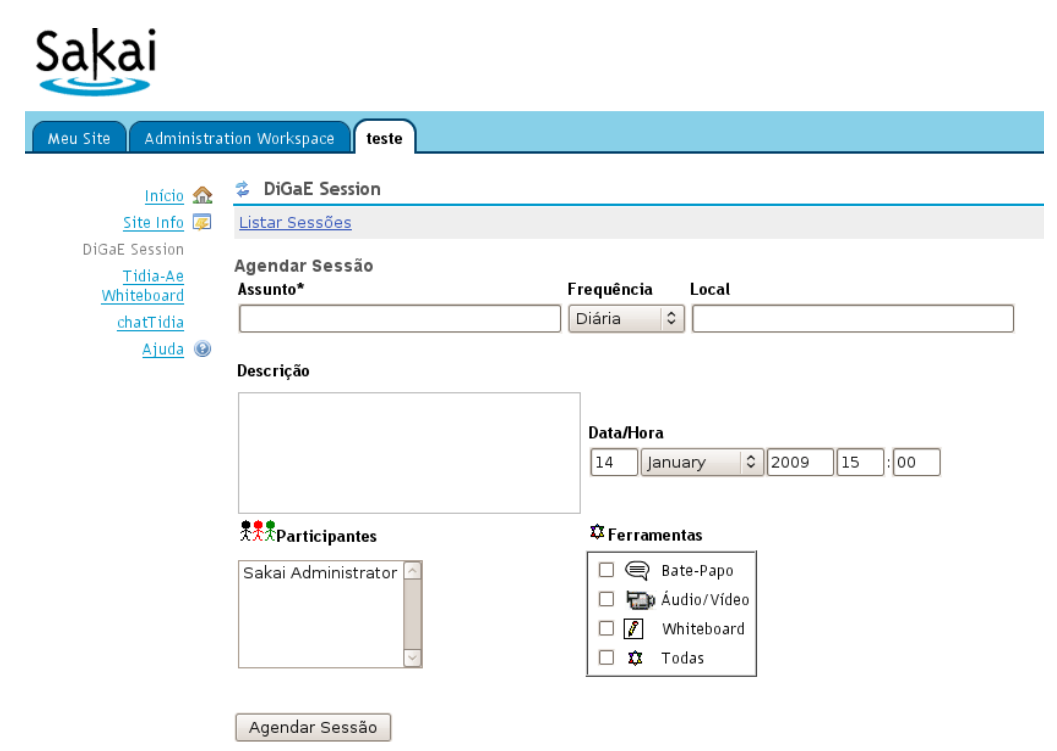

Figura 32: Interface para agendamento da sessão DiGaE.

Quando o usuário chega na sala ele deve ligar o microfone de lapela e prendê-lo junto ao corpo. Deve também posicionar seu cartão com o RFID sobre o leitor (5 $\mathrm{cm}$ de aproximação são suficientes para leitura). O software responsável pelo leitor, um aplicativo executável em Python, extrai o número de identificação do cartão ${ }^{28}$ e envia por mensagem para a aplicação DiGaE, que por sua vez analisa se há sessão agendada para o usuário e quais ferramentas estão associadas a ela. A aplicação DiGaE consulta a base de dados do Sakai, para identificar o usuário correspondente ao código do cartão e efetuar login nas máquinas restantes. Caso haja sessão agendada para aquele momento e todas as ferramentas estejam incluídas, são enviadas mensagens para os agentes inicializados nos dispositivos do ambiente, sendo a ferramenta Whiteboard iniciada automaticamente na lousa eletrônica, a ferramenta Comunicador Instantâneo automaticamente iniciada no notebook e a ferramenta Chat inicializada pelo agente no computador. O ambiente está, portanto, pronto para ser utilizado.

As interfaces permitem que o usuário configure durante o uso quais ferramentas ele deseja utilizar e também o que e como ele deseja visualizálas na interface - por meio de redimensionamento, reposicionamento e minimização de janelas.

\footnotetext{
${ }^{28} \mathrm{~A}$ aplicação utiliza cartão e número USP.
} 


\subsubsection{Avaliação}

Para avaliar a versão funcional do DiGaE no ambiente instrumentado foi prevista a utilização de duas técnicas de IHC: o Think Aloud e questionário SUMI (ambos descritos na Seção 2.4).

Para a avaliação com o método Think Aloud o objetivo era simular um usuário real, então como contexto foi sugerido ao avaliador uma aula na qual ele apresentasse um conteúdo na lousa eletrônica, perguntasse e consultasse dúvidas dos alunos usando a ferramenta Chat e as respondesse usando o Comunicador Instantâneo. Foram feitas 6 avaliações por Think Aloud que duraram em média 20 minutos e foram documentadas com áudio e vídeo.

Um dos problemas observados é que, como a maioria dos avaliadores não tinha interagido com uma lousa eletrônica antes, eles tiveram dificuldades com a caneta, e um pouco de receio de errar. Um deles chegou a comentar que interagir com a caneta é mais legal, mas que o mouse é muito mais fácil para usar a Whiteboard (provavelmente por familiaridade). Eles tiveram mais facilidade ao utilizar o dedo para interagir com o teclado disponível na lousa do que com a caneta da Whiteboard, conforme ilustra a Figura 33. O login ocorreu sem problemas e as ferramentas foram executas

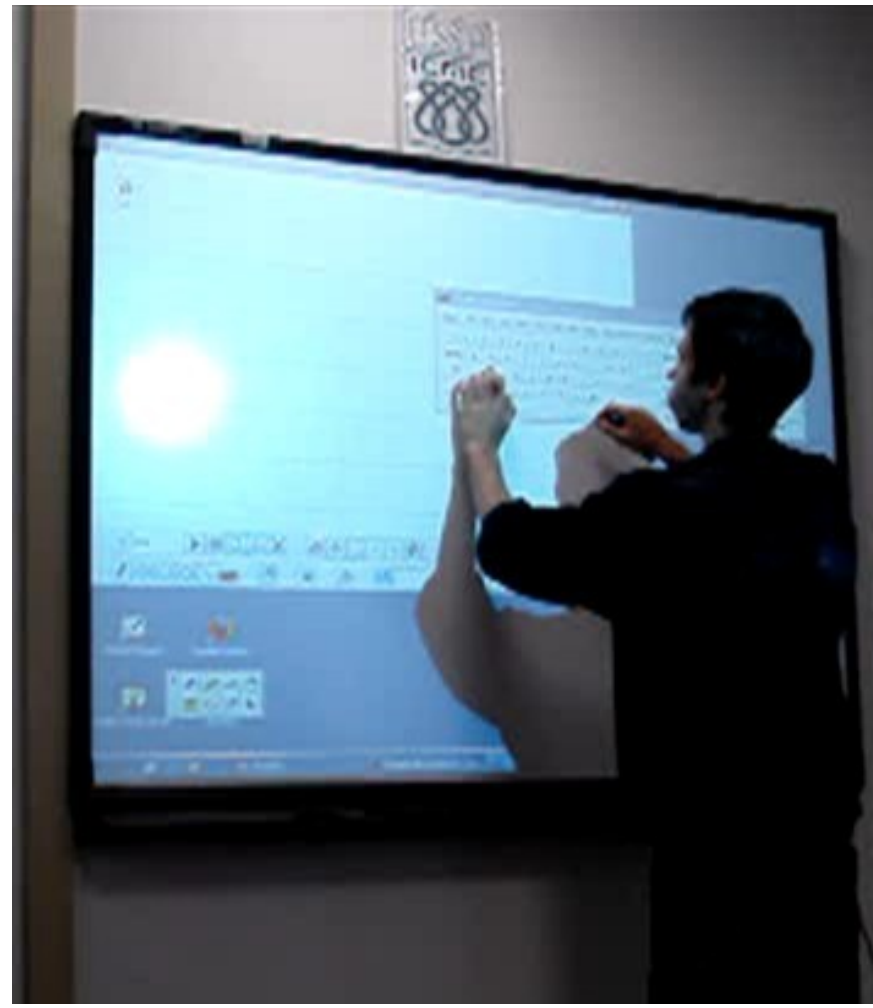

Figura 33: Utilização da Whiteboard na lousa eletrônica. 
em seus respectivos dispositivos corretamente. No entanto, foi necessário incentivar os avaliadores a relatarem suas percepções, e parte dos comentários se referiram mais à ferramenta em si do que sobre a interação.

Oito questionários SUMI foram respondidos e analisados. As principais conclusões resultantes da análise dos dados obtidos foram: poderia haver mais instruções e mensagens de ajuda; há paradas repentinas no funcionamento da aplicação; eles se sentem mais seguros usando funcionalidades básicas e já conhecidas; o DiGaE não ajuda na recuperação de problemas e nem sempre é fácil fazer exatamente o que se quer. Os avaliadores também concordaram que é dificil reiniciar o sistema, que nem sempre as informações são claras e compreensiveis.

Os avaliadores não estavam certos se a quantidade de informações na interface era suficiente para interagir, se a quantidade e a qualidade da informação de ajuda era variável e se era relativamente fácil alternar tarefas.

No entanto os avaliadores julgaram que a resposta do sistema é rápida, a princípio é fácil e rápido aprender a usar a aplicação, suas interfaces e o modo de interação são familiares e consistentes, eles se sentem motivados e no controle ao utilizá-la, as informações fornecidas são claras e estão agrupadas de maneira lógica, são necessários poucos passos para concluir seu objetivo, a aparência estética da aplicação é atraente, o DiGaE não é realmente muito complicado e é fácil ver rapidamente quais são as opções disponíveis em cada passo.

A aplicação desse modelo de questionário se mostrou bastante adequada, pois embora englobe menos características a serem avaliadas do que a Avaliação Heurística, que é realizada por especialistas, os avaliadores, usuários reais, se sentem mais motivados à preenchê-lo e, em linhas gerais, ele inclui fatores importantes para avaliação da interface. Com a análise dos resultados ficou claro que o DiGaE possui fácil aprendizagem mas que há uma série de questões que precisam ser melhoradas para facilitar a exploração da aplicação. Além disso, mensagens de ajuda e instruções detalhadas poderiam auxiliar na utilização da ferramenta e na recuperação de erros também. 


\subsubsection{Discussão}

A utilização da abordagem de design centrado no usuário tem por objetivo atingir uma versão final da aplicação que seja de fácil uso para usuários novatos. As avaliações, quando feitas com métodos complementares, identificam as principais dificuldades na interação e seus resultados podem ser utilizados nas fases seguintes da implementação. No caso do DiGaE, quatro métodos foram utilizados: Avaliação Heurística, Percurso Cognitivo, Think Aloud e Questionário (SUMI).

As técnicas se mostraram adequadas, mas nem sempre foi obtido o resultado esperado das avaliações, pois algumas vezes as respostas mostravam que a avaliação havia sido superficial. Assim, ficou evidente a necessidade de combinar técnicas e avaliadores diferentes. Além disso é visível que um avaliador especialista na área de IHC tende a identificar mais problemas nas interfaces. O que evidencia que nem sempre a quantidade de avaliadores tem relação com a quantidade de problemas detectados. Por outro lado, os problemas identificados por usuários reais são diferentes dos problemas identificados por especialistas em computação, o que reforça a necessidade de combinar técnicas e avaliadores diferentes em um plano de avaliação.

Durante o processo de avaliação foi observado um receio por parte dos desenvolvedores, que sabiam que os resultados das avaliações identificariam um conjunto de erros. Ao mesmo tempo foi observado um receio por parte dos usuários reais em apontar as falhas das aplicações. É provável que uma melhor condução da avaliação, enfatizando o motivo de se avaliar sistemas antes deles estarem finalizados, pudesse ter evitado este tipo de receio.

Para a Avaliação Heurística e Percurso Cognitivo os avaliadores possuiam experiência na área de desenvolvimento de interfaces e já haviam concluído mestrado na área de computação. Já para aplicação dos questionários, os avaliadores possuíam perfis mais diversificados, não necessariamente eram da área de computação e correspondiam ao perfil de usuários reais da aplicação. 


\subsection{Considerações Finais}

As avaliações encontraram diversos problemas nas interfaces das ferramentas, mas foi possivel perceber que os usuários reais nem sempre estão suficientemente motivados para realizar este tipo de análise, e que os resultados obtidos com avaliação por especialista detectaram um maior número de problemas. Apesar disso, a utilização de usuários reais na fase de avaliação foi essencial, pois os problemas encontrados por eles são diferentes dos problemas encontrados por especialistas. Certamente uma recompensa aos avaliadores os estimularia para executar a avaliação com mais afinco.

As técnicas utilizadas foram boas, pois combinaram avaliadores e critérios diferentes, gerando resultados significativos. É provável que a quantidade de problemas detectados esteja fortemente vinculada à motivação do avaliador em realizar a tarefa, já que é necessário alto nível de atenção para detectar os problemas.

Ficou evidente que uma parte dos problemas detectados poderia ter sido evitada caso os desenvolvedores conhecessem e aplicassem as teorias de IHC e soubessem como assegurar alta usabilidade nas aplicações. É evidente que este tipo de prevenção de erros tornaria o desenvolvimento da aplicação mais eficiente e produziria um resultado melhor na aplicação com relação à IHC. 


\section{CONCLUSÕES}

No Capítulo 2 foram apresentados conceitos indispensáveis ao entendimento desta dissertação. Em seguida foram apresentados trabalhos relacionados que embasaram o desenvolvimento deste projeto. No Capítulo 4 estão descritos a metodologia que foi adotada e os materiais resultantes do desenvolvimento do DiGaE, além das discussões conduzidas acerca dos resultados obtidos.

\subsection{Contribuições}

O DiGaE, como ambiente de comunicação remota que provê captura e acesso aos dados de eventos, pode ser utilizado em diferentes contextos como: aulas, reuniões e atendimentos, portanto nem sempre os usuários têm conhecimentos avançados sobre sistemas computacionais. A principal contribuição da abordagem adotada para o desenvolvimento deste projeto está na facilidade de uso por usuários novatos e consequentemente possibilidade de uso do DiGaE para diferentes dominios. A almejada facilidade de uso foi atingida, como mostram os resultados da avaliação do DiGaE no ambiente instrumentado.

Com este projeto foi possivel identificar um conjunto de requisitos necessários para aplicações que envolvam compartilhamento de dados de áudio, vídeo, texto e gráficos, provendo comunicação sincrona e distribuída. Foi proposto um modelo que possibilite esse tipo de comunicação, usando leitor de RFID para autenticação do usuário, agentes de software para inicialização de ferramentas em dispositivos distribuídos, e uma aplicação de suporte que sincronize esses dados capturados em uma sessão. Um protótipo do ambiente foi implementado por membros da equipe de desenvolvimento do grupo de pesquisa.

Com os resultados obtidos das avaliações foi possivel detectar um conjunto de problemas que podem ser encontrados em interfaces gráficas, em especial as de aplicações de comunicação distribuída. Ficou evidente a 
necessidade de se instruir melhor os desenvolvedores com o objetivo de se prevenir falhas de IHC assegurando alto nivel de usabilidade às ferramentas.

As avaliações possibilitaram fornecer à equipe de desenvolvimento uma listagem com os problemas identificados e sugestões fornecidas. Esta listagem orienta as etapas seguintes de implementação e pode inclusive enriquecer a experiência dos desenvolvedores na área de IHC, pois os aproxima da visão do usuário, e pode torná-los mais atentos para questões de usabilidade.

\subsection{Discussões e Limitações}

Considerando que para o desenvolvimento do DiGaE estão envolvidas diversas competências, é possível analisar a interação sob a ótica de cada uma delas. Esta seção discute as limitações atuais e os avanços que podem ser implementados sobre os seguintes aspectos: a ubiquidade da aplicação no ambiente, as ferramentas que foram utilizadas, os dispositivos físicos empregados e suas posições no ambiente, e o sistema computacional da aplicação com relação as suas limitações e extensões possiveis.

\subsubsection{Transparência}

O ideal em um sistema ubíquo é que todos os parâmetros da sessão sejam adquiridos de modo automático, no entanto atualmente ainda não é possivel ser atingido este nível de transparência. Para que o sistema detecte a presença do usuário em um ambiente há diferentes modos de interação, sendo que eles podem ser explícitos ou não; no caso do DiGaE optou-se pelo uso do leitor de RFID, que embora exija interação explícita do usuário, é um método rápido e relativamente seguro, pois cada participante tem o seu cartão $^{29}$. O microfone que está sendo utilizado no ambiente é o de lapela, que tem a vantagem de captar especialmente a voz do usuário, mas exige que ele conecte o dispositivo a sua roupa e o acione antes para permitir a captura.

Para a preparação do ambiente DiGaE ainda há alguns passos que exigem interação explícita do usuário, principalmente para que todos os equipamentos estejam ligados e corretamente inicializados. O uso de uma câmera de vídeo convencional, por exemplo, exige um esforço do usuário

\footnotetext{
${ }_{29}$ Para a aplicação DiGaE foi utilizado o leitor compatível com o cartão de identificação oficial da USP.
} 
para que a captura o acompanhe no ambiente, ou seja, se ele for interagir com a Whiteboard ele terá que manualmente direcionar a câmera para capturar sua interação com a lousa eletrônica. Uma câmera com sensor de seguimento de movimento evitaria este problema. Outra opção é o uso de duas câmeras, uma para a captura da face do usuário e outra para a captura da lousa eletrônica, por exemplo.

\subsubsection{Ferramentas}

Com relação às ferramentas utilizadas, elas foram desenvolvidas no contexto do Projeto TIDIA-Ae, que não previa um ambiente instrumentado para interação, portanto ainda há adequações a serem feitas nas ferramentas para tornar suas funções mais condizentes com os objetivos do DiGaE. Essas limitações estão principalmente relacionadas ao Comunicador Instantâneo, pois pode ser desnecessária a sua opção de trocar mensagens de texto, e às listas de participantes, que devem ser unificadas em um só serviço que informe não apenas quais são os usuários online, mas também quais ferramentas estão em uso por eles. Também há a necessidade de desenvolver um player que sincronize todos os dados capturados da sessão para que sejam executados simultaneamente, conforme foi previsto nos sketches e no levantamento de requisitos.

\subsubsection{Hardware: quanto à interação e disposição no ambiente}

Algumas limitações físicas do ambiente também poderiam ser corrigidas, o ideal seria instalar o leitor de RFID na parede próxima à porta, o uso do notebook para estender o monitor deveria ser substituído por um computador com suporte à conexão de dois ou mais monitores simultâneos, que pudesse utilizar integralmente os recursos da rede Kyatera.

A lousa eletrônica apresenta limitações quanto ao seu uso. É recomendável calibrá-la a cada inicialização para que a interação com ela esteja precisa, o modelo de interação é diferente do tradicional papel e caneta, sua superficie é mais lisa provendo menor aderência e sua posição é vertical. Durante a avaliação do ambiente com usuários reais foi possível observar que eles tiveram dificuldades ao interagir com a lousa. Além disso o projetor da lousa não está atrás dela, então o usuário tem que estar atento 
para não encobrir a região que ele deseja usar. Os gráficos que forem usados da Whiteboard na lousa devem ter boa definição, porque o usuário que interage com ela fica muito próximo à imagem projetada e os objetos sem boa definição não são corretamente visualizados. O software da lousa possui um teclado próprio, mas sua utilização não é tão eficiente quanto um teclado convencional, o usuário precisaria de um tempo para adaptação e pode se aborrecer com isto.

Outra restrição da lousa eletrônica é com relação à acessibilidade, na disposição que ela se encontra hoje, não é acessível para usuários em cadeiras de rodas ou com baixa estatura.

Em um computador convencional, por exemplo para um usuário que não estivesse na sala, poderia ser utilizado um tablet com interação via caneta para uso da Whiteboard, conforme ilustra a Figura 34 foto da direita. Embora o tablet também possua o problema de ter uma superficie mais lisa do que o papel e ter menor aderência na interação, ele fica na posição horizontal, que é familiar ao modelo tradicional de escrita e desenho em mesa. Por outro lado, há uma questão que exige adaptação do usuário também quando ele utiliza o tablet: o feedback da interação aparece no monitor, então ele interage com o dispositivo mas deve estar olhando para outro. Para evitar este problema pode ser utilizado um tablet PC, conforme ilustra a Figura 34, foto da esquerda, no qual o usuário interage com a caneta, mas diretamente na tela, e ele se mantêm também na posição horizontal, assim como uma folha de papel.
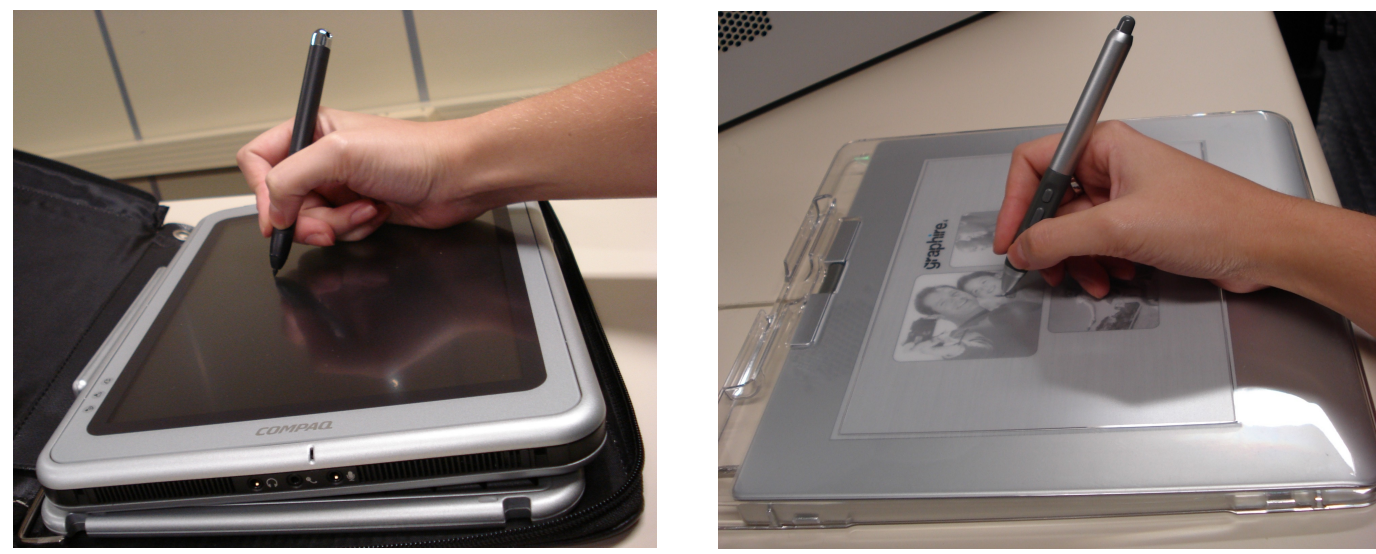

Figura 34: Tablet PC (esquerda) e Tablet (direita) com interação por caneta.

A principal vantagem da lousa com relação ao tablets está na sua dimensão, que é maior. Esta vantagem permite que caso haja mais 
participantes da sessão no ambiente, como é comum em uma reunião com vários participantes presenciais: todos podem ver o conteúdo projetado. Já os tablets são mais limitados em relação ao espaço físico para interagir.

Para tornar a utilização dos dispositivos mais familiar ao usuário, um cenário possivel seria dispor a lousa e um computador para o Chat sobre uma mesa, de modo que com o movimento do braço o usuário pudesse alternar o uso das ferramentas. Colocando dois monitores para exibir o vídeo na frente do usuário, e colocando entre os monitores uma câmera, para capturar seus movimentos, produziria um vídeo no qual ele estivesse olhando diretamente para câmera e isso evitaria ângulos não familiares a uma conversa face a face, mas comuns em comunicação remota com vídeo.

\subsubsection{Software}

Há limitações no que foi desenvolvido do DiGaE até agora implementado, pois está previsto para uma nova etapa do projeto o tratamento dos dados capturados e o desenvolvimento de inteligência computacional que forneça ao usuário recuperação eficiente das informações capturadas na sessão. Até este momento não foram tratadas questões de visualização das informações de modo profundo, embora dados estejam sendo capturados nas sessões, é necessário desenvolver um player, conforme previsto nos sketches, que exiba para o usuário, de modo sincronizado, todas as informações capturadas na sessão (áudio, vídeos, strokes e slides).

Além disso, podem ser explorados aspectos de busca de informação. A recuperação em arquivos de texto, como os gerados pelo Chat, é bastante comum e utilizada, por exemplo no Filochat (Whittaker et al., 2008) exigindo do usuário apenas a inserção de um termo chave. No entanto há alguns trabalhos que exploram a busca em arquivos de áudio, por exemplo no Filochat (Whittaker et al., 2008) e no CAS (Portella, 2008) tentando, por exemplo, um reconhecimento das palavras utilizadas pelo usuário enquanto fala para retornar resultados; por enquanto este tipo de busca não retorna resultados precisos (Whittaker et al., 2008), e assim como a recuperação de informação em vídeo ou slides deve ser melhor explorada. 
Por outro lado, considerando a extensão de acessibilidade implementada na ferramenta Whiteboard, que permite que um mediador inclua descrições aos componentes do slide, há, nesses casos, informações semânticas associadas às imagens, sendo possivel portanto, realizar as busca pelo conteúdo do slide usando cadeias de texto convencionais.

Sobre a recuperação das informações no contexto do DiGaE, pode-se dizer que ele tem como vantagem a recuperação online das informações da sessão, ou seja, o usuário não precisa baixar todo o conteúdo para visualizálo, ele pode acessá-lo via web. Entretanto, mais esforços computacionais serão necessários para que esta recuperação seja eficiente para os usuários.

\subsection{Trabalhos Futuros}

Para o Projeto DiGaE, são necessários esforços de implementação para fornecer ao usuário opções de pós-produção e de acesso ao conteúdo capturado. Para acessar o conteúdo capturado é necessário sincronizar as diferentes midias, para tal pode ser adotada a abordagem utilizada no sistema LiteMinutes (Chiu et al., 2001) e no projeto iClass (Pimentel et al., 2005), colocando-se a data e hora de criação como índice para as mídias, ou a abordagem sugerida por Portella (2008) de se utilizar algoritmos de extração de palavras-chave para sincronizar o áudio capturado da sessão com texto. Para execução sincrona das mídias geradas em uma sessão, pode ser usada a linguagem NCL, que é padrão para TV digital brasileira, para construção de um documento hipermídia, conforme realizado por Portella (2008).

No projeto CAS (Portella, 2008) e no projeto iClass (Pimentel et al., 2005), propõe-se a extração de meta-informação de áudio e vídeo para melhorar as buscas de informação, para o DiGaE, esta meta-informação embora já possa ser incluída nas imagens dos slides da Whiteboard, ainda precisa ser desenvolvida para conteúdo em áudio e em vídeo. Portella (2008) cita também a extração de palavras-chave por algoritmos speech-to-text visando sincronizá-las com as demais mídias, para que o usuário ao pesquisar por um termo falado em uma sessão, possa recuperar e visualizar os dados no instante de interesse. Lee et al. (2002) utilizam quadros chaves 
do vídeo capturado na sessão para permitir acesso a um instante específico da reunião, esta abordagem permite ao usuário recuperação mais precisa da informação buscada, e pode ser explorada como trabalho futuro para o DiGaE.

Outra questão a ser explorada considerando-se a etapa de pósprodução, é a possibilidade de um revisor editar o conteúdo textual produzido durante a sessão, para revisão ou correção, conforme proposto por Chiu et al. (2003) no LiteMinutes. Além da revisão de texto, para o DiGaE, também podem ser exploradas revisões nas anotações da Whiteboard. O sistema LiteMinutes envia automaticamente emails aos participantes da sessão com o conteúdo gerado e o sistema Portable Meeting Records (Lee et al., 2002) gera automaticamente uma transcrição do áudio capturado na sessão. Seria interessante incluir estas funcionalidades no DiGaE.

Com relação à privacidade, os dados, uma vez capturados, podem ser acessados pelos participantes que estiveram na sessão; até o momento não foi previsto um mecanismo para restringir o acesso aos dados - exceto pela ferramenta Chat, que, no momento da produção da informação de texto, permite a um mediador controlar as mensagens que serão publicadas. Este controle de acesso pode ser explorado em trabalhos futuros, permitindo que usuários solicitem permissão de acesso e que um mediador controle o conteúdo disponivel para consulta.

Há vários aspectos na consulta às informações geradas durante a sessão que podem ser explorados em trabalhos futuros, como por exemplo a qual informação o usuário associa o evento e qual a precisão do resultado da consulta usando essa informação. Para a recuperação de informações capturadas na lousa eletrônica do projeto DUMMBO, o usuário acessa uma página web na qual ele insere a data e o local do evento, faz a consulta e visualiza os resultados (Brotherton et al., 1999).

Outra questão interessante a ser estudada se refere às preferências do usuário durante a interação, tanto com relação às ferramentas que ele comumente utiliza quanto com relação ao modo pelo qual ele interage com o sistema, podendo ser explorados diferentes perfis de usuários para que a 
interação seja mais eficiente (com alternativas de acesso às funções por exemplo).

O DiGaE é uma aplicação ubíqua no que tange aspectos computacionais, ou seja, o ambiente está instrumentado com dispositivos de informática, mas atualmente não estão incluídas na aplicação alterações na iluminação e na ventilação do ambiente, entre outras. Essas informações também poderiam ser contempladas para avançar o projeto da aplicação e tornar sua ubiquidade mais abrangente.

A disposição física dos equipamentos no ambiente pode ser repensada para evitar que o usuário tenha de se deslocar pela sala conforme alterna entre as ferramentas, uma opção seria em uma só mesa colocar a lousa eletrônica com o projetor sobre ela para que o usuário interagisse com a caneta sobre a lousa no formato tradicional de escrita. Os monitores com os vídeos poderiam estar paralelos ao rosto do usuário para facilitar a visualização. A câmera pode ser inserida entre os monitores para evitar que o vídeo seja capturado com a face voltada para baixo (o que é comum quando a câmera está sobre o monitor). Um notebook na lateral facilitaria o uso do Chat. Uma outra câmera poderia ser acoplada próxima ao projetor, para capturar a interação do usuário com a lousa. Isto também exigiria um algoritmo apropriado de seleção que alternasse apropriadamente a transmissão do vídeo conforme a movimentação do usuário no ambiente.

Outros trabalhos que podem dar continuidade ao reportado nesta dissertação, em ambientes do tipo do DiGaE, se relacionam a uma situação na qual os usuários pudessem assistir juntos a uma mídia contínua - como por exemplo à televisão. Isso traria ao ambiente novos desafios para ubiquidade, principalmente se houvesse a possibilidade do usuário fazer comentários sobre o vídeo que assiste, de modo que esses comentários fossem capturados e pudessem ser acessados a posteriori, em sincronia com a mídia original. Os trabalhos de Pimentel et al. (2008) e Cattelan et al. (2008) discutem respectivamente esse problema do ponto de vista de anotações sobre vídeo e sobre TV; seria interessante, como parte do trabalho reportado nesta dissertação, que essas anotações pudessem ocorrer em ambientes com o DiGaE. 


\subsection{Considerações Finais}

Embora a versão funcional do DiGaE obtida ainda possua muitas limitações, foram atingidos os objetivos previstos inicialmente para o escopo deste projeto. Como resultados, a aplicação foi especificada, de modo que seu desenvolvimento fosse centrado no usuário, as interações do usuário com o ambiente foram analisadas e discutidas, tanto com relação às ferramentas utilizadas, como com relação ao ambiente instrumentado, e foram obtidas as contribuições de IHC para aplicações ubíquas de comunicação remota e síncrona.

É importante destacar que muitas características de interação foram observadas no ambiente e permitiram concluir detalhes que podem aprimorar a usabilidade do sistema em aplicações deste tipo. A abordagem centrada no usuário, estruturada pela iteratividade das etapas de desenvolvimento, se mostrou adequada para obter versões com níveis maiores de usabilidade a cada fase. Os métodos de avaliação utilizados também foram adequados ainda que nem todos os avaliadores tenham se mostrado suficientemente motivados para realizar tal atividade.

A possibilidade de capturar automaticamente os dados produzidos em um evento permite não apenas que as pessoas revisitem o conteúdo gerado, mas também o armazenamento dos dados, o que é fundamental para a extração de informação que pode ser empregada para diversos fins.

Um dos problemas detectado por este trabalho é que há um desconhecimento por parte dos desenvolvedores em como assegurar a usabilidade nas aplicações durante seu desenvolvimento. Os princípios, guias, regras e técnicas de usabilidade em geral se caracterizam por detalhes simples que facilitam a interação do usuário, mas que nem sempre são óbvios para o desenvolvedor que a implementa. Uma orientação na área de IHC evitaria grande parte dos problemas que foram detectados nas avaliações, em especial àqueles identificados por especialistas na área, uma vez que as avaliações feitas por usuários reais tendem a encontrar problemas diferentes, que em geral não são os previstos na teoria, por ser específicos ao contexto da aplicação. 
A capacitação de desenvolvedores para reconhecer detalhes na interface que podem dificultar a interação dos usuários previne problemas de usabilidade em um sistema e poupa esforços na fase de avaliação, além de se obter uma aplicação de uso mais eficaz, eficiente e satisfatório.

Tornar uma aplicação de comunicação distribuída - que envolva áudio, vídeo, imagens e textos - suficientemente ubíqua para ser utilizada em ambientes instrumentados é um desafio grande, seja pelo envolvimento de diferente competências no seu desenvolvimento ou pela quantidade de recursos necessários, por isso é fundamental adotar estratégias de IHC para facilitar seu uso e tornar a aplicação tão transparente quanto possivel no ambiente.

Ainda que tenham sido obtidas contribuições para avanço das pesquisas que envolvam ambientes instrumentados de captura e acesso para comunicação sincrona e distribuída, também há muitos desafios ainda a serem pesquisados no que tange a interação dos usuários em ambientes instrumentados e mais esforços são necessários para atingir um ideal de ubiquidade e transparência nesses ambientes. 


\section{PUBLICAÇÕES}

Artigo Completo Aprovado:

MOTTI, V. G.; FAGA, R.; CATTELAN, R. G.; TEIXEIRA, C. A. C. E PIMENTEL, M. G. C. CWaCTool: Watching and Commenting Videos in a Collaborative Way. Approved in: $7^{\text {th }}$ EuroITV - European Interactive TV Conference, 3-5 June 2009, Leuven, Belgium.

\section{Minicursos Aprovados:}

MOTTI, V. G.; GOUlaRTe, R. E PIMENTEL; M. G. C. Aplicando Transformações em XML usando XSL-T e XSL-FO (Formatting Objects). In: ERBASE 2009. $9^{a}$ Escola Regional de Computação Bahia-Alagoas-Sergipe Universidade Estadual de Santa Cruz Ilhéus, BA. 4 a 8 de maio de 2009.

FAGA, R.; MOTTI, V. G. e PIMENTEL; M. G. C. Construindo um jogo

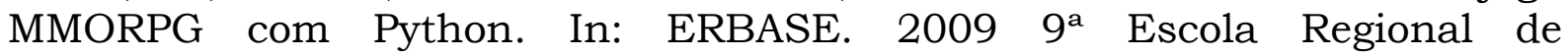
Computação Bahia-Alagoas-Sergipe Universidade Estadual de Santa Cruz Ilhéus, BA. 4 a 8 de maio de 2009.

\section{Artigo Resumido Apresentado:}

OLIVEIRA JUNIOR, E. A.; MOTTI, V. G.; FREIRE, A. P. e FORTES, R. P. M. Supporting Web Page Accessibility by using Earl Reports. In: XIII Brazilian Symposium on Multimedia and the Web (WebMedia 2007), 2007, Gramado. XIII Brazilian Symposium on Multimedia and the Web (WebMedia 2007), 2007. 


\section{REFERENNCIAS}

(Abowd et al., 1996) Abowd, G.; Atkeson, C.; Feinstein, A.; Melo, C. H.; Kooper, R.; Long, S.; Sawhney, N. e Tan, M. Teaching and Learning as Multimedia Authoring: The Classroom 2000 Project. ACM Multimedia Conference, pages 187-198, 1996.

(Abowd, 1999) Abowd, G. Classroom 2000: An experiment with the instrumentation of a living educational environment. IBM Systems Journal, 38(4):508-530, 1999.

(Abowd et al., 2002) Abowd, G. D.; Mynatt, E. and Rodden, T. The Human Experience. IEEE Pervasive Computing, vol. 1, no. 1, 2002, pp. 48-57.

(Blaha e Rumbaugh, 2006) Blaha, M. e Rumbaugh, J.. Modelagem e projetos baseados em objetos com UML 2. Rio de Janeiro: Elsevier, 2006.

(Brotherton et al., 1999) Brotherton, J. A.; Truong, K. N. and Abowd, G. D. Supporting capture and access interfaces for informal and opportunistic meetings. Technical Report GITGVU -99-06, GVU Center, Georgia Institute of Technology, January 1999. 13 pags. Em: http://people.csail.mit.edu/ rudolph/Teaching/Articles/Dummbo.pdf Último acesso em 23/01/2009.

(Cattelan, 2004) Cattelan, R. G. Construção de Aplicações de Captura e Acesso Baseada em Recorrência de Funcionalidades. Dissertação de Mestrado, Universidade de São Paulo, São Carlos. Abril de 2004. 80 pags. Em:http://www.teses.usp.br/teses/disponiveis/55/55134/tde-06052004-1 80541/ Último acesso em 23/01/2009.

(Cattelan et al., 2008) Cattelan, R. G.; Teixeira, C.; Goularte, R.; Pimentel, M. G. C.. Watch-and-comment as a paradigm toward ubiquitous interactive video editing. ACM Transactions on Multimedia Computing, Communications and Applications, v. 4, p. 1-24, 2008.

(Chin et al., 1988) Chin, J.; Diehl, V.; Norman, K. Development of an Instrument Measuring User Satisfaction of the Human-Computer Interface. Proceedings of Computer - Human Interaction, - CHI - Conference, 1988, p. 213-218.

(Chiu et al., 2001) Chiu, P. et al. LiteMinutes: An Internet-Based System for Multimedia Meeting Minutes, In Proceedings of 10th Int'1 World Wide Web Conf., 2001, pp. 140-149.

(Conference XP, 2008) Conference XP. Acesso em fevereiro de 2008. Disponivel em: http://research.microsoft.com/conferencexp/ 
(Connect, 2008) Adobe Acrobat Connect. Acesso em fevereiro de 2008. Disponivel em: http:/ /www.adobe.com/products/connect/

(Evo, 2008) Evo. Acesso em fevereiro de 2008. Disponivel em: http: / / evo.caltech.edu /

(Filardi e Traina, 2008) Filardi, A. L. e Traina, A. J. Montando questionários para medir a satisfação do usuário: Avaliação de interface de um sistema que utiliza técnicas de recuperação de imagens por conteúdo. In: VIII Simpósio Sobre Fatores Humanos em Sistemas Computacionais. Outubro 21-24, 2008, Porto Alegre, RS, Brasil.

(Flower e Scott, 2000) Flower, M. e Scott, K., UML Distilled: A Brief Guide to the Standard Object Modeling Language, 2000 (Addison-Wesley: Massachusetts).

(Hansen e Bardram, 2005) Hansen, T. e Bardram, J. ActiveTheatre-A Collaborative, Event- Based Capture and Access System for the Operating Theatre, UbiComp 2005. In Proc. Of: Ubiquitous Computing, LNCS 3660, Springer, 2005, pp. 375-392.

(Hix e Hartson, 1993) Hix, D., Hartson, H.R. Developing User Interfaces: Ensuring Usability Through Product \& Process. John Wiley \& Sons, New York, 1993.

(Hom, 1998) Hom, J. The Usability Methods Toolbox Handbook, 1998. Em:http://www.idemployee.id.tue.nl/g.w.m.rauterberg/lecturenotes / UsabilityMethodsToolboxHandbook.pdf. Acesso: 23/01/2009.

(ISO 9241, 1998) ISO-9241-11. Ergonomic requirements for office work with Visual Display Terminals (VDTs): part 11, guidance on usability. Genebra, 1998.

(ISO 18000, 2003) International Organization for Standardization. ISO/IEC 18000 Part 6: Information technology automatic identification and data capture techniques - Radio frequency identification for item management air interface, 2003.

(Jardim et al., 2005) Jardim, C. H.; Martelini JR, A.; Freire, J.; Silva, E. Q.; Lara, S. S. A.; Santos, F. S.; Kudo, T. N.; Fortes, R. P. M.; Pimentel, M. G. C.. Whiteboard: uma Ferramenta de Apoio ao Ensino e Aprendizado com Uso de Anotação Eletrônica. In: XVI Simpósio Brasileiro de Informática na Educação (Mostra de Software), 2005, Juiz de Fora MG, Brasil.

(Kientz et al., 2005) Kientz, J. et al., "Abaris: Evaluating Automated Capture Applied to Structured Autism Interventions," Proc. UbiComp 2005: Ubiquitous Computing, LNCS 3660, Springer, 2005, pp. 323-339. 
(Lee et al., 2002) Lee, D.; Erol, B.; Graham, J.; Hull; Jonathan, J. e Murata, N. (2002) Portable meeting recorder. In: Proceedings of ACM Multimedia, pp 493-502.

(Lewis, 1982) Lewis, C. (1982) Using the 'thinking-aloud' method in cognitive interface design. IBM Research Report RC9265 (\#40713), IBM Thomas J. Watson Research Center, Yorktown Heights, NY.

(Lobato et al., 2005) Lobato, D. C.; Baldochi JR, L. A.; Pires, D. F. ; Pessoa, T. R. M.; Gasparin, R.; Montoro, F. A. ; Teixeira, C. A. C.. A Multimedia Instant Messenger for an e-Learning Environment. In: Workshop TIDIA, 2, 2005, São Paulo, SP. Proceedings of the II TIDIA Workshop. São Paulo, SP : Fundação de Amparo a Pesquisa do Estado de São Paulo, 2005. pp. 1-8.

(Minneman et al., 1995) Minneman, S. et al., A Confederation of Tools for Capturing and Accessing Collaborative Activity, In Proc. 3rd ACM Int'l Conf. Multimedia, 1995, pp. 523-534.

(Moraes et al., 2008) Moraes, C. R.; Santos, L. S.; Linhalis, F.; Pimentel, M. G. C.. Uma Ferramenta de Chat com Ajax e Spring para um Ambiente de Aprendizado Eletrônico. In: VII Workshop de Ferramentas e Aplicações (WFA) do Webmedia'2008, 2008, Vila Velha-ES. WFA/Webmedia'08, 2008. v. 2. p. 176-178.

(Nielsen e Molich, 1990) Nielsen, J., and Molich, R. (1990). Heuristic evaluation of user interfaces, Proc. ACM CHI'90 Conf. (Seattle, WA, 1-5 April), 249-256.

(Nielsen, 1992) Nielsen J. (1992) How to conduct a Heuristic Evaluation. Disponivel em: http://www.useit.com/papers/heuristic/heuristic evaluation.html Acesso em: setembro de 2007.

(Nielsen, 1993) Nielsen, J. Usability Engineering. Ed. Morgan Kaufmann, San Diego, CA, 1993.

(Norman, 1988) Norman, D. A. The design of everyday things. Ed. Doubleday, Broadway, NY, 1988.

(OMG, 1997) OMG - UML (Unified modeling language). Disponivel em: http://www.uml.org. Acesso em janeiro de 2008.

(OpenMeeting, 2008) OpenMeeting. Acesso em fevereiro de 2008. Disponivel em: http:/ / code.google.com/p/openmeetings /

(Pedersen et al., 1993) Pedersen, E. L.; McCall, K; Moran, T. P. e Halasz, F. G. Tivoli: an electronic whiteboard for informal workgroup meetings, Proceedings of the INTERCHI '93 conference on Human factors in computing systems, pp. 391-398, May 1993, Amsterdam, The Netherlands. 
(Pimentel et al., 2005) Pimentel, M. G. C.; Prazeres, C.; Ribas, H.; Lobato, D.; e Teixeira, C. 2005. Documenting the pen-based interaction. In Proceedings of the 11th Brazilian Symposium on Multimedia and the Web (Pocos de Caldas - Minas Gerais, Brazil, December 05 - 07, 2005). R. P. Fortes, Ed. WebMedia '05, vol. 125. ACM, New York, NY, 1-8. DOI= http://doi.acm.org/ $10.1145 / 1114223.1114232$

(Pimentel et al., 2008) Pimentel, M. G. C.; Macedo, A. A.; Cattelan, R. G.; Guerrero, J. A. C.; Baldochi JR, L. A.. Automatically Linking Live Experiences Captured with a Ubiquitous Infrastructure. Multimedia Tools and Applications, v. 37, p. 93-115, 2008.

(Portella, 2008) Portella, F. A. Um serviço de captura e acesso para espaços ativos. Rio de Janeiro, 2008. 133 p. Dissertação de Mestrado Departamento de Informática, Pontificia Universidade Católica do Rio de Janeiro.

(Portella e Cerqueira, 2007) Portella, F. A. e Cerqueira, R. Capture \& Access Service (CAS): Um serviço de arquivamento para salas inteligentes. In Proc. $13^{\text {th }}$ Brazilian Symposium on Multimedia and the Web. WebMedia '07. ACM Press, pp. 176-180.

(Preece, 2002) Preece, J.; Rogers, Y. e Sharp, H. (2002) Interaction Design: Beyond Human-Computer Interaction. New York, NY: John Wiley \& Sons. (519 pages)

(Roibás, A. e Sala, R., 2007) Roibás, A. e Sala, R. "Beyond mobile tv: Understanding how mobile interactive systems enable users to become digital producers," 2007, pp. 801-810. [Online]. Available: http://dx.doi.org/ 10.1007/978-3-540-73110-8_87

(Sanchez-Reillo e Sanchez-Avila, 2001) Sanchez-Reillo, R. Sanchez-Avila, C. Fingerprint verification using smart cards for access controlsystems. 2001, pp. 250-253. Security Technology, 2001 IEEE 35th International Carnahan Conference on. DOI: 10.1109/.2001.962840

(Shi et al., 2003) Shi, Y.; Xie, W.; Xu, G.; Shi, R.; Chen, E.; Mao, Y. \& Liu, F. (2003) The Smart Classroom: Merging Technologies for Seamless TeleEducation. IEEE Pervasive Computing, 2(2):47-55.

(Silva, 2000) Silva, A. (1999) Agentes de Software na Internet. Lisboa, Portugal: Central Atlântico Ltda. (33 págs)

(TalkAndWrite, 2008) TalkAndWrite. Acesso em fevereiro de 2008. Disponível em: http://www.talkandwrite.com.br/portugues/index.php

(Weiser, 1999) Weiser, M. 1999. The computer for the 21st century. SIGMOBILE Mob. Comput. Commun. Rev. 3, 3 (Jul. 1999), 3-11. DOI= http://doi.acm.org/10.1145/329124.329126 
(Whittaker et al., 2008) Whittaker, S.; Tucker, S.; Swampillai, K.; e Laban, R. 2008. Design and evaluation of systems to support interaction capture and retrieval. Personal Ubiquitous Comput. 12, 3 (Jan. 2008), 197-221. DOI= http://dx.doi.org/10.1007/s00779-007-0146-3

(Windows, 2008) Informações sobre o Windows. Acesso em fevereiro de 2008. Disponivel em:http://windowshelp.microsoft.com/Windows/enUS/Help/bb91b26f-7a9b-40d3-b397-b3c1cfac94411033.mspx 


\section{APÊNDICE A}

SUMI: questionário para avaliação de usabilidade em software

Nome:

\section{Software: DiGaE}

Data: _L___

As informações aqui fornecidas são confidenciais.

Esta avaliação leva cerca de 5 minutos para ser feita.

Você deve marcar o primeiro quadro se você concorda em geral com a sentença. Marque o quadro central se você está indeciso, não consegue se decidir ou a sentença não é relevante para o sistema, sua situação, ou não se aplica. Marque o quadro direito se você discorda de modo geral com a sentença. Ao marcar o quadro da esquerda ou direita você não está necessariamente indicando que concorda ou discorda fortemente mas sua percepção geral na maior parte do tempo.

Marque os quadros com um $\mathrm{X}$.

\begin{tabular}{|c|c|c|c|c|}
\hline & & Concordo & Indeciso & $\begin{array}{l}\text { Não } \\
\text { concordo }\end{array}$ \\
\hline 1 & Este software responde muito lentamente à entrada de dados & & & \\
\hline 2 & Eu recomendaria este software aos meus colegas & & & \\
\hline 3 & As instruções e mensagens ajudam & & & \\
\hline 4 & O software alguma vez parou de repente & & & \\
\hline 5 & Aprender a usar este software inicialmente é difícil & & & \\
\hline 6 & Nem sempre sei como concluir uma tarefa & & & \\
\hline 7 & Eu gosto de interagir com este software & & & \\
\hline 8 & A informação de ajuda não é muito útil & & & \\
\hline 9 & Se o software pára, não é fácil reiniciá-lo & & & \\
\hline 10 & Demora muito para aprender a interagir com o $\mathrm{DiGaE}$ & & & \\
\hline 11 & Nem sempre sei se estou fazendo a ação correta & & & \\
\hline 12 & Trabalhar com este software é satisfatório & & & \\
\hline 13 & A informação que o DiGaE apresenta é clara e compreensível & & & \\
\hline 14 & Me sinto seguro somente usando funções básicas & & & \\
\hline 15 & A documentação do software é muito informativa & & & \\
\hline 16 & O DiGaE não funciona de modo familiar para mim & & & \\
\hline 17 & Me sinto motivado ao interagir com o DiGaE & & & \\
\hline 18 & Nunca há informação suficiente na tela quando necessário & & & \\
\hline 19 & Me sinto no controle do DiGaE quando estou usando-o & & & \\
\hline 20 & Eu prefiro utilizar as funções que conheço melhor & & & \\
\hline 21 & Eu acho que o DiGaE é inconsistente & & & \\
\hline 22 & Eu não gostaria de usar o DiGaE diariamente & & & \\
\hline 23 & Eu consigo entender a informação fornecida pelo DiGaE & & & \\
\hline 24 & É complicado fazer tarefas avançadas no DiGaE & & & \\
\hline 25 & Há muito para ler antes de poder usar o DiGaE & & & \\
\hline 26 & As tarefas podem ser executadas de modo claro usando o $\mathrm{DiGaE}$ & & & \\
\hline 27 & Usar o DiGaE é frustrante & & & \\
\hline 28 & O DiGaE ajuda a superar os problemas que tive durante a interação & & & \\
\hline
\end{tabular}




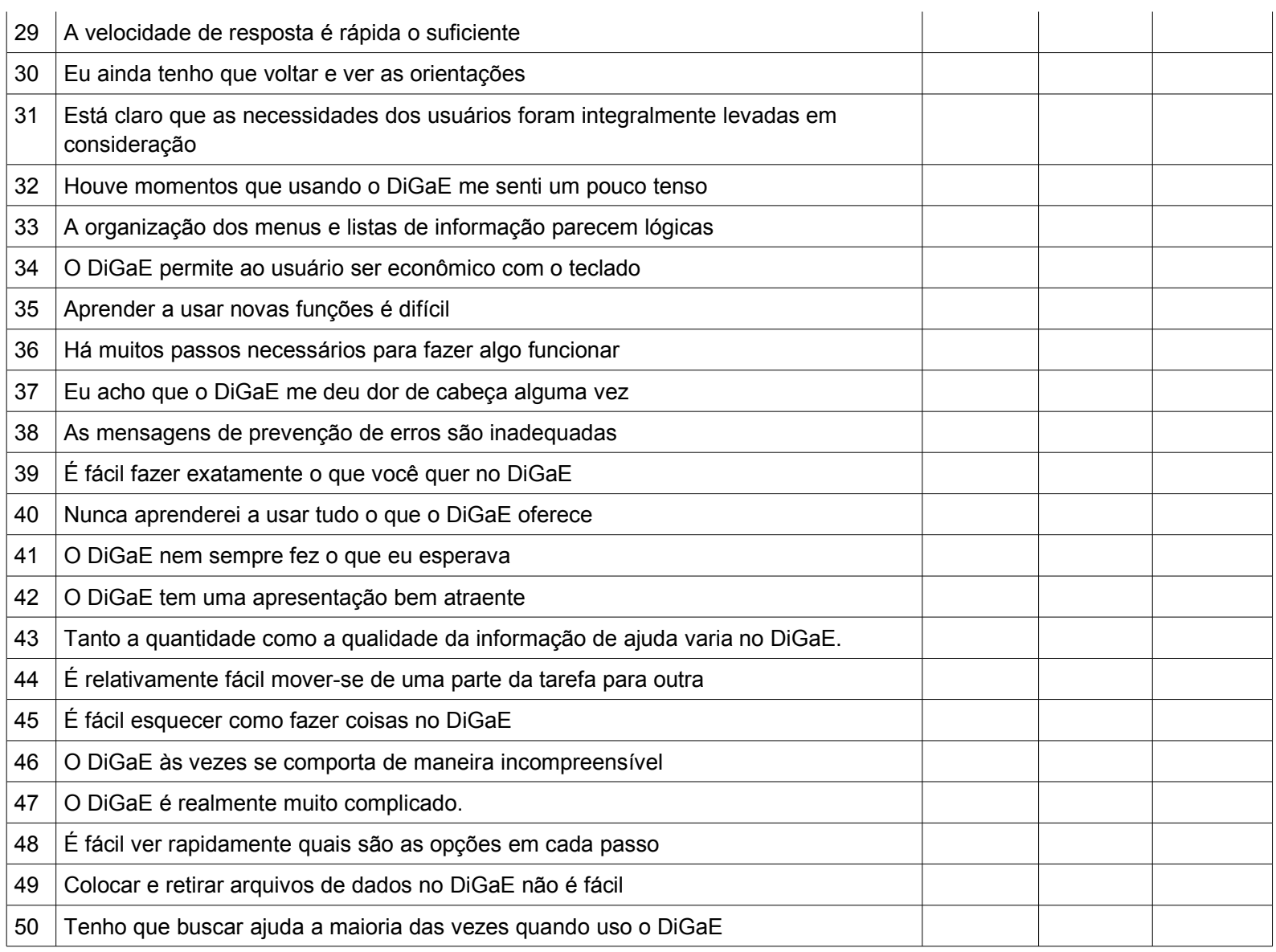

Cheque se todos os itens foram preenchidos, por favor. 


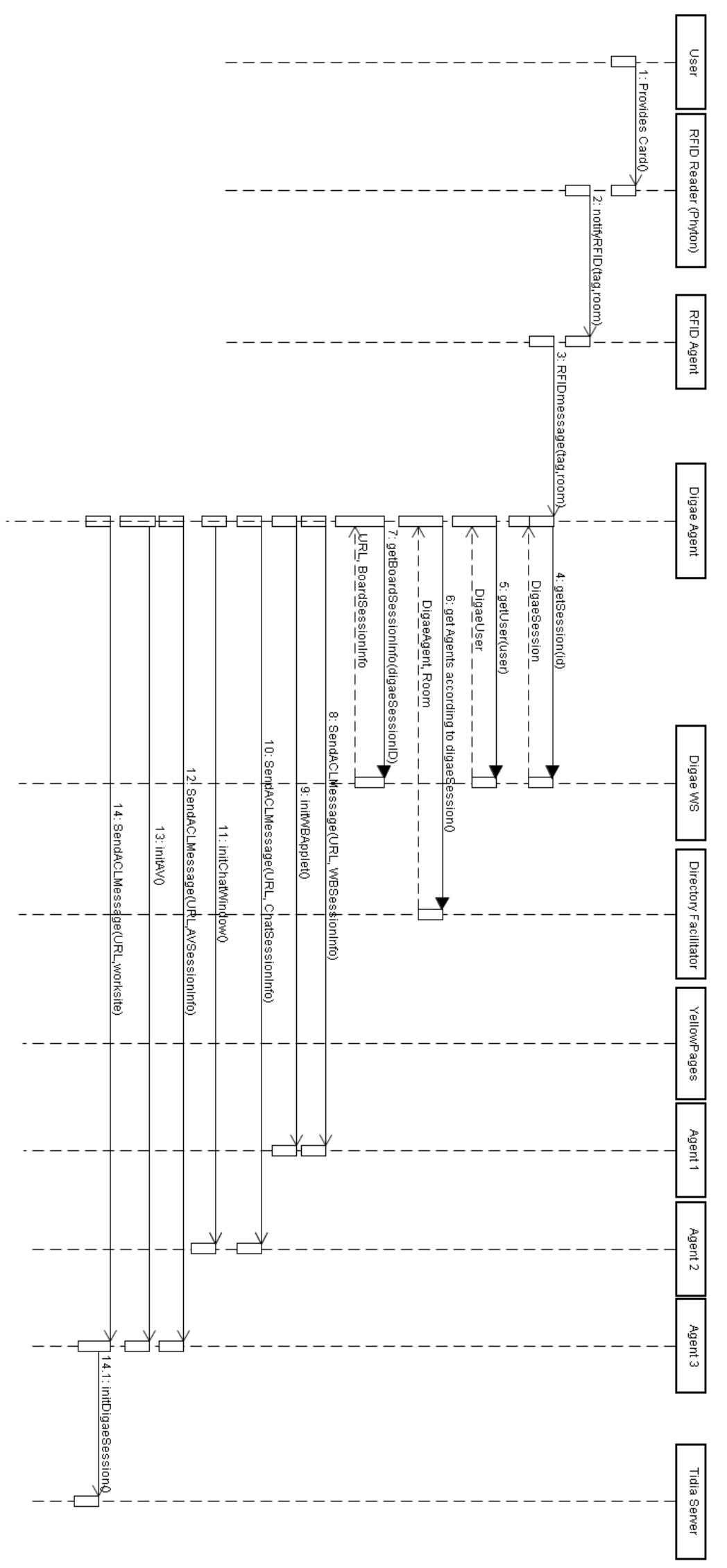




\section{APÊNDICE C}

\begin{tabular}{|c|c|}
\hline $\begin{array}{l}\text { I.D. do Caso de Uso: } 4.1 \\
\text { Nome do Caso de Uso: Acessar Digae } \\
\text { Criado por: Vivian Genaro Motti } \\
\text { Data de criação: } 30 / 07 / 2008 \\
\text { Última atualização realizada por: Vivian Genaro Motti } \\
\text { Data da última atualização: } 30 / 07 / 2008 \\
\text { Ator: Usuário } \\
\text { Descrição: Este caso de uso corresponde à } \\
\text { funcionalidade de acessar o ambiente DiGaE. } \\
\text { Prioridade: Alta } \\
\text { Pré-condições: } \\
\text { 1. Usuário cadastrado no sistema } \\
\text { 2. Tendo selecionado o link para acesso ao DiGaE no } \\
\text { menu (ou passado o cartão no leitor RFID) } \\
\text { Pós-condições: } \\
\text { 1. Usuário faz login no ambiente tendo acesso às } \\
\text { funções nele disponíveis } \\
\text { Fluxo Básico de Eventos } \\
\text { Ações do Ator } \\
\text { 1. Usuário escolhe a opção DiGaE (ou passa o cartão } \\
\text { na sala) } \\
\text { 3. Usuário acessa o conteúdo da sessão caso haja } \\
\text { uma em andamento, se não pode cadastrar uma nova, } \\
\text { realizar uma consulta, consultar a ajuda ou sair } \\
\text { Ações do Sistema } \\
\text { 2. Sistema abre o DiGaE e exibe as sessões que o } \\
\text { usuário esteja cadastrado como participante (ou todas } \\
\text { as ferramentas caso haja sessão cadastrada para ele } \\
\text { no instante do acesso) }\end{array}$ & $\begin{array}{l}\text { I.D. do Caso de Uso: } 4.1 .1 \\
\text { Nome do Caso de Uso: Ver Lista de Sessões } \\
\text { Criado por: Vivian Genaro Motti } \\
\text { Data de criação: } 30 / 07 / 2008 \\
\text { Última atualização realizada por: Vivian Genaro Motti } \\
\text { Data da última atualização: } 25 / 01 / 2009 \\
\text { Ator: Usuário } \\
\text { Descrição: Este caso de uso corresponde à } \\
\text { funcionalidade de visualizar todas as sessões } \\
\text { agendadas para o usuário no ambiente DiGaE e dados } \\
\text { básicos sobre elas (assunto, dia, hora, local, } \\
\text { ferramentas e participantes) } \\
\text { Prioridade: Alta } \\
\text { Pré-condições: } \\
\text { 1. Usuário estar autenticado no sistema } \\
\text { 2. Ter acessado o DiGaE no menu } \\
\text { 3. Ter uma ou mais sessões agendadas para ele no } \\
\text { DiGaE } \\
\text { Pós-condições: } \\
\text { 1. Usuário tem acesso a lista de sessões agendadas } \\
\text { Fluxo Básico de Eventos } \\
\text { Ações do Ator } \\
\text { 1.Usuário visualiza os dados da sessão agendada } \\
\text { Ações do Sistema } \\
\text { 2. Exibir os dados da sessão agendada }\end{array}$ \\
\hline $\begin{array}{l}\text { I.D. do Caso de Uso: } 4.2 \\
\text { Nome do Caso de Uso: Agendar Sessão } \\
\text { Criado por: Vivian Genaro Motti } \\
\text { Data de criação: } 30 / 07 / 2008 \\
\text { Última atualização realizada por: Vivian Genaro Motti } \\
\text { Data da última atualização: } 25 / 01 / 2009 \\
\text { Ator: Usuário } \\
\text { Descrição: Este caso de uso corresponde à } \\
\text { funcionalidade de agendar uma nova sessão do } \\
\text { ambiente DiGaE. } \\
\text { Prioridade: Alta } \\
\text { Pré-condições: } \\
\text { 1. Usuário estar autenticado no sistema } \\
\text { 2. Ter acessado o DiGaE } \\
\text { Pós-condições: } \\
\text { 1. A sessão está cadastrada e pode ser consultada } \\
\text { pelo usuário } \\
\text { Fluxo Básico de Eventos } \\
\text { Ações do Ator } \\
\text { 1.Usuário acessa o cadastro de sessões } \\
\text { 3.Usuário preenche o formulário disponível e salva seu } \\
\text { cadastro } \\
\text { Ações do Sistema } \\
\text { 2. Sistema exibe formulário para preencher os dados } \\
\text { da nova sessão } \\
\text { 4. Armazenar a sessão no banco tornando-a disponível } \\
\text { para consulta e exibe mensagem confirmando o } \\
\text { sucesso da operação }\end{array}$ & $\begin{array}{l}\text { I.D. do Caso de Uso: } 4.3 \\
\text { Nome do Caso de Uso: Sair } \\
\text { Criado por: Vivian Genaro Motti } \\
\text { Data de criação: } 30 / 07 / 2008 \\
\text { Última atualização realizada por: Vivian Genaro Motti } \\
\text { Data da última atualização: } 25 / 01 / 2009 \\
\text { Ator: Usuário } \\
\text { Descrição: Este caso de uso corresponde à } \\
\text { funcionalidade de sair do ambiente DiGaE. } \\
\text { Prioridade: Alta } \\
\text { Pré-condições: } \\
\text { 1. Usuário estar autenticado no sistema e ter acessado } \\
\text { o DiGaE no menu } \\
\text { Pós-condições: } \\
\text { 1. Usuário tem seus dados salvos e deixa de ter } \\
\text { acesso ao ambiente, é desautenticado } \\
\text { Fluxo Básico de Eventos } \\
\text { Ações do Ator } \\
\text { 1.Usuário seleciona o botão de sair } \\
\text { Ações do Sistema } \\
\text { 2. Salvar os dados do usuário e encerrar a execução } \\
\text { desautenticando-o }\end{array}$ \\
\hline
\end{tabular}




\begin{tabular}{|c|c|}
\hline $\begin{array}{l}\text { so de Uso: } 4.4 \\
\text { Caso de Uso: Participar da Sessão } \\
\text { pr: Vivian Genaro Motti } \\
\text { riação: } 30 / 07 / 2008 \\
\text { ualização realizada por: Vivian Genaro Motti } \\
\text { Ittima atualização: 02/02/2009 } \\
\text { ário } \\
\text { o: Este caso de uso corresponde à } \\
\text { dade de participar da sessão agendada, } \\
\text { hando dados e recebendo-os de outros } \\
\text { tes } \\
\text { e: Alta } \\
\text { ições: } \\
\text { estar autenticado no sistema } \\
\text { ssão agendada oiGaE } \\
\text { lições: } \\
\text { tem acesso à sessão (contendo: a lista de } \\
\text { tes, seus status e dispositivos que estejam } \\
\text { em como os dados por eles capturados e } \\
\text { zados, tem acesso à opção de alterar seu } \\
\text { ısar as ferramentas da sessão, além de } \\
\text { sico de Eventos } \\
\text { Ator } \\
\text { visualiza a lista de sessões agendadas e } \\
\text { uma em andamento ele seleciona a opção } \\
\text { nela } \\
\text { pode interagir com as opções da sessão } \\
\text { Sistema } \\
\text { atualizar periodicamente todas as } \\
\text { es da sessão: a lista de participantes, seus } \\
\text { asositivos, dados compartilhados e } \\
\text { uso }\end{array}$ & $\begin{array}{l}\text { Uso: } 4.4 .1 \\
\text { de Uso: Configurar Status } \\
\text { ian Genaro Motti } \\
\text { o: } 30 / 07 / 2008 \\
\text { ção realizada por: Vivian Genaro Mot } \\
\text { atualização: } 30 / 07 / 2008 \\
\text { e caso de uso corresponde à } \\
\text { de alterar o status do usuário no } \\
\text { dia } \\
\text { : } \\
\text { autenticado no sistema } \\
\text { o DiGaE no menu } \\
\text { ando de uma sessão no momento } \\
\text { s: } \\
\text { seu status alterado } \\
\text { le Eventos } \\
\text { he e seleciona um status dentre as } \\
\text { la de status (online -default-, offline, } \\
\text { ado) } \\
\text { na } \\
\text { iza o status do usuário no ambiente } \\
\text { fluxo de eventos } 3 \text {; offline, fluxo de } \\
\text { ivel, fluxo de eventos } 5 \text { e ocupado, } \\
\text { s } 6 \text { ) } \\
\text { vo de Eventos } \\
\text { ama } \\
\text { amentas e permitir interação com elas } \\
\text { r o usuário da sessão, não permitir } \\
\text { mentas } \\
\text { amentas mas não permite interação } \\
\text { s do usuário (mantém exibições das } \\
\text { ermite interação com elas) }\end{array}$ \\
\hline $\begin{array}{l}\text { le Uso: } 4.4 .2 \\
\text { o de Uso: Visualizar Lista de } \\
\text { vian Genaro Motti } \\
\text { ao: } 30 / 07 / 2008\end{array}$ & $\begin{array}{l}\text { Uso: } 4.4 .2 .1 \\
\text { de Uso: Abrir Lista de Participantes } \\
\text { fian Genaro Motti } \\
\text { o: } 30 / 07 / 2008 \\
\text { cção realizada por: Vivian Genaro Motti } \\
\text { atualização: } 25 / 01 / 2009 \\
\text { e caso de uso corresponde à } \\
\text { de acessar a lista de participantes que } \\
\text { jiente DiGaE. } \\
\text { dia } \\
\text { : } \\
\text { autenticado no sistema } \\
\text { o DiGaE } \\
\text { mais participantes da sessão } \\
\text { ticipantes estar minimizada ou fechada }\end{array}$ \\
\hline
\end{tabular}




\begin{tabular}{|c|c|}
\hline $\begin{array}{l}\text { I.D. do Caso de Uso: } 4.4 .2 .2 \\
\text { Nome do Caso de Uso: Fechar Lista de Participantes } \\
\text { Criado por: Vivian Genaro Motti } \\
\text { Data de criação: } 30 / 07 / 2008 \\
\text { Última atualização realizada por: Vivian Genaro Motti } \\
\text { Data da última atualização: } 25 / 01 / 2009 \\
\text { Ator: Usuário } \\
\text { Descrição: Este caso de uso corresponde à } \\
\text { funcionalidade de fechar a lista de participantes que } \\
\text { estejam no ambiente DiGaE. } \\
\text { Prioridade: Média } \\
\text { Pré-condições: } \\
\text { 1. Usuário estar autenticado no sistema } \\
\text { 2. Ter acessado o DiGaE } \\
\text { 3. Estar participando de uma sessão } \\
\text { 4. Haver um ou mais participantes da sessão } \\
\text { 5. A lista de participantes estar aberta } \\
\text { Pós-condições: } \\
\text { 1. Usuário tem acesso ao ícone da lista com os } \\
\text { participantes } \\
\text { Fluxo Básico de Eventos } \\
\text { Ações do Ator } \\
\text { 1.Usuário seleciona a opção de fechar a lista de } \\
\text { participantes } \\
\text { Ações do Sistema } \\
\text { 2. Fechar a lista de participantes }\end{array}$ & $\begin{array}{l}\text { I.D. do Caso de Uso: } 4.4 .3 \\
\text { Nome do Caso de Uso: Usar Whiteboard } \\
\text { Criado por: Vivian Genaro Motti } \\
\text { Data de criação: } 30 / 07 / 2008 \\
\text { Última atualização realizada por: Vivian Genaro Motti } \\
\text { Data da última atualização: } 26 / 01 / 2009 \\
\text { Ator: Usuário } \\
\text { Descrição: Este caso de uso corresponde à } \\
\text { funcionalidade de visualizar e interagir com a } \\
\text { whiteboard } \\
\text { Prioridade: Alta } \\
\text { Pré-condições: } \\
\text { 1. Usuário estar autenticado no sistema } \\
\text { 2. Ter acessado o DiGaE no menu } \\
\text { 3. Estar participando de uma sessão com a whiteboard } \\
\text { incluída } \\
\text { Pós-condições: } \\
\text { 1. A ferramenta whiteboard é carregada e os } \\
\text { participantes da sessão passam a interagir e visualizar } \\
\text { as interações nela } \\
\text { Fluxo Básico de Eventos } \\
\text { Ações do Ator } \\
\text { 2. Utilizar a ferramenta } \\
\text { Ações do Sistema } \\
\text { 1. Exibir a ferramenta whiteboard e permitir interação e } \\
\text { visualização da mesma }\end{array}$ \\
\hline $\begin{array}{l}\text { I.D. do Caso de Uso: } 4.4 .4 \\
\text { Nome do Caso de Uso: Usar Comunicador } \\
\text { Instantâneo } \\
\text { Criado por: Vivian Genaro Motti } \\
\text { Data de criação: } 30 / 07 / 2008 \\
\text { Última atualização realizada por: Vivian Genaro Motti } \\
\text { Data da última atualização: } 25 / 01 / 2009 \\
\text { Ator: Usuário } \\
\text { Descrição: Este caso de uso corresponde à } \\
\text { funcionalidade de capturar e exibir fluxos de áudio e de } \\
\text { vídeo do participante da sessão e de seus contatos } \\
\text { com os quais ele esteja se comunicando, } \\
\text { respectivamente } \\
\text { Prioridade: Alta } \\
\text { Pré-condições: } \\
\text { 1. Usuário estar autenticado no sistema, ter acessado } \\
\text { a sessão do DiGaE com ferramenta Cl incluída e ter } \\
\text { dispositivos de captura de áudio e vídeo } \\
\text { Pós-condições: } \\
\text { 1. Usuário tem seus dados capturados e distribuídos } \\
\text { na sessão do DiGaE } \\
\text { Fluxo Básico de Eventos } \\
\text { Ações do Ator } \\
\text { 1.Usuário conecta seus dispositivos } \\
\text { 2. Usuário seleciona a opção de fornecer áudio e vídeo } \\
\text { ao sistema } \\
\text { Ações do Sistema } \\
\text { 3. Captar, exibir, distribuir e atualizar periodicamente } \\
\text { os fluxos de áudio e vídeo do próprio usuário }\end{array}$ & $\begin{array}{l}\text { I.D. do Caso de Uso: } 4.4 .5 \\
\text { Nome do Caso de Uso: Usar Chat } \\
\text { Criado por: Vivian Genaro Motti } \\
\text { Data de criação: } 30 / 07 / 2008 \\
\text { Última atualização realizada por: Vivian Genaro Motti } \\
\text { Data da última atualização: } 25 / 01 / 2009 \\
\text { Ator: Usuário } \\
\text { Descrição: Este caso de uso corresponde à } \\
\text { funcionalidade de tornar disponível a ferramenta de } \\
\text { bate-papo na sessão, permitindo postar e visualizar } \\
\text { mensagens postadas } \\
\text { Prioridade: Alta } \\
\text { Pré-condições: } \\
\text { 1. Usuário estar autenticado no sistema, ter acessado } \\
\text { a sessão do DiGaE com a ferramenta Chat incluída } \\
\text { Pós-condições: } \\
\text { 1. Usuário interage com a ferramenta } \\
\text { Fluxo Básico de Eventos } \\
\text { Ações do Ator } \\
\text { 2.Usuário posta e lê mensagens da ferramenta } \\
\text { Ações do Sistema } \\
\text { 1. Exibir a ferramenta Chat }\end{array}$ \\
\hline
\end{tabular}




\begin{tabular}{|c|c|}
\hline $\begin{array}{l}\text { I.D. do Caso de Uso: } 4.4 .6 \\
\text { Nome do Caso de Uso: Mover Janelas } \\
\text { Criado por: Vivian Genaro Motti } \\
\text { Data de criação: } 30 / 07 / 2008 \\
\text { Última atualização realizada por: Vivian Genaro Motti } \\
\text { Data da última atualização: } 25 / 01 / 2009 \\
\text { Ator: Usuário } \\
\text { Descrição: Este caso de uso corresponde à } \\
\text { funcionalidade de movimentar janelas no DiGaE } \\
\text { Prioridade: Alta } \\
\text { Pré-condições: } \\
\text { 1. Usuário estar autenticado no sistema } \\
\text { 2. Ter acessado o DiGaE } \\
\text { Pós-condições: } \\
\text { 1. Usuário tem as janelas exibidas de acordo com sua } \\
\text { preferência } \\
\text { Fluxo Básico de Eventos } \\
\text { Ações do Ator } \\
\text { 1.Usuário visualiza as janelas na sessão e arrasta-as } \\
\text { Ações do Sistema } \\
2 . \text { Exibir a janela no local correspondente }\end{array}$ & $\begin{array}{l}\text { I.D. do Caso de Uso: } 4.4 .7 \\
\text { Nome do Caso de Uso: Redimensionar Janelas } \\
\text { Criado por: Vivian Genaro Motti } \\
\text { Data de criação: } 30 / 07 / 2008 \\
\text { Última atualização realizada por: Vivian Genaro Motti } \\
\text { Data da última atualização: } 25 / 01 / 2009 \\
\text { Ator: Usuário } \\
\text { Descrição: Este caso de uso corresponde à } \\
\text { funcionalidade de redimensionar janelas no DiGaE } \\
\text { Prioridade: Alta } \\
\text { Pré-condições: } \\
\text { 1. Usuário estar autenticado no sistema } \\
\text { 2. Ter acessado o DiGaE } \\
\text { Pós-condições: } \\
\text { 1. Usuário tem as janelas exibidas de acordo com sua } \\
\text { preferência } \\
\text { Fluxo Básico de Eventos } \\
\text { Ações do Ator } \\
\text { 1.Usuário visualiza as janelas na sessão e seleciona o } \\
\text { botão com a opção desejada (minimizar) } \\
\text { Ações do Sistema } \\
\text { 2. Exibir um ícone na parte inferior da tela para reabrir } \\
\text { a janela correspondente }\end{array}$ \\
\hline $\begin{array}{l}\text { I.D. do Caso de Uso: } 4.4 .8 \\
\text { Nome do Caso de Uso: Finalizar Sessão } \\
\text { Criado por: Vivian Genaro Motti } \\
\text { Data de criação: } 30 / 07 / 2008 \\
\text { Última atualização realizada por: Vivian Genaro Motti } \\
\text { Data da última atualização: } 25 / 01 / 2009 \\
\text { Ator: Usuário } \\
\text { Descrição: Este caso de uso corresponde à } \\
\text { funcionalidade de finalizar uma sessão que tenha } \\
\text { ocorrido ou que esteja ocorrendo no ambiente DiGaE. } \\
\text { Prioridade: Alta } \\
\text { Pré-condições: } \\
\text { 1. Usuário estar autenticado no sistema } \\
\text { 2. Usuário ter uma sessão selecionada (participando } \\
\text { dela ou retornada de uma consulta) que já tenha } \\
\text { iniciado } \\
\text { Pós-condições: } \\
\text { 1. Usuário tem acesso a opção de finalizá-la, o sistema } \\
\text { salvá-a e torna disponível para consultas futuras } \\
\text { Fluxo Básico de Eventos } \\
\text { Ações do Ator } \\
\text { 1.Usuário seleciona a opção de finalizar uma sessão } \\
\text { Ações do Sistema } \\
\text { 2. Verificar se a sessão está em andamento, nesse } \\
\text { caso executa o fluxo de eventos } 3 \text {. Caso contrário } \\
\text { executa o } 4 \\
\text { Fluxo Alternativo de Eventos } \\
\text { Ações do Ator } \\
\text { 5. Usuário preenche os dados que julgar necessário e } \\
\text { salva-os selecionando esta opção } \\
\text { Ações do Sistema } \\
\text { 3. Notifica os participantes que a sessão está sendo } \\
\text { finalizada } \\
\text { 4. Salva os dados gerados na sessão e fornece um } \\
\text { formulário para que o usuário preencha ou atualize } \\
\text { 6. Sistema salva os dados gerados na sessão e } \\
\text { cadastrados pelo usuário e exibe mensagem } \\
\text { confirmando o sucesso da operação } \\
\end{array}$ & $\begin{array}{l}\text { I.D. do Caso de Uso: } 4.5 \\
\text { Nome do Caso de Uso: Consultar Sessão } \\
\text { Criado por: Vivian Genaro Motti } \\
\text { Data de criação: } 30 / 07 / 2008 \\
\text { Última atualização realizada por: Vivian Genaro Motti } \\
\text { Data da última atualização: } 25 / 01 / 2009 \\
\text { Ator: Usuário } \\
\text { Descrição: Este caso de uso corresponde à } \\
\text { funcionalidade consultar as sessões que foram } \\
\text { cadastradas no DiGaE usando termos do assunto e/ou } \\
\text { data } \\
\text { Prioridade: Alta } \\
\text { Pré-condições: } \\
\text { 1. Usuário estar autenticado no sistema } \\
\text { 2. Ter acessado o DiGaE no menu } \\
\text { 3. Ter acessado a consulta } \\
\text { Pós-condições: } \\
\text { 1. Usuário tem acesso aos resultados retornados com } \\
\text { as sessões ou uma mensagem dizendo que nenhum } \\
\text { resultado foi encontrado com os parâmetros utilizados } \\
\text { Fluxo Básico de Eventos } \\
\text { Ações do Ator } \\
\text { 1.Usuário acessa a consulta de sessões } \\
\text { 3. Usuário preenche formulário disponível com a data e } \\
\text { / ou assunto da sessão a ser buscada e seleciona a } \\
\text { opção de consulta } \\
\text { Ações do Sistema } \\
\text { 2. Exibir um formulário contendo data e assunto para } \\
\text { edição } \\
\text { 4. Exibir uma lista com as sessões retornadas ou } \\
\text { mensagem especificando que nenhum resultado foi } \\
\text { obtido }\end{array}$ \\
\hline
\end{tabular}




\begin{tabular}{|c|c|}
\hline $\begin{array}{l}\text { Dio do amblente DIGat. } \\
\text { ma consulta de sessões }\end{array}$ & $\begin{array}{l}\text { ção realizada por: Vivian Genaro Motti } \\
\text { atualização: } 25 / 01 / 2009 \\
\text { caso de uso corresponde à } \\
\text { e selecionar um sessão dentre um } \\
\text { sões retornadas da busca do usuário } \\
\text { jaE. } \\
\text { autenticado no sistema } \\
\text { o DiGaE } \\
\text { uma consulta de sessões } \\
\text { icesso aos dados da sessão retornada, } \\
\text { a sido finalizada ele também tem } \\
\text { ss gerados durante a sessão } \\
\text { e Eventos } \\
\text { iza a lista de sessões retornadas da } \\
\text { os associados e faz a seleção de uma } \\
\text { ma } \\
\text { acesso ao conteúdo, edição e exclusão }\end{array}$ \\
\hline $\begin{array}{l}\text { Nome do Caso de Uso: } \\
\text { Criado por: Vivian Gena } \\
\text { Data de criação: } 30 / 07 / 2 \\
\text { Última atualização realiz } \\
\text { Data da última atualizaç } \\
\text { Ator: Usuário } \\
\text { Descrição: Este caso de } \\
\text { funcionalidade de visualiz } \\
\text { sessão já realizada no an } \\
\text { Prioridade: Média } \\
\text { Pré-condições: } \\
\text { 1. Usuário já autenticado } \\
\text { DiGaE no menu, ter realiz } \\
\text { de sessão } \\
\text { Pós-condições: } \\
\text { 1. Usuário tem acesso ao } \\
\text { sessão consultada } \\
\text { Fluxo Básico de Evento } \\
\text { Ações do Ator } \\
\text { 1.Usuário realiza uma co } \\
\text { Ações do Sistema } \\
\text { 2. Exibe os conteúdos da } \\
\text { de sessões }\end{array}$ & $\begin{array}{l}\text { Última atualização realizada por: Vivian Genaro Motti } \\
\text { Data da última atualização: } 25 / 01 / 2009 \\
\text { Ator: Usuário } \\
\text { Descrição: Este caso de uso corresponde à } \\
\text { funcionalidade de visualizar dados de uma sessão já } \\
\text { agendada no ambiente DiGaE. } \\
\text { Prioridade: Média } \\
\text { Pré-condições: } \\
\text { 1. Usuário já autenticado no sistema, ter acessado o } \\
\text { DiGaE no menu, ter realizado uma consulta e seleção } \\
\text { de sessão } \\
\text { Pós-condições: } \\
\text { 1. Usuário tem acesso aos dados da sessão } \\
\text { selecionada } \\
\text { Fluxo Básico de Eventos } \\
\text { Ações do Ator } \\
\text { 1.Usuário seleciona um sessão para consulta no } \\
\text { sistema } \\
\text { Ações do Sistema } \\
\text { 2. Exibe os dados das sessões resultantes da consulta }\end{array}$ \\
\hline
\end{tabular}




\begin{tabular}{|c|c|}
\hline $\begin{array}{l}\text { I.D. do Caso de Uso: } 4.5 .1 .1 .3 \\
\text { Nome do Caso de Uso: Editar Dados da Sessão } \\
\text { Criado por: Vivian Genaro Motti } \\
\text { Data de criação: } 30 / 07 / 2008 \\
\text { Última atualização realizada por: Vivian Genaro Motti } \\
\text { Data da última atualização: } 25 / 01 / 2009 \\
\text { Ator: Usuário } \\
\text { Descrição: Este caso de uso corresponde à } \\
\text { funcionalidade alterar os dados de uma sessão já } \\
\text { cadastrada, atualizando-os. } \\
\text { Prioridade: Alta } \\
\text { Pré-condições: } \\
\text { 1. Usuário estar autenticado no sistema } \\
\text { 2. Ter acessado o DiGaE no menu } \\
\text { 3. Sessão a ser editada já estar cadastrada } \\
\text { Pós-condições: } \\
\text { 1. Dados da sessão são atualizados } \\
\text { Fluxo Básico de Eventos } \\
\text { Ações do Ator } \\
\text { 1.Usuário acessa uma sessão já cadastrada e opta por } \\
\text { editá-la } \\
\text { 3. Usuário digita os novos dados da sessão que ele } \\
\text { deseja alterar e seleciona o botão de confirmação da } \\
\text { alteração } \\
\text { Ações do Sistema } \\
\text { 2. Exibir todos os dados da sessão cadastrada e } \\
\text { permitir edição destes } \\
\text { 4. Sistema armazena os novos dados no banco } \\
\text { disponibilizando-os para uma consulta futura e exibe } \\
\text { uma mensagem confirmando o sucesso na operação }\end{array}$ & $\begin{array}{l}\text { I.D. do Caso de Uso: } 4.5 .1 .1 .4 \\
\text { Nome do Caso de Uso: Editar Conteúdo } \\
\text { Criado por: Vivian Genaro Motti } \\
\text { Data de criação: } 30 / 07 / 2008 \\
\text { Última atualização realizada por: Vivian Genaro Motti } \\
\text { Data da última atualização: } 25 / 01 / 2009 \\
\text { Ator: Usuário } \\
\text { Descrição: Este caso de uso corresponde à } \\
\text { funcionalidade editar o conteúdo de uma sessão } \\
\text { realizada no DiGaE } \\
\text { Prioridade: Alta } \\
\text { Pré-condições: } \\
\text { 1. Usuário estar autenticado no sistema } \\
\text { 2. Ter acessado o DiGaE no menu } \\
\text { 3. Consultar uma sessão já realizada } \\
\text { 4. Sessão não esteja em andamento } \\
\text { 4. Selecionar a opção de Edição } \\
\text { Pós-condições: } \\
\text { 1. O conteúdo da sessão é editado no sistema } \\
\text { Fluxo Básico de Eventos } \\
\text { Ações do Ator } \\
\text { 1.Usuário consulta uma sessão, tem acesso aos seus } \\
\text { conteúdos e seleciona a opção de editá-la } \\
\text { Ações do Sistema } \\
\text { 2. Atualizar o conteúdo da sessão no banco conforme } \\
\text { a edição do usuário }\end{array}$ \\
\hline $\begin{array}{l}\text { I.D. do Caso de Uso: } 4.5 .1 .1 .5 \\
\text { Nome do Caso de Uso: Excluir Sessão } \\
\text { Criado por: Vivian Genaro Motti } \\
\text { Data de criação: } 30 / 07 / 2008 \\
\text { Última atualização realizada por: Vivian Genaro Motti } \\
\text { Data da última atualização: } 25 / 01 / 2009 \\
\text { Ator: Usuário } \\
\text { Descrição: Este caso de uso corresponde à } \\
\text { funcionalidade excluir uma sessão previamente } \\
\text { cadastrada no DiGaE } \\
\text { Prioridade: Alta } \\
\text { Pré-condições: } \\
\text { 1. Usuário estar autenticado no sistema } \\
\text { 2. Ter acessado o DiGaE no menu } \\
\text { 3. Consultar uma sessão já cadastrada } \\
\text { 4. Sessão não esteja em andamento } \\
\text { 4. Selecionar a exclusão } \\
\text { Pós-condições: } \\
\text { 1. A sessão é deletada do sistema } \\
\text { Fluxo Básico de Eventos } \\
\text { Ações do Ator } \\
\text { 1.Usuário consulta uma sessão, tem acesso aos seus } \\
\text { dados e seleciona a opção de exclui-la } \\
\text { Ações do Sistema } \\
\text { 2. Remover a sessão do banco e fornecer uma } \\
\text { mensagem para o usuário confirmando o sucesso da } \\
\text { operação }\end{array}$ & $\begin{array}{l}\text { I.D. do Caso de Uso: } 4.6 \\
\text { Nome do Caso de Uso: Acessar Ajuda } \\
\text { Criado por: Vivian Genaro Motti } \\
\text { Data de criação: } 30 / 07 / 2008 \\
\text { Última atualização realizada por: Vivian Genaro Motti } \\
\text { Data da última atualização: } 25 / 01 / 2009 \\
\text { Ator: Usuário } \\
\text { Descrição: Este caso de uso corresponde à } \\
\text { funcionalidade de acessar a ajuda do DiGaE } \\
\text { Prioridade: Alta } \\
\text { Pré-condições: } \\
\text { 1. Usuário estar autenticado no sistema, ter acessado } \\
\text { o Digae e sua ajuda } \\
\text { Pós-condições: } \\
\text { 1. Usuário tem acesso às informações disponíveis na } \\
\text { sessão de ajuda } \\
\text { Fluxo Básico de Eventos } \\
\text { Ações do Ator } \\
\text { 1.Usuário seleciona a opção de ajuda } \\
\text { Ações do Sistema } \\
\text { 2. Exibir os tópicos de ajuda e suas informações }\end{array}$ \\
\hline
\end{tabular}

